تأثير الانتباه والحالة المزاجية في الذاكرة اللفظية والدلالية في ضوء نموذج ديزي/روديجر -ماكديرموت (DRM)

*. محمد حسين سعيد حسين

\title{
المقدمة
}

يمثل اتجاه تجهيز المعلومات أحد الاتجاهات المعرفية الحديثة في

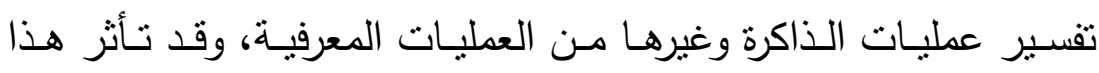

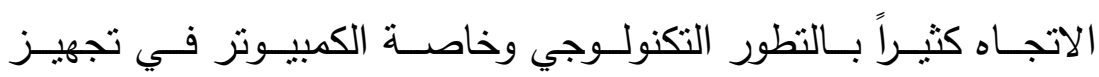
المعلومـات. ويُعد الانتباه العمليـة الأولى في اكتسـاب الخبـرات التربويـة

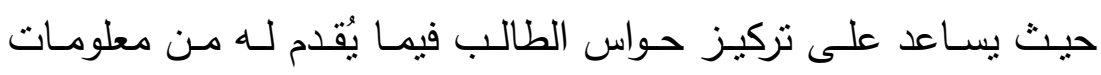
ويجعله يُعِلِ ذهنه في دلالاتها ومعانيها وبالتالي يساعد في استيعابها

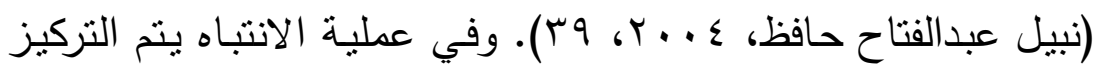

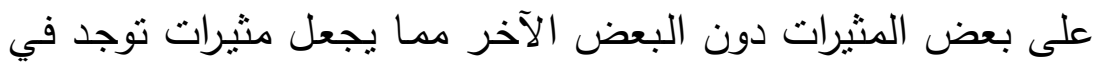

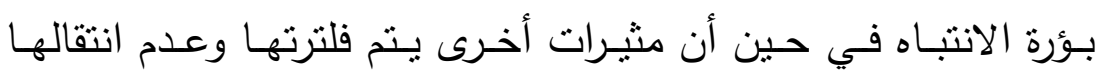

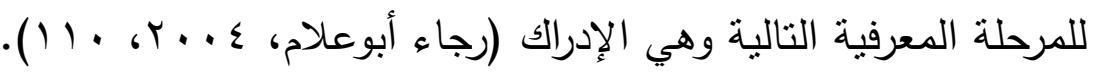

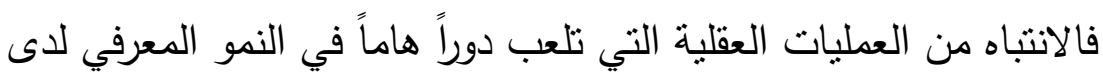

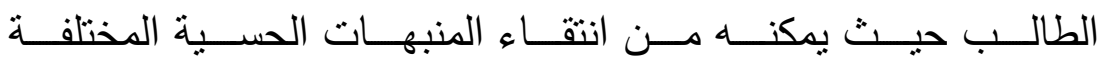

$$
\text { (السيد أحمد، فائقة بدر، } 999 \text { (1)، 10 ). }
$$

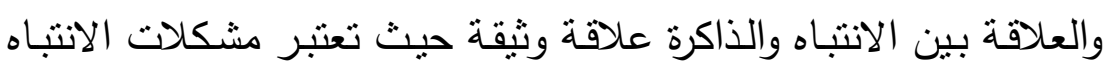
السبب الرئيس لاضطراب العديد من العمليات المعرفية المترتبة عليه مثل الإدراك والذاكرة التي هي نشاط عقلي يعكس القدرة على ترميز ومعالجة

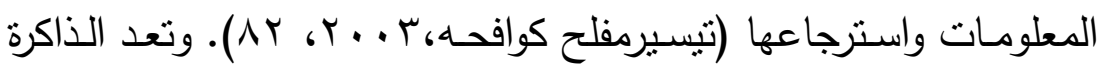

* أستاذ علم النفس التطليمي المساعد-كلية التربية-جامعة بني سويف 
العمود الفقري لكل العمليات المعرفية وبدونها لا يتم التعلم والذي يقوم على

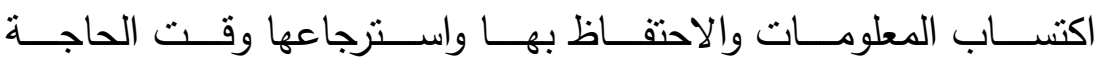

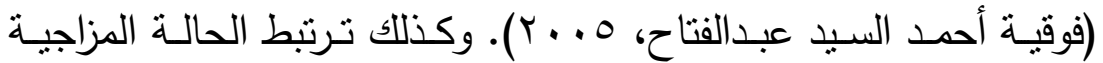
للطالب بالذاكرة، فالتغيرات في الحالة المزاجية تؤثر بصورة ملحوظة في قدرة الطالب على تذكر المعلومـات التي تم تعلمها؛ فالمعلومـات يمكن تخزينها واسـتدعاؤها بسـهولة عنـدما تتسـق مـع الحالـة المزاجيـة للفـرد.

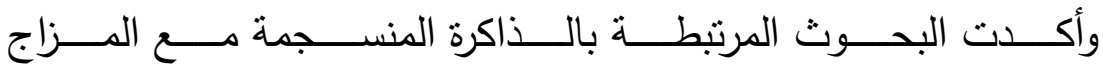
Mood-Congruent Memory

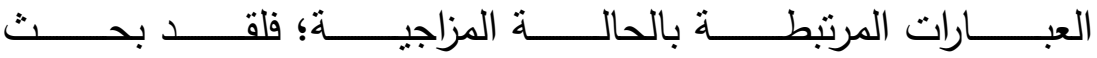
(Gilboa-Schechtman, Erhard-Weiss \& Jeczemien, 2002)

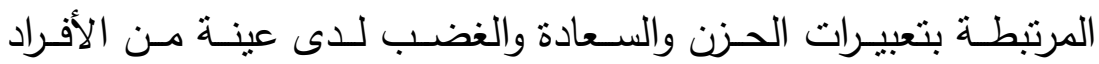
المكتئبين والمصـابين بـالقلق والعـاديين، وبين أن الاكتئياب ارتبط سلبياً

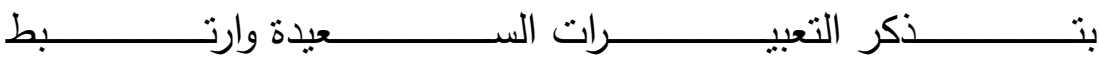

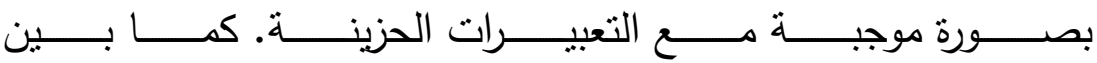
(Surguladze, Young, Senior, Bre'bion, Travis, \& Phillips, 2004) أن الأفـراد المكتبـبـين وجـدوا صــوبة فـي تمييـز التعبيـرات المرتبطــة

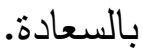

إن الأفـراد يميلــون لتجهيـز المعلومـات المرتبطــة بحـالتهم المزاجيـة بصورة أفضل من تجهيز المعلومات غير المنسجمة مع حالتهم المزاجية؛

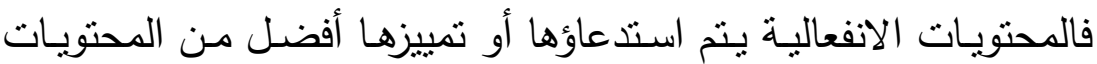

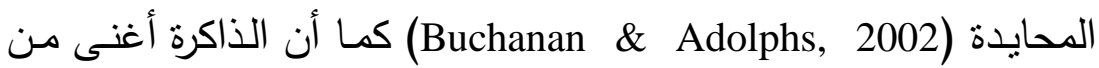
حيث التفاصيل بالنسبة للمحتويات الانفعالية أكثر من المحتويات غير

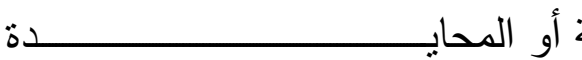

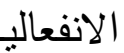

‘(Doerksen \& Shimamura, 2001; Kensinger \& Corkin, 2003a) ويدعم ذلك تصوير الأعصاب وبيانات علم النفس العصبي التي كثفت 
عن أن المحتويات الانفعالية والعصبية تعتمد على آليات معرفية وعصبية

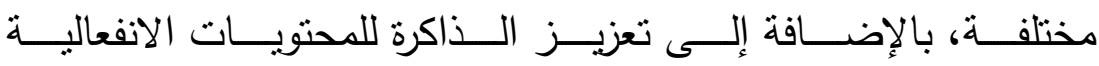
.(Hamann, 2001)

ويمكـن أن تعـزز الانفعــالات أداء الــذاكرة فـي أوقــات وفــي

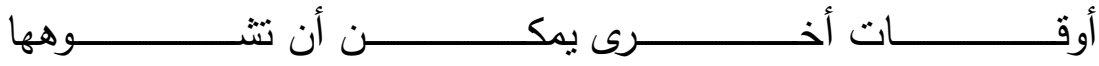
(Gray, 2001; Gray, Braver, \& Raichle, 2002) فقد وجد "جراي" (Gray, 2001)

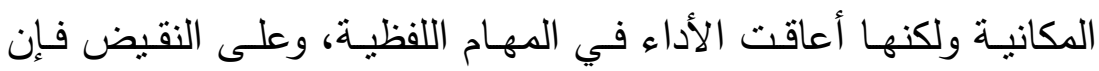

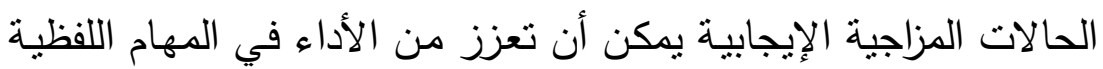
ولكنها تعوق الأداء في المهام المكانية. وإذا تعرض الطـلاب إلى سلسـلة مـن المثيـرات الانفعاليـة والمحايـة فإنهم يستدعون لاحقاً أو يتعرفون على نسبة أكبر من المثيرات الانفعالية

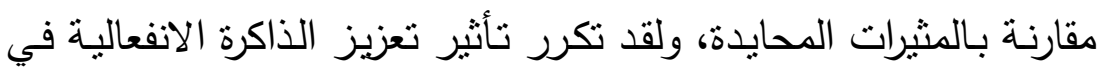

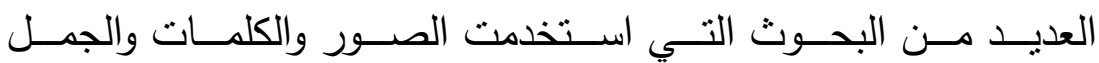
(Ochsner, ويرى). (Buchanan \& Adolphs, 2002; Hamann, 2001) (2000 أن تأثير الانفعالات ينشأ من الاستجابات الفسيولوجية المترتبـة

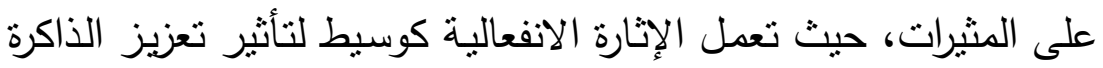
لأنواع عديدة من المعلومات.

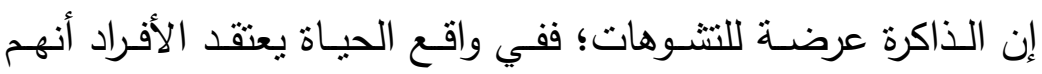
يتذكرون أحداثاً لم تحدث لهم قط أو يتذكرون بصورة غير دقيقة أجزاء من الأحداث لم تحدث قط، ولقد تم دراسـة أخطاء الذاكرة في البحوث

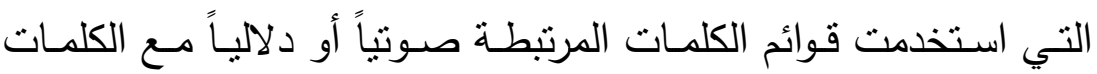
الموضـوع من قِبَل "ديزي" (1959) Deese والذي تم تطوير نموذجـهـ

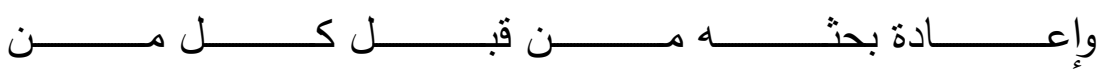


(Roediger, \& McDermott, 1995; Roediger, Balota, \& Watson, .2001; Roediger, Watson, McDermott, \& Gallo, 2001).

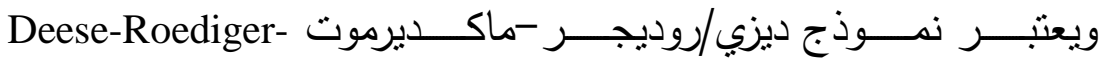
من النماذج الحديثة في الذاكرة، وبصفة خاصـة (DRMermott (DRM) في أخطاء الذاكرة المرتبطة بدلالـة أو معاني كلمات القائمـة. وفي هذا النموذج يتم تقديم مجموعة من الكلمات (كيكة-سكر -حلوى-لذيذ-...) والتي تزتبط دلالياً بكلمة لا يتم تقديمها في القائمة منل كلمة "حلو" والتي تسمى الكلمـة الموضوع Critical Lure للقائمـة، وعند استـدعاء الطلاب لكلمات هذه القوائم فإنهم يميلون إلى تذكر الكلمة الموضوع "حلو" على

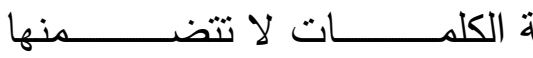
قائم

(Pimentel \& Albuquerque, 2011; Cadavid, Beato, \& Fernandez, 2012; Pimentel \& Albuquerque, 2013) في نموذج ديزي/روديجر -ماكديرموت DRM في ضوء كل من: مستوى التجهيز السطحي للمعلومات وهو تذكر كلمات القائمة كما هي وهو ما يطلق عليه الذاكرة اللفظية Verbal Memory، أو مستوى التجهيز القائم

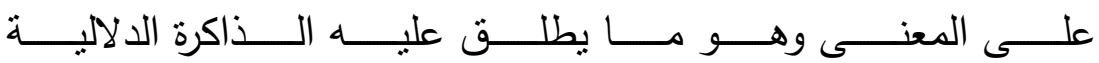
.(Brainerd \& Reyna, 2002) Gist Memory وعلى نقيض الأدلة القوية على تأثير الانفعالات على الأحداث التي تم دراستها، لـ يتم حتى الآن الكثف عن كيفيـة تأثير الانفعـالات في أخطاء الذاكرة لنموذج ديزي/روديجر -ماكديرموت DRM للأحداث التي لـم يـتم دراستها، نظـراً لأن التذكر الخـاطئ للأحداث التي لـم تقع أبـداً أصبح ظـاهرة تحتاج إلى البحث Gallo, 2006). بالإضـافة إلى أن

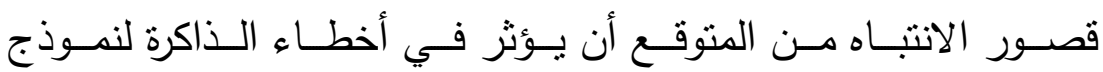
ديزي/روديجر -ماكديرموت DRM ومن هنا نبعت مشكلة البحث الحالي والتي يمكن عرضها كالنالي. 


\section{مشكنة البحث}

يعتبر نموذج ديزي/روديجر -ماكديرموت DRM من النماذج الحديثة

التي فسرت كيف أن الأفراد يمكنهم تذكر أحداث لم تحدث على أنها وقعت بالفعل، ولقد نال هذا النموذج اهتمام العديد من الباحثين في الفترة (Wu \& Barsalou, 2009; Gallo, 2010; Van Damme, \& الأخيرة d'Ydewalle, 2010; Cann, McRae, \& Katz, 2011; Arndt, 2012; Otgaar, Peters, \& Howe, 2012; Beato, Cadavid, Pulido, \& Pinho, 2013; Blau, 2013; Jou \& Flores, 2013; Pimentel \& Albuquerque, 2013; Beato \& Arndt, 2014).

$$
\text { . }
$$

وفي نموذج ديزي/روديجر -ماكديرموت DRM، توجد الذاكرة اللفظية

وتعبر عن الاسـتـاءعاء الصـحيح للكلمــات كمـا وردت بالقائمـة، والذاكرة الدلالية وتعبر عن استدعاء الكلمات الموضوع والتي لم يتم تقديمها في قوائم الكلمـات، ويوجد الاسـتدعاء الخـاطئ وهـو أي كلمـات أخرى يتم

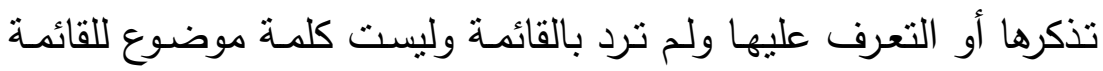
(محمد حسين سعيد، 10 • بأ). ولقد ظهر اتجاه يبحث في تفاعل الحالة

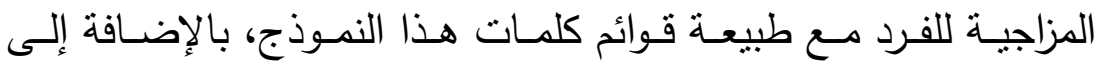
الكلمات الموضوع الخاصة بكل قائمة؛؛ حيث يوجد كلمات موضوع ذات

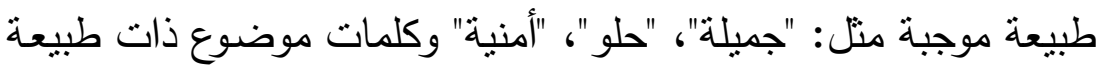

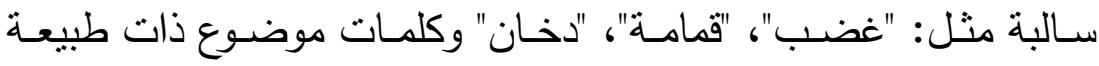

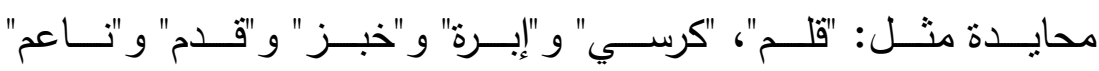
(محمد حسين سعيد، 0 ( باب).

وفي نموذج ديزي/روديجر -ماكديرموت DRM يميل الأفراد إلى إنتاج

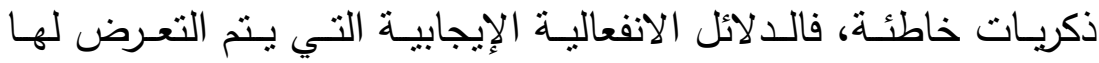
كتغذية مرتدة مناسبة للمهمة تشجع المعالجة العلاقية للكلمات في البنى 
المعرفية للأفراد خلال عملية الترميز والذي يعزز بدوره تأثنيرات أخطاء

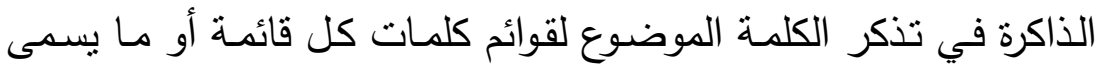

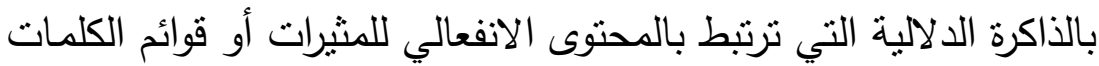
التي يتم تقديمها، فقد بين "ستوربيك وكلور" (Storebeck \& CLore, 2005)

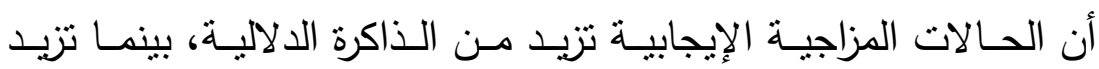

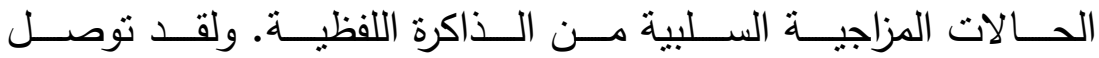
(Pesta, Murphy \& Sanders, 2001) تذكر الكلمـات الموضـوع الانفعاليـة (الذاكرة الدلاليـة) أكثر مـن الكلمـات الكات الموضوع غير الانفعالية؛ نظراً لاحتماليـة تزايد التعرف المرتبط بـالبنود الانفعالية. وعلى النقيض بين (Windmann \& Kutas, 2001) وجود

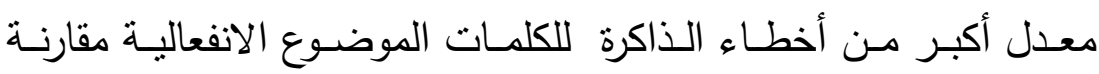
بالكلمات الموضوع المحايدة خلال مهمة التعرف. مهن. كما أن الأفراد الأكبر سناً على عكس الأفراد الأصغر سناً ينتجون

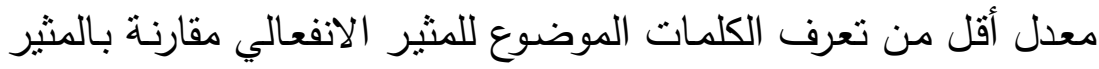

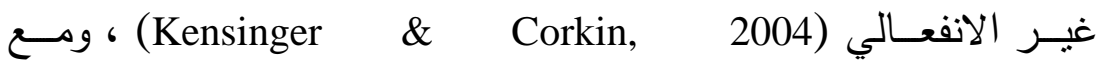

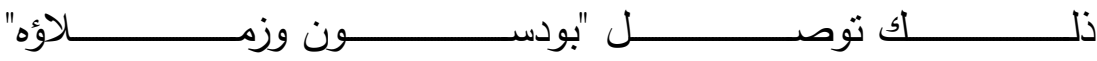
(Budson, Todman, Chong, Adams, Kensinger, Krangel, \& إلى احتماليـة متزايدة للتعرف على المثير الانفعـالي بغض النظر عن التعرض المسبق لـه لدى الكبار والصـغار في مهام قوائم كلمات نموذج ديزي/روديجر -ماكديرموت DRM. كما يؤدي تعزيز الذاكرة الانفعاليـة إلى تفاصيل أغني وأكثر حيويـة للأحداث الانفعاليـة

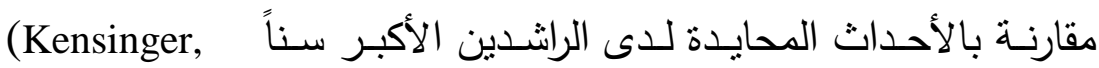
Brierley, Medford, Growdon, \& Corkin, 2002; Denburg, Buchanan, Tranel, \& Adolphs, 2003; Mather \& Carstensen,

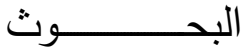

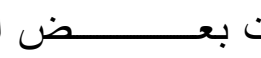
(2003) 
ذاكرة مساوية (Kensinger et al., 2002; Denburg et al., 2003)

للمثيرات الايجابية والمثيرات السلبية لدى الصغار والأفراد الأكبر سناً.

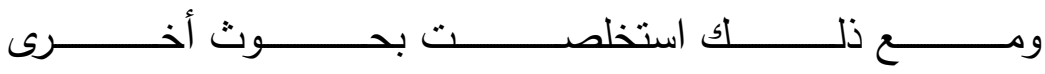

وجود ميل مرتبط بالمرحلة العمرية نحو (Mather \& Carstensen, 2003) تأثثير تعزيز الذاكرة الانفعالية، أي أن الراشدين الأكبر سناً يظهرون ذاكرة

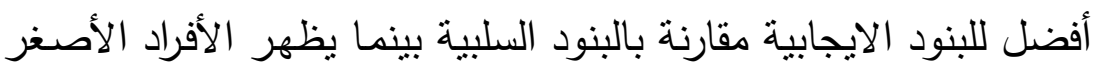

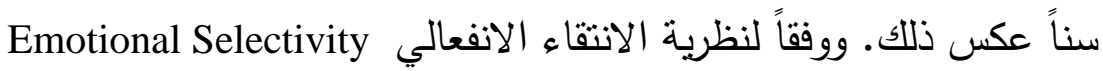
فإن هذا الميل الايجابي لدى الراشدين الأكبر سناً يعكس تحولاً في التركيز نحو المعلومات الانفعالية ذات الصلة (Carstensen, 1995). وعلى الرغم من أن البحوث السابقة وجدت ذكريات منسجمة مـع الحالة

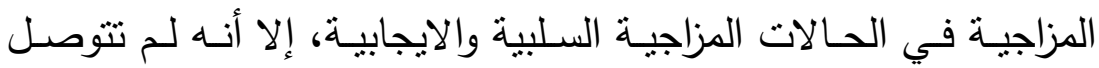
بحوث أخرى إلى منل هذه النتائج (Anderson \& Shimamura, 2005). وبين (Choi \& Kensinger, 2013) أن الانفعـالات تعزز الذاكرة الصحيحة أو اللفظية كما يمكنها أن تحد من الذاكرة الدلالية، ولقد كان

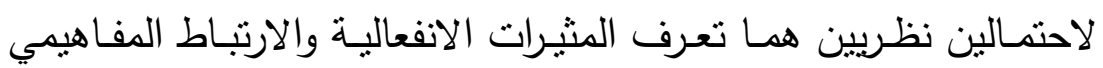

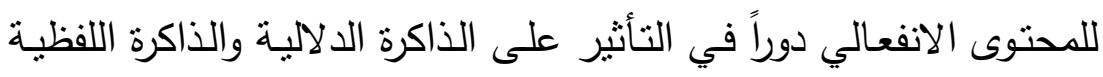
للاحتوى الانفعالي. كما بين (Baure, Lheiser, Altarrib, \& Landi, 2009) أن الكلمات التي تصف الانفعالات قد تؤثز على عمليات الذاكرة اللفظية

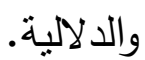

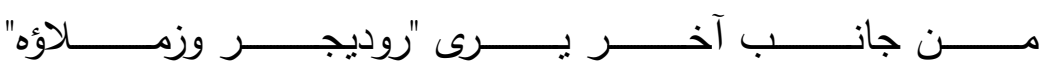

(Roediger, Balota, et al., 2001) Activation/Monitoring Theory ديزي/روديجر -ماكديرموت DRM ينتج عن تنشيط الكلمة الموضوع من خلال العلاقات الترابطية بينها وبين عناصر القائمة، ووفقا لهذه النظرية 
فإن المفاهيم المرتبطة والتي لم يتت تقديمها مثل الكلمـة الموضوع، يتم

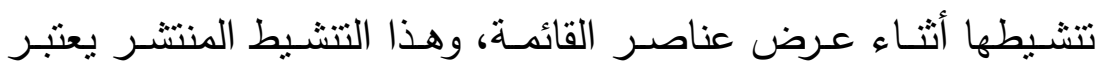

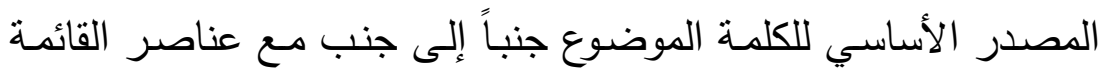

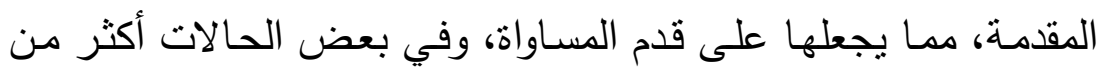

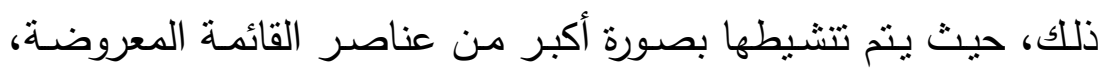

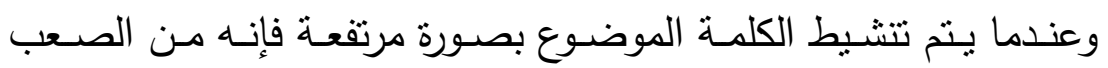

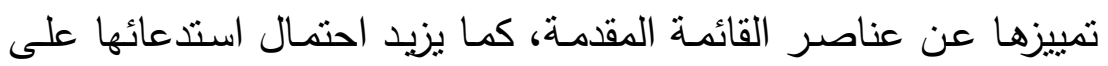
أنها ذكرت كبند من بنود القائمة المقدمة.

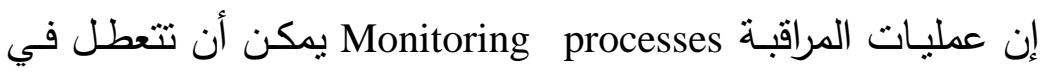
حالة عدم وجود معلومات كافية لدى الطالب لتمييز الكلمات المرتبطة

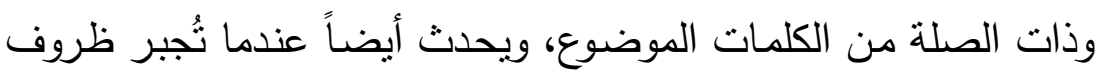
المعالجة الطالب على توزيع الانتباه والتتشت بين مثيرات مختلفة أو أداء

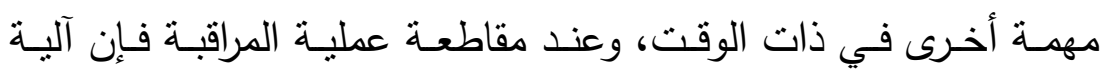
التتشيط يمكن أن تدفع الطالب نحو تكوين افتراضـات غير صحيه صحيحة بخصوص مصدر ذكرياتهم، إلى جانب أن تقسيم الانتباه وتشتته بمكن

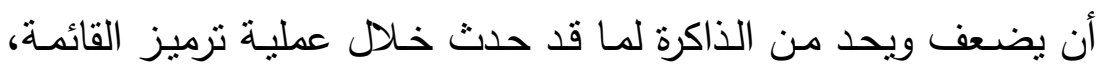
على سبيل المثال التفاصبل الإدراكية وردود الأفعال الانفعالية والعمليات

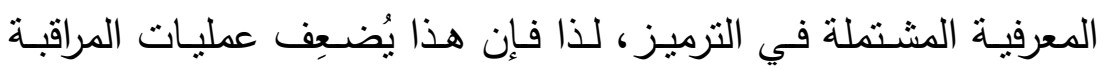

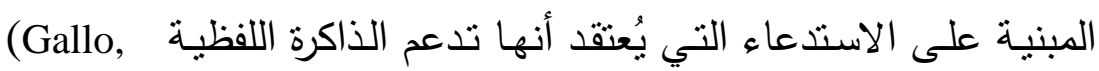
$.2006)$

(Pérez-Mata, Rad \& Diges, ولقد توصلت العديد من البحوث 2002; Dodd \& MacLeod, 2005; Dewhurst, Barry, \& Holmes, 2005; Dewhurst, Barry, Swannell, Holmes, \& Bathurst, 2007; Peters, Jelilic, Gorski, Sijstermans, Giesbrecht, \& Merckelbach, 2008; Wimmer \& Howe, 2010)

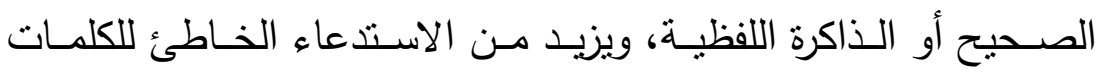




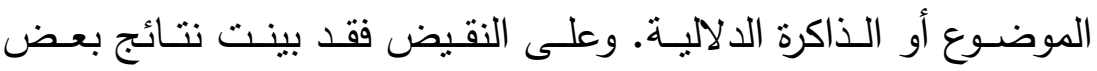
(Rhodes \& Anastasi, 2000; Benyamin, 2001; Thaper \& البحوث McDermott, 2001; Seamon, Goodkind, Dumey, Dick, Aufseeser, \& Strickland, 2003)

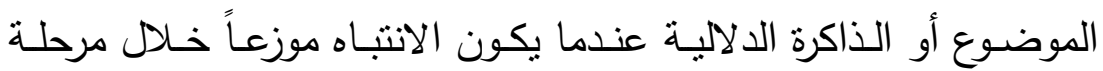

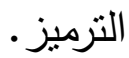

يتضح مما سبق تباين نتائج البحوث التي تتاولت العلاقة بين الحالة المزاجيـة وقوائم كلمات نموذج ديزي/روديجر -ماكديرموت DRM، ومن المتغيرات الأخرى التي تم بحثها في علاقتها بالنموذج الانتباه (انتباه

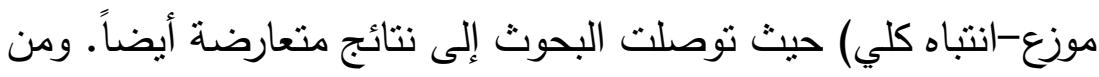

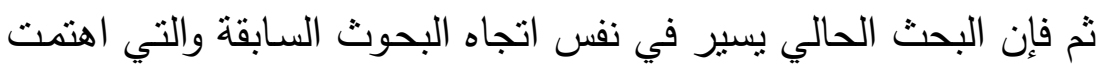

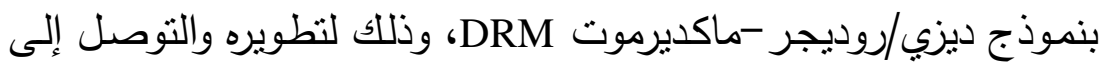
العوامل والمتغيرات التي يمكن أن تؤثز في أداء الطلاب فيهه، وسيركز

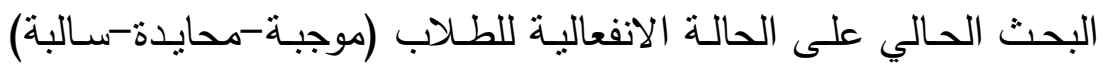
ومستوى الانتباه (موزع-كلي) في تأثيرهما على الذاكرة اللفظية والدلالية في نمـوذج ديزي/روديجر -ماكديرموت DRM. ويمكن تحديد مشكلة البحث الحالي في الأسئلة التالية: ا ـ مـا تأثير الحالـة المزاجيـة (موجبـة-محايـدة-سـالبة) في الـذاكرة

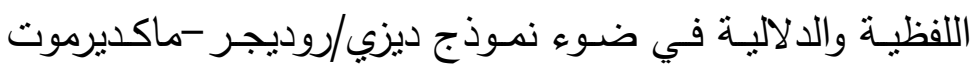
?DRM r. مـا تأثثر الانتباه (كلي-موزع) في الذاكرة اللفظية والدلالية في

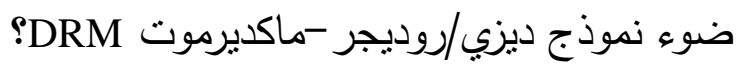
r. ما تأثير التفاعل بين الحالة المزاجية والانتباه في الذاكرة اللفظية والد لالية في ضوء نموذج ديزي/روديجر -ماكديرموت DRM 
أهداف البحث

تتبثت أهدف البحث الحسالي من بعض أهداف العلم وهي التعرف والضبط والتفسير؛ حيث يهدف البحث الحالي إلى تعرف تأثير كل من: الانتباه (كلي-موزع) والحالة المزاجية (موجبة-محايدة-سلبية) في الذاكرة اللفظيـة والدلاليـة في ضـوء نمـوذج ديزي/روديجر -ماكديرموت DRM، بالإضـافة إلى تعرف تأثنير التفاعل بينهمـا في الذاكرة اللفظيـة والدلاليـة لاى عينة من طلاب المرحلة الجامعية، وقد تم ذلك عن طربق تعريض مجموعـة من الطـلاب لقوائم كلمات نموذج ديزي/روديجر -ماكديرموت بعد تقسيمهم في ضوء حالتهم المزاجية إلى ثلاثث مجموعات تم تقسيم كل منها إلى مجموعتين في ضوء الانتباه (الكلي أو الموزع)، ثم تم تقسير النتائج التي توصل إليها البحث في ضوء البحوث المرتبطة. أهمبة البحث

\section{الأهمية النظرية}

تثمثل الأهمية النظرية للبحث الحالي في أهمية المجال الذي يتتاوله، والذي يجمـع بين المجال الوجداني والمجال المعرفي، فعلى الرغم من تعدد البحوث التي تتاولت كل منهما إلا أن البحوث التي اهتمت بالربط بينهما قليلة، فالمجال الوجداني يؤثز وبتأثز بالجانب المعرفي ولا يمكن تتـاول أحدهما بمعزل عن الآخر، ويزداد الأمر أهمية إذا تم تتاول ذلك في علاقته بالذاكرة اللفظية والدلاليـة والانتباه، وهما منغيرين هامين في تحصـيل الطـلاب وفهمهم لمـا يقدم لهم أثتـاء التدريس أو مـا يقومـون باستذكاره. كما يضيف هذا البحث إلى المكتبة العربية إطاراً نظرباً حديثاً في مجـال الذاكرة اللفظيـة والدلاليـة وعلاقتهما بكل مـن الانتبـاه والحالة الانفعالية للطلاب. 


\section{الأهمية التطبيقية}

تفيد نتائج البحث الحالي التربويين وأعضاء هيئة التدريس والطلاب في توفير حالة نفسية انفعالية جيدة أثناء التدريس بعيدة عن عوامل الترل

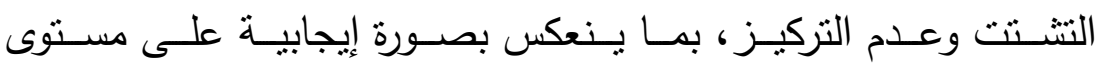

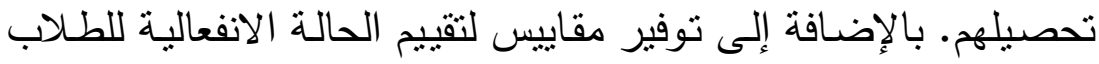
أو غيرهم من الأفراد، وكنلك توفير أدوات لتقييم الذاكرة الدلالية واللفظية

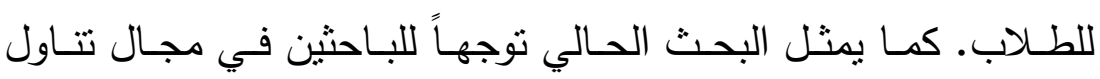
المعرفة كوجدان أو الحالة الانفعالية كمعرفة والربط بينهما لدى فئات البـات

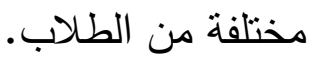
مصطحات البحث

الانتباه

الانتباه هو قدرة الطالب على حصر وتركيز حواسه في شيء ما؛ قد الأد يكون فكرة أو صورة أو شخص أو موقف أو كلمة استعداداً للتفكير فيه.

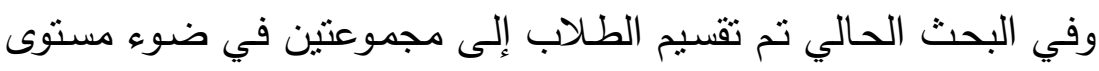

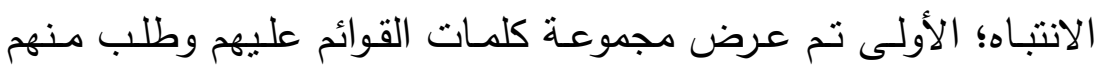

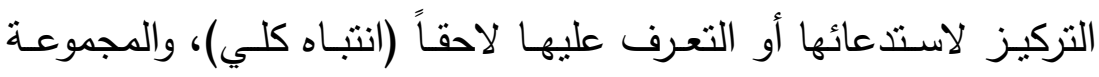

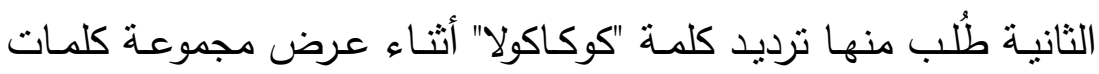

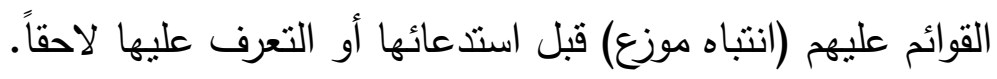

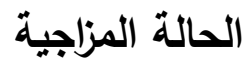

تثتير الحالة المزاجية إلى الميل العام للطالب نحو السلوك السعيد أو الو الس

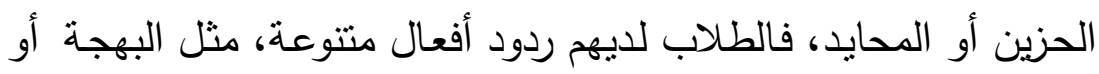
السعادة والحزن. وفي البحث الحالي تم تقسيم الطلاب في ضواء النهاب النهاية العظىى لمقياس الحالة المزاجية إلى: 
الطـلاب ذوو الحالـة المزاجيـة الموجبـة: والذين حصلـوا على درجـات

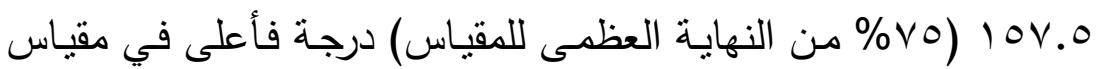
الحالة المزاجية المستخدم في البحث الحالي.

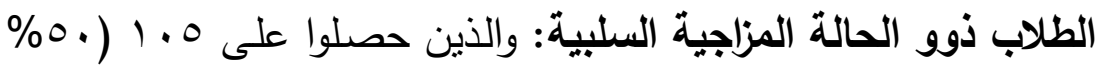
مـن النهايـة العظمى للمقيـاس) درجـة فأققل في مقيـاس الحالـة المزاجيـة المستخدم في البحث الحالي. الطلاب ذوو الحالة المزاجية المحايدة: والذين حصلوا على درجات ثقع بين هـ 1 درجة و ov.0V درجة في مقياس الحالة المزاجية المستخدم في

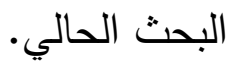

الأكرة الالالية في نموذج ديزي/روديجر -ماكديرموت DRM:

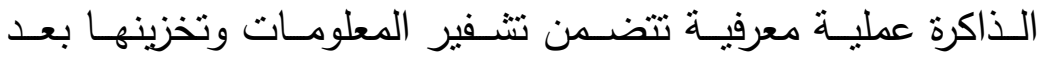

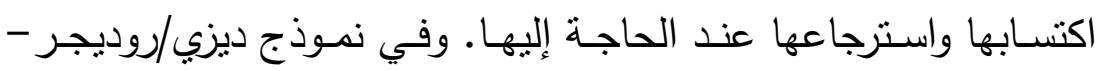

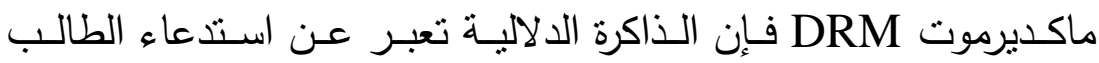

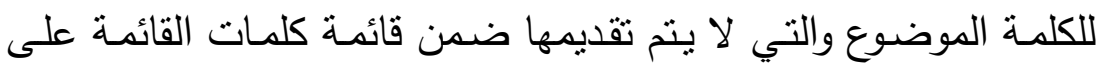
أنها وردت بالقائمة، ويتم قياسها بنسبة الكلمات الموضوع التي تم تعرفها على أنها وردت بالقائمة.

الذاكرة اللفظية في نموذج ديزي/روديجر -ماكديرموت DRM: في نموذج ديزي/روديجر -ماكديرموت DRM تعبر الذاكرة اللفظية مونية عن الاستدعاء الصحيح للكلمات التي وردت بالقائمة، ويتم قياسها بنسبة عدد الكلمات الصحيحة التي تم تعرفها في اختبار التعرف. الإطار النظري والبحوث السابقة: يتتاول هذا الجزء من البحث عرضـاً لنظريـة الثبكة الانفعاليـة Network Theory of Affect Socio-Emotional Selectivity Theory للذاكرة المنسـمة مـع الحالـة المزاجيـة، بالإضـافة إلى البحوث المرتبطـة 
بأثر كل من توزيع الانتباه، والحالة المزاجية في الذاكرة اللفظية والذاكرة

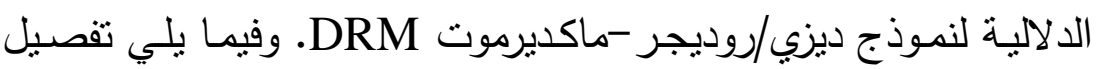
ذلك:

\section{Network Theory of Affect}

نظرية الثبكة الانفعالية

في نظريـة الثـبكة الانفعاليـة، يـتم عـزو أخطـاء الـذاكرة الخاصــة بالكلمات الموضوع غير الانفعالية إلى الارتباطات الدلالية بين الكلمات

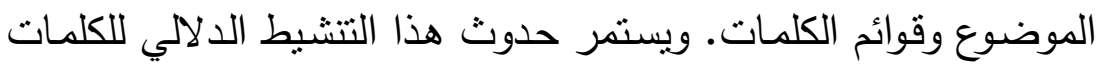
الموضـوع عندما يكون هنالك تكافؤ بين الكلمـات الموضـوع، ومـع ذلك فئ

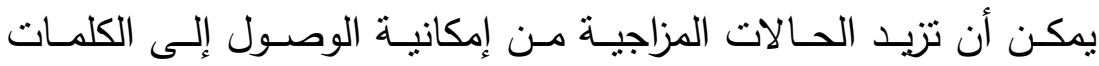

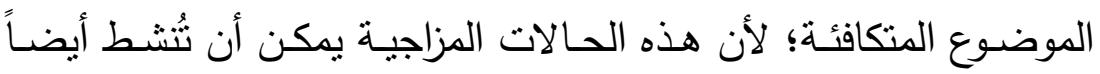

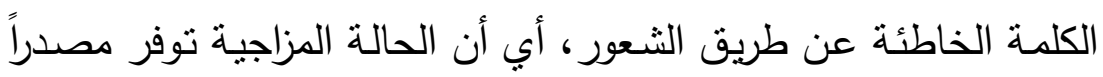

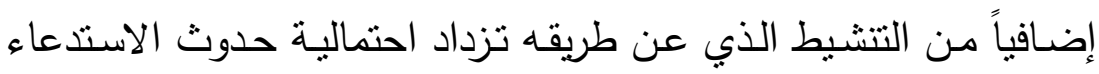

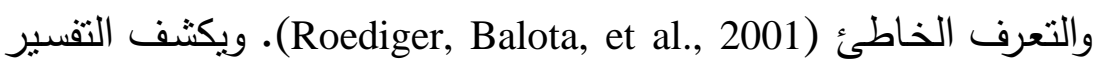

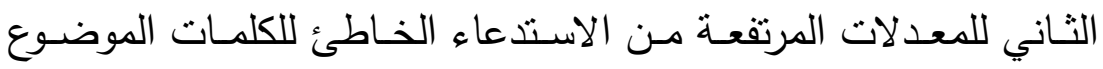

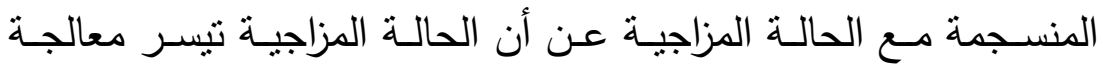
القوائم المنسمة مي الحالة المزاجية عند عرضها، ومن ثم تعزز الحالة المزاجية المستحثة (المصطنعة) الارتباطات الموجودة بالفعل بين قوائم

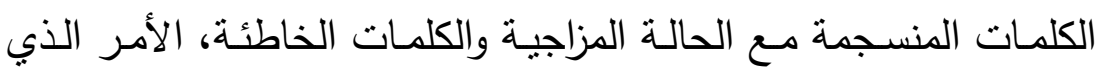

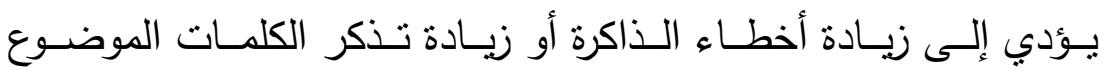
.(Ruci, Tomes, \& Zelenski, 2009) كما تقدم نظريـة الأثر الغامض تفسيراً آخر مفاده أن الخبرات تترك

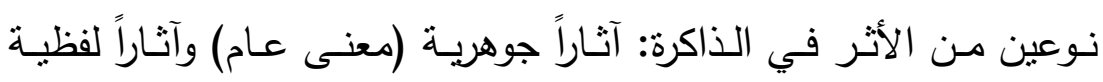

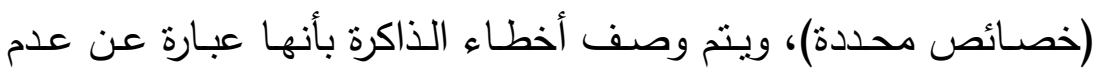

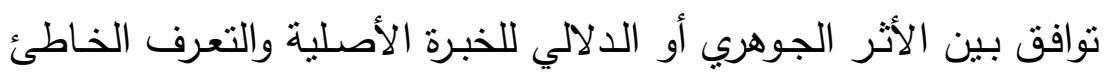




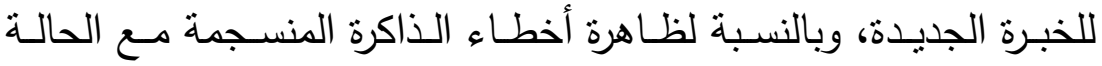
المزاجية فمن الممكن أن بدعم تكافؤ الحالة المزاجية المعلومات الداهلاهية

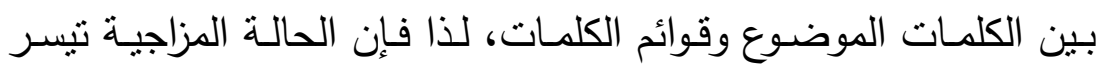
الاستدعاء الخاطئ لنفس الكلمات الموضوع عندما يتم تقديم قوائم انفعالية متكافئة)(Ruci et al., 2009).

يتبين من العرض السـابق لنظريـة الثبكة الانفعاليـة أن التذكر

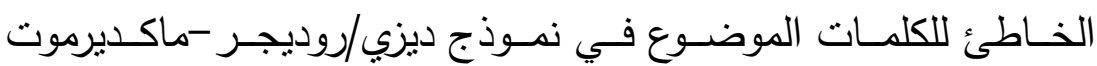

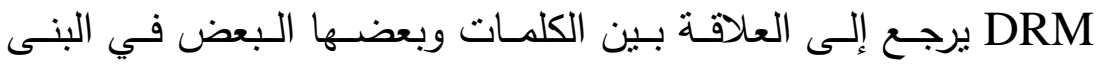
المعرفية للطلاب، ومـا تكونـه هذه الكلمات من شبكة ترابطات، فإذا تم

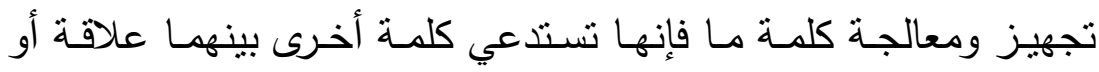
ارتبـاط، وهكذا مكونـة بـللك شبكة ترابطـات أثنـاء تجهيز ومعالجـة هذه الكلمات، وهذا التجهيز وانتقاء الكلمات في تلك الثبكة يرتبط بالحالة

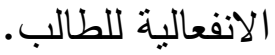
نظريـة الانتقاء الانفعالي/الاجتماعي: Socio-Emotional Selectivity Theory

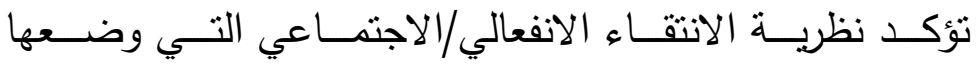
كارستتسن (Carstensen, 1992) على أنه مـع التقدم في السن، يصبح

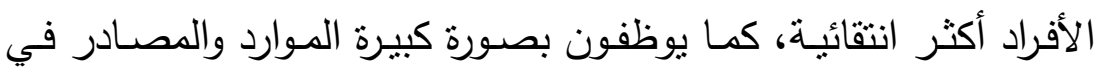

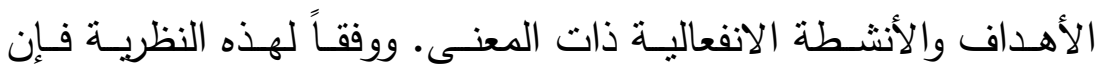
التحولات التحفيزيـة تؤثر في العمليات المعرفية. حيث يرتبط التقدم في العمر مع التفضيل النسبي للمعلومات الإيجابية على المعلومات السلبية في الانتباه والذاكرة ويسمى "تأثنير الإيجابية" Positivity Effect. ويمثل الرضا الانفعالي لكبار السن أهمية كبيرة، لذا غالباً ما يقضون الكثير من الإيجايه ونه

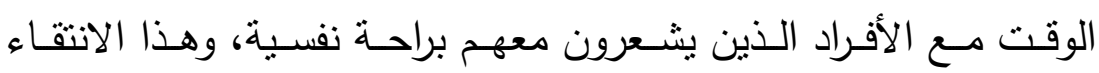

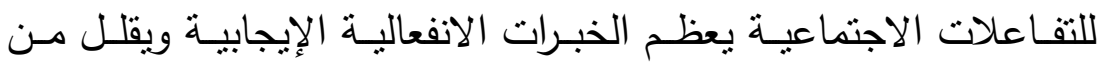


المشكلات الانفعالية كلما أصبح الأفراد أكبر سناً. ووفقاً لهذه النظرية، فإن كبار السن يوسعون بانتظام من شبكة علاقاتهم الاجتماعية بحيث الاتئ

يلبي شركاؤهم الاجتماعيين احتياجاتهم الانفعالية (Santrock, 2008).

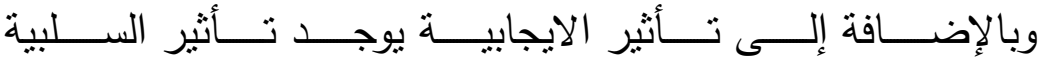
Negativity Effect المنكافئة، فإن الأثياء ذات الطبيعة السلبية (على سبيل المثال الأفكار

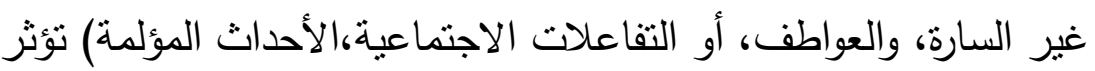

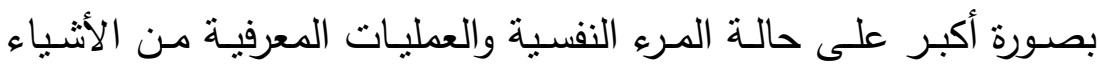
الدحايدة أو الإيجابية، وبعبارة أخرى، فإن الشيء السار جداً أو الإيجابي

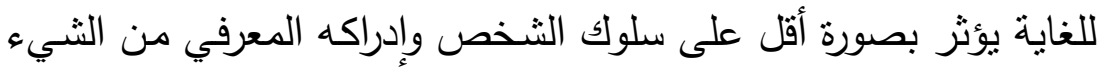

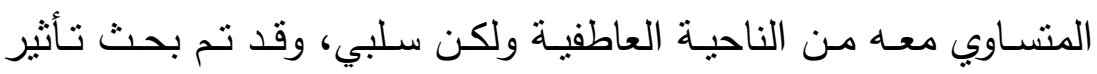
السلبية في علاقته بالعديد من المجالات المختلفة، بما في ذلك نتكيل الكيل الانطباعات والانتباه والتعلم والذاكرة وصنع القرار ، فقد قضى الششاركون وقتا أطول في النظر في الصور السلبية من الصور الإيجابية، وبالمثل، الصاكل سجل المشاركون أكثر وميضاً للعين Eye Blinks عند دراسة الكلمات السلبية من الكلمات الإيجابية كما ارتبط معدل الومض إيجابياً مع النثاط ر للف المعرف

.(Baumeister, Finkenauer, \& Vohs, 2001; Rozin, \& Royzman, 2001) وبصرف النظر عن بحوث وميض العين، لاحظ "باوميستير وزملاؤه" (Baumeister et al., 2001)

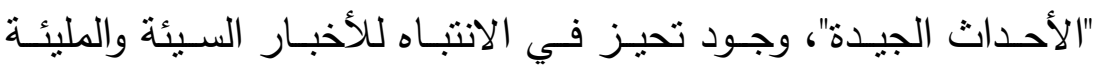

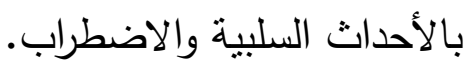
وفي هذه النظرية يوجد نوعين من الأهداف والتي يحرص الأفراد على الإلى

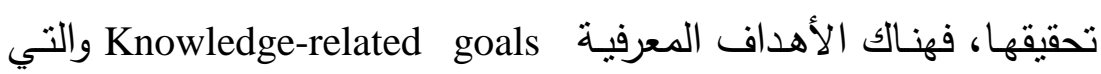


تسـهم في: اكتســاب المعرفـة، والتخطيط الـوظيفي، وتطـوير العلاقـات

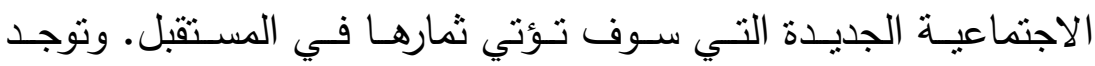

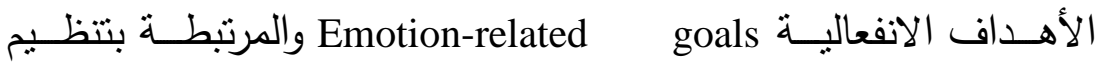
الانفعـالات، والسـعي للتفـاعلات المرضـية مـن الناحيـة الانفعاليـة مـع

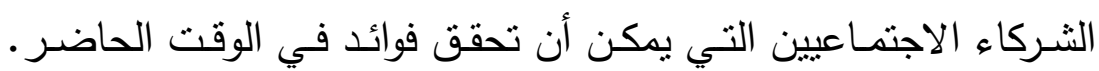
عندما يدرك الأفراد مستقبلهم كنهايات مفتوحة، فإنهم يميلون إلى التركيز

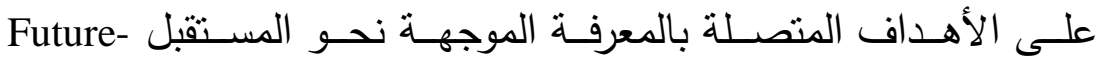

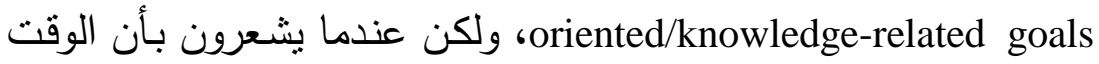

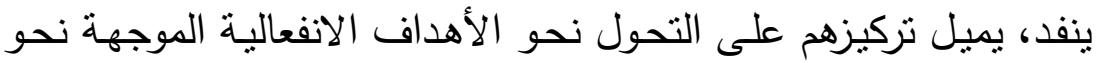
(Santrock, Present-oriented/emotion-related goals الحاضـر $.2008)$

إن سبب هذه التحولات في الهدف ليس السن نفسه، بمعنى أنه ليس مرور الوقت نفسـه، وإنما التحول المرتبط بـادراك الوقت في هذا العمر (Santrock, 2008) Age-associated shift in time perspective التحول لـه مـا يبرره في هذا المنظور هو مـا يعرف باضطراب الإدراك

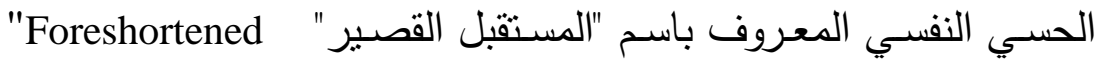

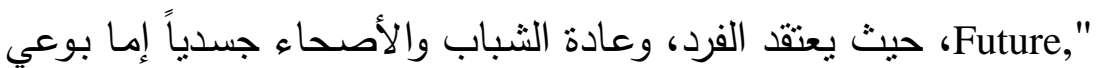

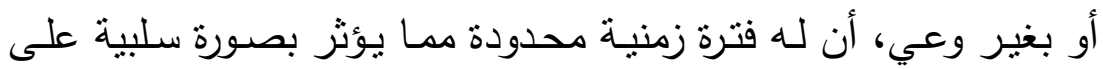

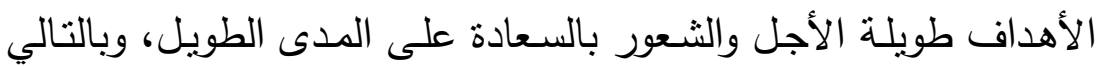
التحول من الاستثمار للمستقبل إلى تقليل النشاط في كثير من الأحيان (Grossmann, Karasawa, Kan, \& Kitayama, 2014)

العرض السـابق لنظريـة الانتقاء الانفعالي/الاجتمـاعي فإنسه ووفقاً لهذهـ

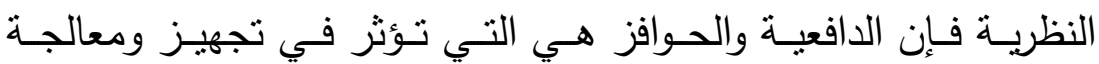

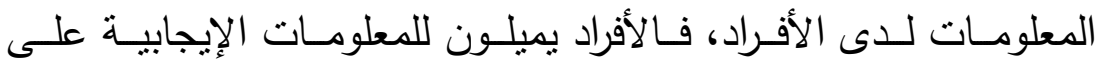

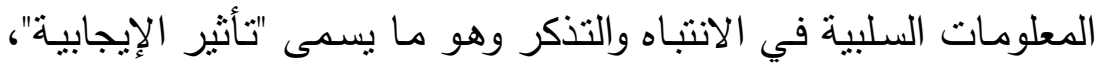


وعلى الـرغم مـن ذلك إلا أن الأحـداث أو المعلومـات السـلبية أو غيـر

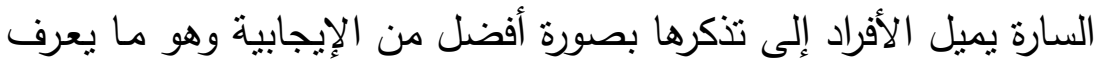

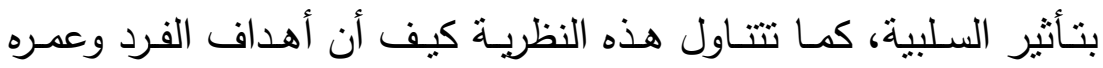
يمكن أن يؤثرا في مستوى انتباهه وإدراكه ومن ثم التعلم والتنكر .

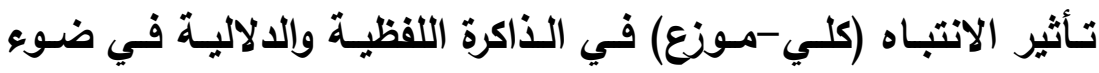
:DRM نموذج ديزي/روديجر -ماكديرموت يتضمن التنشيط المدرك للكلمـات الموضوع أهميـة قصوى من أجل الحصول على درجات موثوق فيها من الذاكرة الدلالية، ومع ذللك فإنه من النه الممكن أن يكون لمهمة الكبت أو توزيع الانتباه تأثيراً أكبر محدداً للقدرات

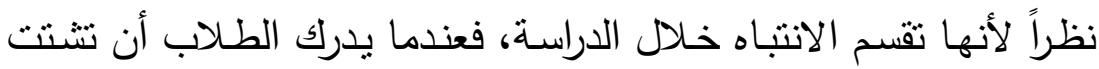
أو توزيع الانتباه سيؤدي إلى ضعف أدائهم في التعرف على كلمات قوائم

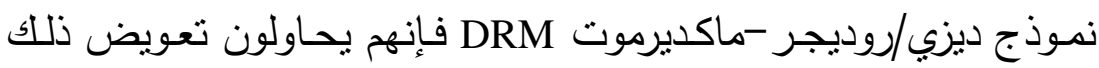

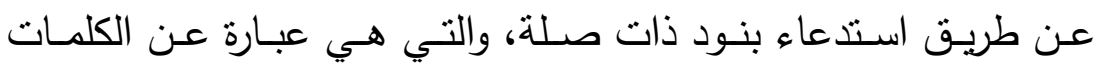
الموضوع، لذا فإن تشتت الانتباه يؤدي إلى زيادة في الاستدعاء الخاطئ للكلمات الموضوع (Dewhurst et al., 2005; 2007). كما بين "بيريز ماتا وزمـاؤه" (Pérez-Mata et al., 2002) أن التجهيز السطحي لكلمات قوائم نموذج DRM بسبب تتنت الانتباه يمكن أن يؤدي إلى زيادة في

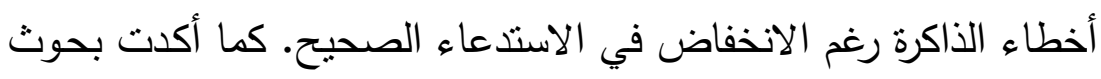

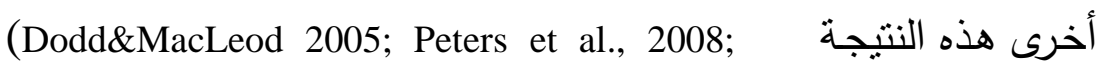
(Pérez-Mata et al., 2002) كما أثنار (Wimmer \& Howe, 2010) أن الذاكرة الدلالية أو الاستدعاء الخاطئ للكلمات الموضوع يزيد عندما ينقسم الانتباه مع أداء المهمة الثانوية أثناء الاستماع لكلمات القواء القوائم التي

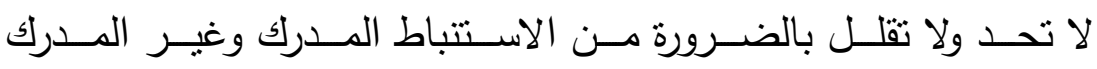
للاستجابات المرتبطة، ولكنها تمنع المشاركين من ترميز أو مراقبـة أو 
تحديد العمليات المعرفية والخبرات الصوتية المصاحبة للارتباطات. وهذا الحد والانخفاض في المعلومات المميزة والصوتية المنمركزة حول الكلمات

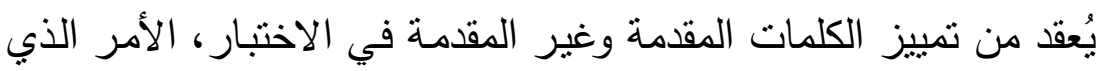

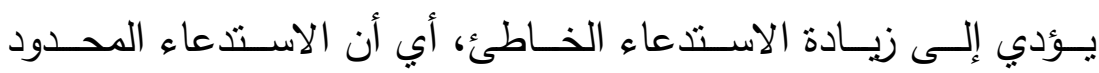

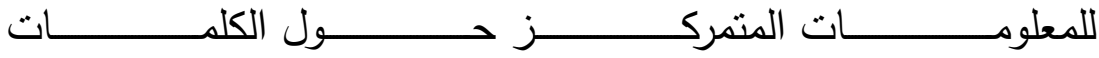

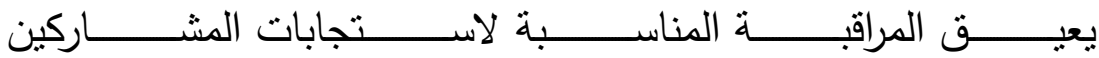
.(Goodwin, Meissner, \& Ericsson, 2001; Marsh \& Bower, 2004) وعلى النقيض فقد بينت نتائج بعض البحوث انخفاضاً في استدعاء

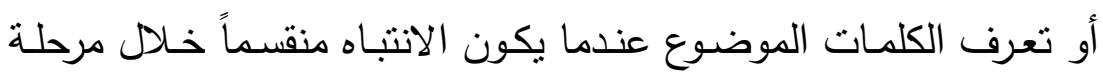

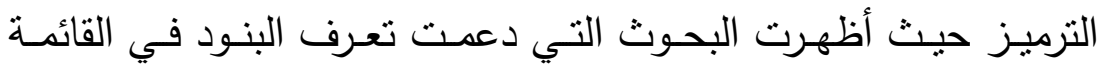
أن تكرار كلمات القائمة (Benyamin, 2001; Seamon et al., 2003) واستماع وكتابة الكلمات المقدمة يؤدي إلى انخفاض في الذاكرة الدلالية في نموذج ديزي/روديجر -ماكديرموت DRM ، الأمر الذي دعم دور الآثار اللفظية Verbatim Traces في دعم عمليات المراقبة المستتدة إلى

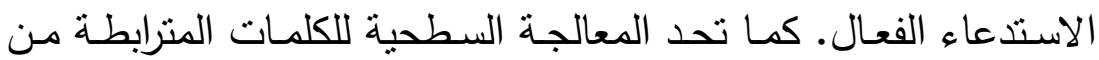

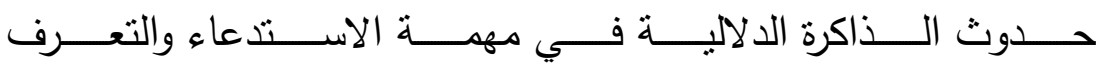

(Toglia,Neuschatz,\&Goodwin,1999;Rhodes\&Anastasi,2000; . Thaper \& McDermott, 2001) يتبين من عرض البحوث السابقة والمرتبطة بتأثير الانتباه في الذاكرة

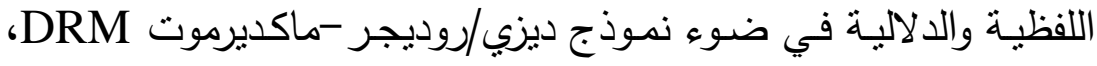
تعارض نتائج هذه البحوث، فمن هذه البحوث ما يؤكد أن نتشت الانتباه

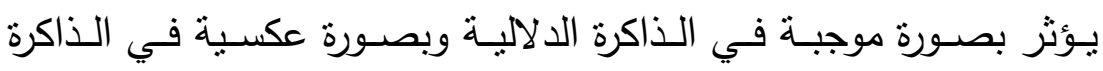
(Dewhurst et al.,2005;2007;Peters et al.,2008;Wimmer\&Howe, اللفظية (2010، مفسرين ذلك في ضـوء نظريـة الثبكة الانفعالية ونظريـة الأثر الغامض. ومنها مـا توصل إلى نتائج مناقضـة لهذا فيما يتعلق بالذاكرة 
الدلاليـة، حيث توصـلت هذه البحوث إلى أن تثـتت الانتبـاه يقلل مـن

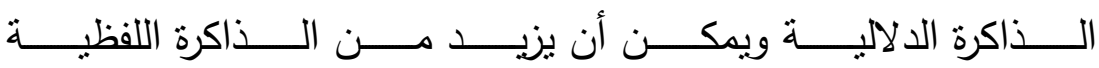
(Rhodes \& Anastasi, 2000; Benyamin, 2001; Thaper \& .McDermott, 2001; Seamon et al., 2003) تأثير الحالـة المزاجيـة في الذاكرة اللفظيـة واللالاليـة في ضوء نمـوذج :DRM ديزي/روديجر -ماكديرموت

تعزز الذاكرة المثيرات الانفعالية بصورة أفضل عند مقارنتها بالمثيرات

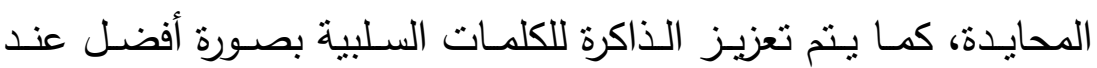
(Cahill \& McCaugh, 1996; Ochsner, مقارنتها بالكلمات المحايدة 2000; $\quad$ Hamann, $\quad$ 2001) إلى تزايد احتمالية تذكر الأفراد (Kensinger \& Corkin, 2003b)

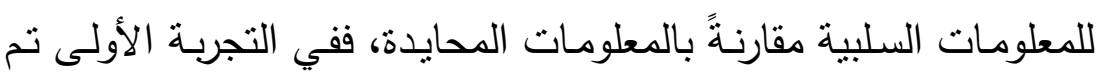

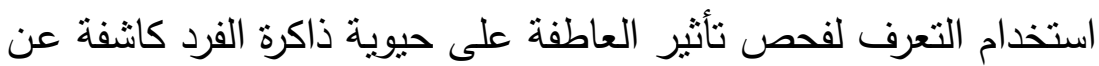
أن استجابات التذكر يتم تخصيصها بصورة أكبر للكلمات السلبية مقارنة بالكلمات المحايدة، وفي التجربة الثانية نم استخدام نموذج ذاكرة المصدر لهر

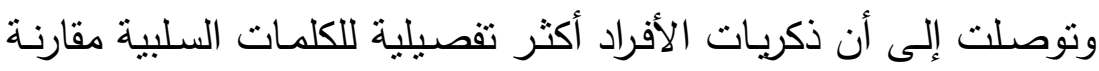

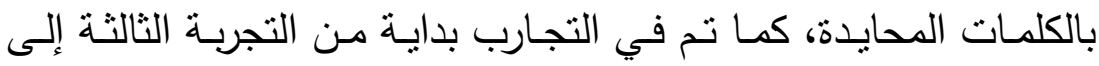
التجربـة السادسـة فحص المسـاهمة النسـبية للكلمـات المحايـدة والمثيـرة للانفعالات Valence and Arousal، مستخلصين أن البعدين يزيدان من

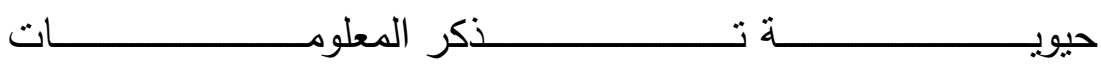
Vividness of Remembered Information بصورة أكبر من المعلومات الحيادية. قام (Moritz, Glascher, \& Brassen, 2005) ببحث تعرف أخطاء الذاكرة (الذاكرة الدلاليـة) والذاكرة الصحيحة (الذاكرة اللفظيـة) في حالـة 


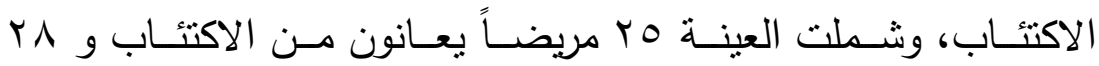

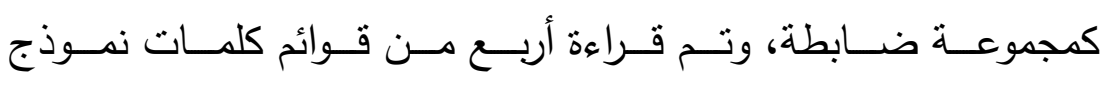
ديزي/روديجر -ماكديرموت DRM للمشاركين بالتسلسل ثم تبع ذلك مهمة تعرف، وارتبطت الكلمات في كل قائمة من القوائم الأربع بكلمة موضوع باتع

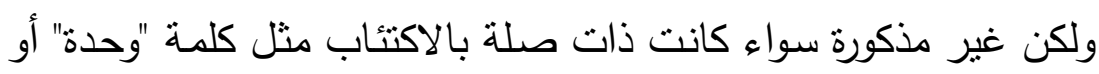

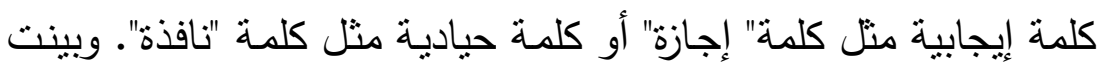
النتائج وجـود فـروق دالـة بـين مرضسى الاكتئـاب والعـاديين في تـذكر الكلمـات الموضـوع (الذاكرة الدلاليـة) المرنبطـة بالحالـة المزاجيـة السلبية

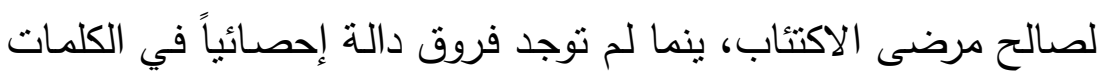
المحايدة ولا الكلمات الموجبة، وكذللك الذاكرة اللفظية. وأكدت نتائج بحث (Anderson \& Shimamura, 2005) التأثنرات المتعددة للانفعالات على أداء الذاكرة، فقد استمع المشاركون إلى كلمات قوائم نمـوذج ديزي/روديجر -ماكديرموت DRM أثنـاء مشــاهدة مقاطع

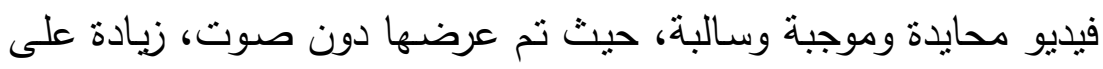
ذلك تـم تقيـم الذاكرة بطـرق ثـلاث كمـا يلي: استـدعاء محتوى الفيلم واستدعاء الكلمات وتعرف السياق، وفي اختبار تعرف السياق تم تقديم

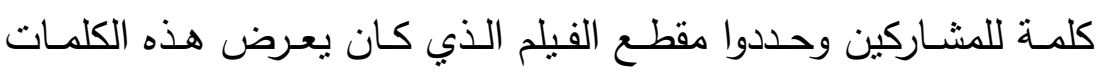
عندما تم عرض الكلمة في الأول. وبينت النتائج قصور في أداء الذاكرة

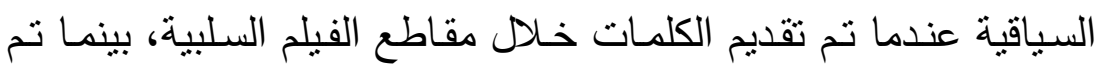

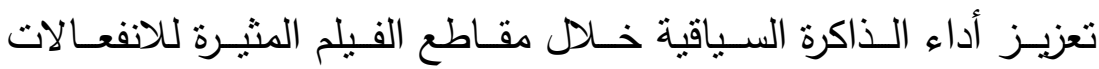
الإيجابية، كذللك بينت النتائج وجود قصور في الاستدعاء الحر للكلمات المقدمة خلال الأفلام السلبية. وبين بحث (Storbeck \& Clore, 2005) انخفاضاً ملحوظاً في الذاكرة الدلاليـة في نمـوذج ديزي/روديجر -ماكديرموت DRM للأفراد ذوي الحالات المزاجية السلبية مقارنة بالأفراد ذوي الحالات المزاجية الايجابية 
أو الأفراد ذوب الحالات المزاجية المحايدة، وأكدت نتائج البحث أن الحالة

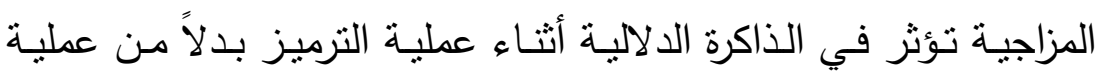
المراقبة عند الاسترجاع. وفي بحث (Piguet, Connally, Krendl, Huot, \& Corkin, 2008) للى

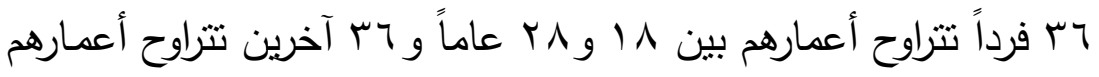

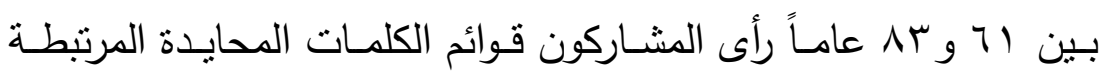
بالكلمـات الموضـوع السـلبية أو المحايـدة أو الإيجابيـة غيـر الموجـودة،

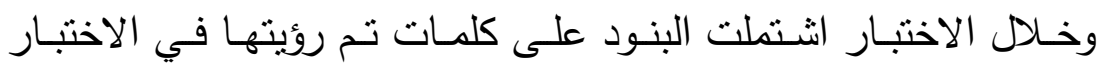

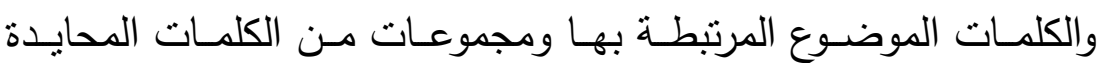
المرتبطة التي لم يتم رؤيتها في الاختبار والكلمات الموضوع المرتبطة

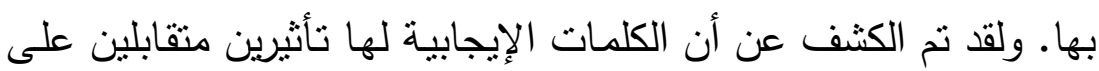

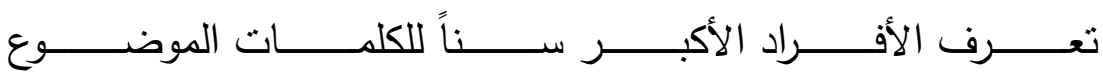
(الذاكرة الدلالية)، حيث أنه زاد من الذاكرة الدلالية للكلمات الموضوع ولم يحسن من التذكر الصحيح لقوائم الكلمات (الذاكرة اللفظية).

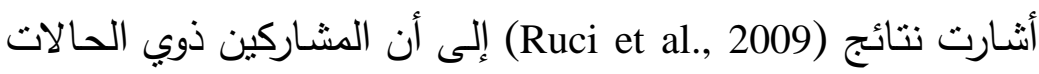

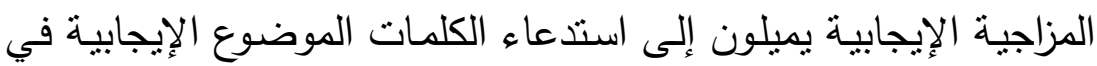
نموذج ديزي/روديجر -ماكديرموت DRM استدعاءً خاطئاً، بينما يميل الإيل المشاركون في الحالات المزاجية السلبية إلى استدعاء الكلمات الموضوع ديرئ

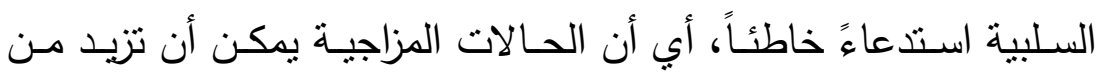
الذاكرة الدلالية لنموذج ديزي/روديجر -ماكديرموت DRM. ويرى (Knight \& Mather, 2009) أن التعزيز المستحث (المستثار) عن طريق الانفعالات Emotion-Induced Enhancement من المحتمل

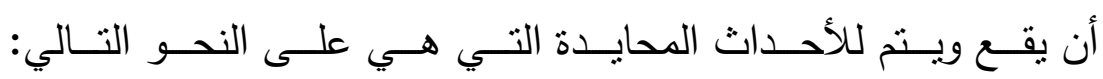

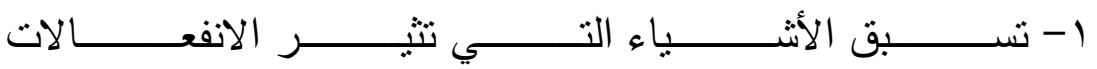




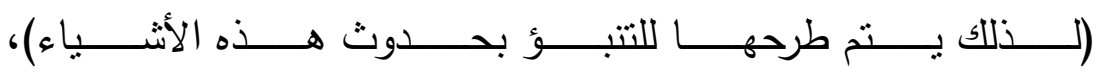

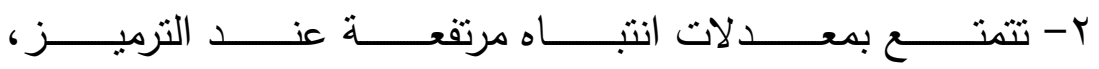

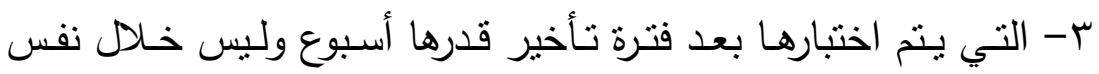
جلسـة التجربة، وعلى النقيض، من المحتمل أن يقع التشويه المستحث

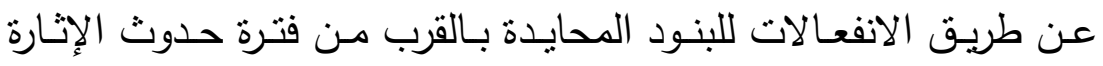
الانفعالية التي تغطيها البنود التي ينم تتشيطها بصورة كبيرة خلال فترة التزميز

وفي بحث (Choi \& Kensinger, 2013) عندما تطلبت مهمة الترميز معالجـة الارتبــاط الموضـوعي للكلمـات، ظهـر تعزيـز حقيقـي للـذاكرة

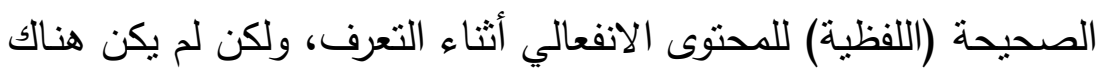

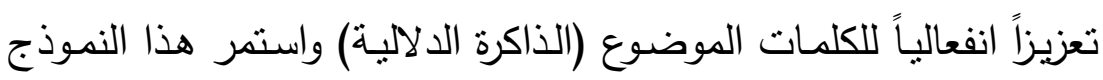
للاكرة الصحيحة لفترة زمنية أطول للاستبقاء بين الدراسة والاختبار قدرها أربع وعشرين سـاعة وانخفض مستوى الذاكرة الدلالية للبنود الانفعالية، كما أكدت النتائج أنه عندما تكون المنيرات الانفعالية والمحايدة مرتفعة واندة بصسورة منسـاوية تستمر الحالـة الانفعاليـة في تحسين التذكر الصـحيح (الذاكرة اللفظية) ولكن لا يتم ذلك في الذاكرة الدلالية. وقام (Baure et al., 2009) ببحث أثر نوع الكلمة في الذاكرة الدالالية في نموذج ديزي/روديجر -ماكديرموت DRM حيث استمع المشـاركون

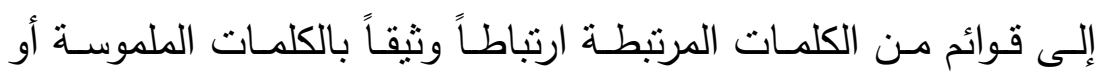

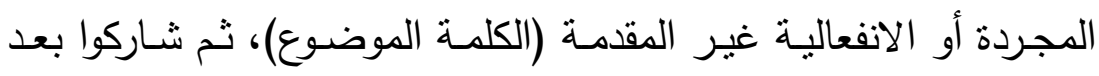

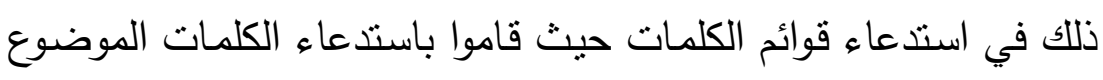
بصورة خاطئة (ذاكرة دلالية) بمعدل مرتفع بصورة دالة إحصائياً مقارنةً بالكلمات الموضوع المجردة والملموسة. كما بحث (McKeon, Pace-Schott, \& Spence, 2012) إمكانية تغيير الانفعالات من تأثنر النوم على تكوين الذاكرة الدلالية في نموذج 
ديزي/روديجر -ماكديرموت DRM، حيث استمع المشـاركون إلى قوائم الكلمات المترابطة دلالياً وتحتاج إلى كلمات موضوع تمثل خلاصـة كل

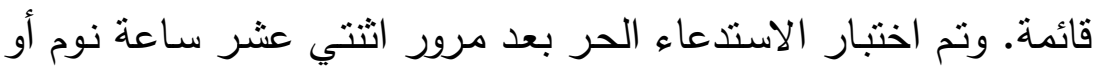

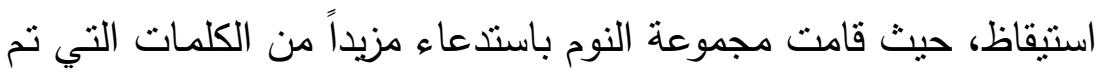
دراستها مقارنـة بمجموعـة الاستيقاظ فيمـا يتعلق فقط بـالقوائم المحايدة. وأكدت النتائج أن الذكريات الخاطئة للكلمات الموضوع السلبية والمحايدة كانت أكثر بعد النوم مقارنة بالاستيقاظ.

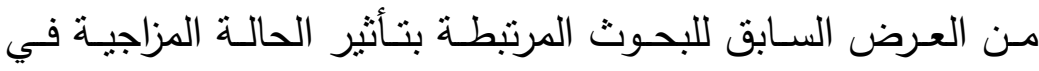

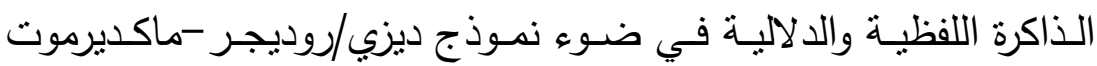
يتبين كيف أن الحالة الانفعالية للفرد أو الطالب يمكن أن تؤئز في معالجته وتجهيزه لما يقدم له من معلومات، فهناك الانفعالات كمعرفة

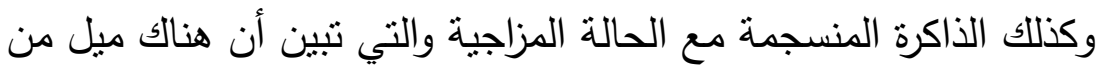
قبل الطلاب لمعالجة المعلومات الانفعالية سواء كانت موجبة أو سالبة والتي تتسق مـع حالتهم المزاجية بصورة أفضل من تلك التي لا ترتبط

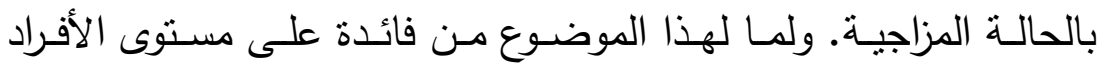
والطلاب وغيرهم فقد نال اهتمام العديد من الباحثين في الفترة الأخيرة (Knight\&Mather,2009; Baure et al., 2009; McKeon et al., 2012;

.Choi \& Kensinger, 2013)

\section{فروض البحث}

في ضوء ما سبق عرضها من بحوث مرتبطة بهدف البحث الحالي،

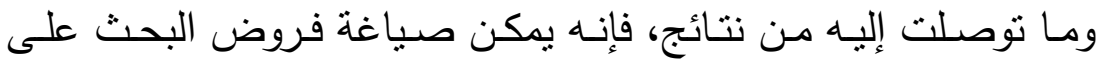

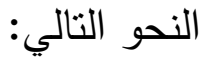


ا ـ لا يوجد نأثير دال إحصائياً للحالة المزاجية (موجبة-محايدة-سلبية)

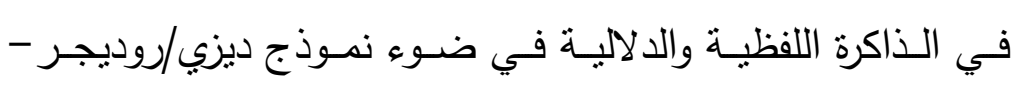

$$
\text { ماكديرموت DRM. }
$$

r. لا يوجد تأثنر دال إحصائياً للانتباه (كلي -موزع) في الذاكرة اللفظية

والدالية في ضوء نموذج ديزي/روديجر -ماكديرموت DRM.

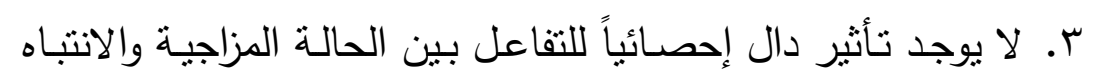

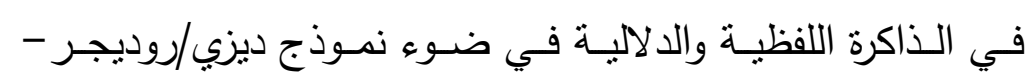

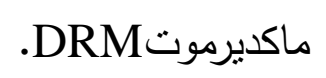

إجراعات البحث

$$
\text { منهج البحث }
$$

تم استخدام المنهج شبه التجريبي لملاعمته لطبيعة وأهداف البحث.

$$
\text { المشاركون في البحث }
$$

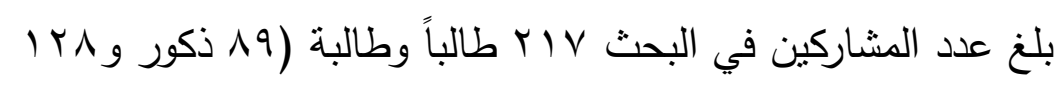

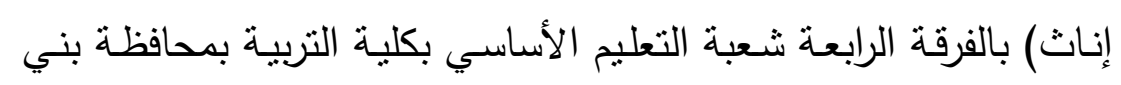

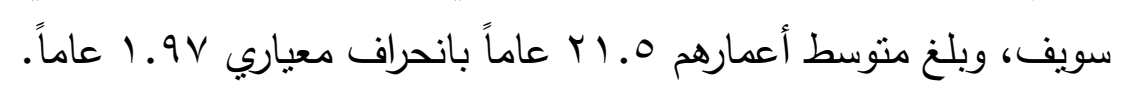

\begin{tabular}{|c|c|c|c|}
\hline \multirow{2}{*}{ المجموع } & \multicolumn{2}{|c|}{ الانتباه } & \multirow{2}{*}{ الحالية المزاجية } \\
\hline & هونع & كلي & \\
\hline 10 & $r \mu$ & rr & موجبة \\
\hline 19 & $\vdots \xi$ & $\leqslant 0$ & محايدة \\
\hline $4 \pi$ & $r r$ & $r 1$ & سالبة \\
\hline riv & 1.9 & 1.1 & المجموع \\
\hline
\end{tabular}

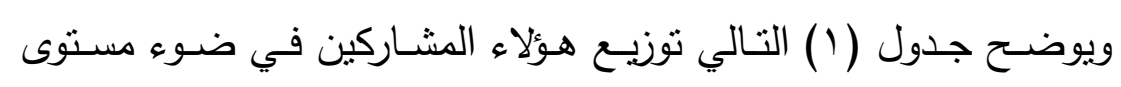
الانتباه (كلي -موزع) والحالة المزاجية (موجبة-محايدة-سالبة). جدول (1) توزيع المشاركون في البحث في ضوء مستوى الانتباه والحالة المزاجية 


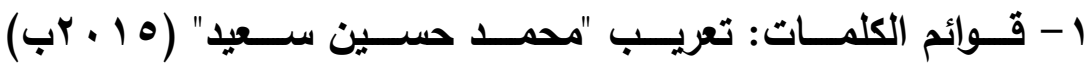

(ملحق r (r)

تم استخدام مجموعة من قوائم الكلمات الموجبـة والمحايدة والسـالبة

(ملحق r) والمشتقة من قوائم (Roediger, Watson, et al., 2001) والتـي قـام "محمـد حسين سـعيد" (10 • Yب) بتعريبهـا. وكانـت القوائم

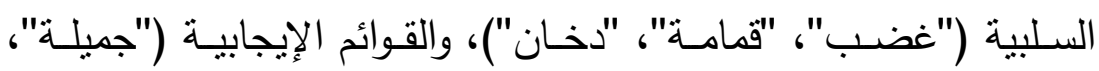

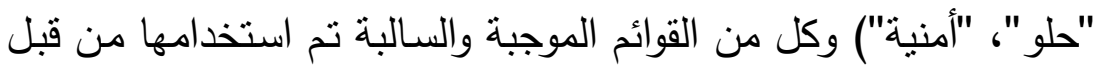

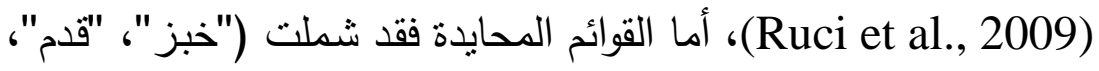

r - اختبار التعرف: إعداد الباحث (ملحق r)

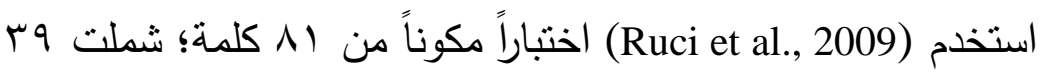

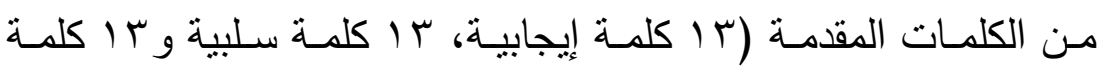
محايدة)، و ع كلمة جديدة غير معروضة (1 كلمات إيجابية، 1 كلمات

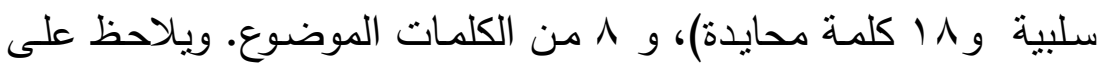
هذا الاختبـار أن الكلمات الـ بات التهي تم اختبارهـا في كل قائمـة منها كلمات ذات طابع موجب وآخر سلبي في قائمسة الكلمات الموجبة فمثنا تحتوي قائمسة الغضب على كلمة لطيف وكلمـة نـاعم وهي عكس صفة القائمة، كما لم يشتمل الاختبار على جميع الكلمات الموضوع في القوائم،

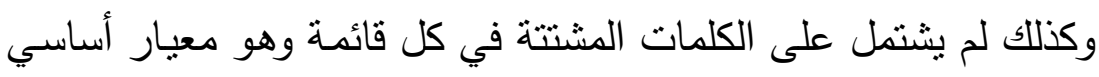
في اختبارات التعرف لهذه القوائم اتبعه العديد من الباحثين في بحوثهم لقوائم نموذج ديزي/روديجر -ماكديرموت Sugrue \& Hayne, DRM 2006; Howe, Wimmer, Gagnon, \& Plumpton 2009; Van Damme, Menten, \& d'Ydewalle, 2010; Pimentel \& Albuquerque, 2013; Beato \& Arndt, 2014;

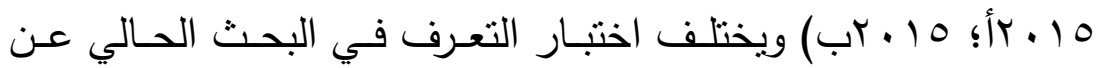


اختبار التعرف في بحث (Ruci et al., 2009) حيث يتضمن البحث

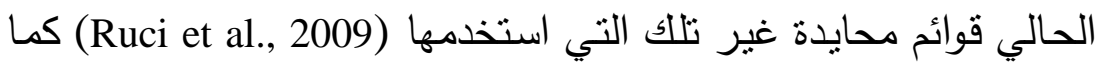

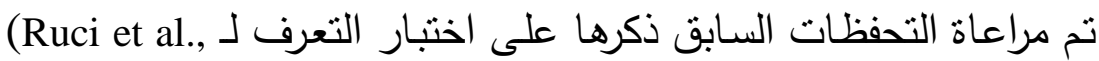
(2009 حيث تم استخدام اختبار مكون من • 9 كلمـة (ملحق م) شملت 0؛ من الكلمات المقدمـة (بواقع م كلمـات تعبر عن نوع القائمـة؛ 10

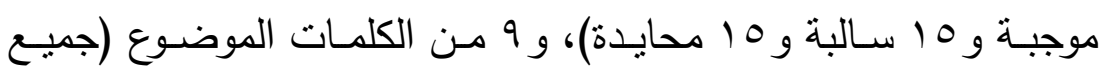

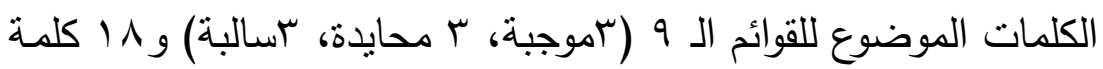

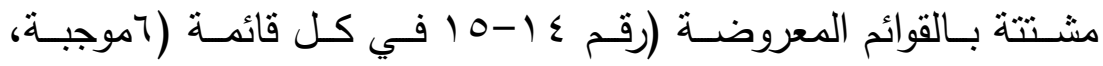

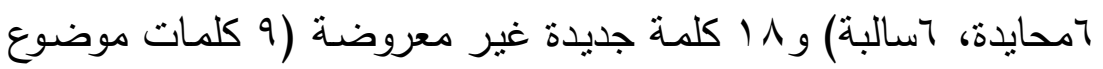
و و كلمات مشتتة لـ قوائم غير معروضة). وتم عرض الاختبار على

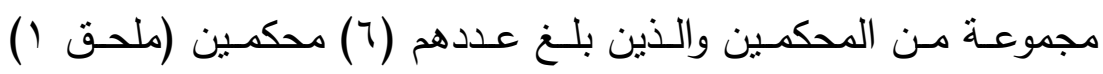

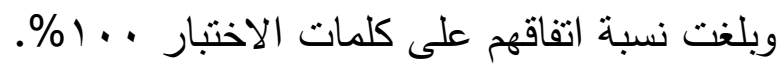

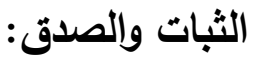

تم استخدام صـدق المحك حيث بلغت قيمـة معاملـ الارتبـاط بين

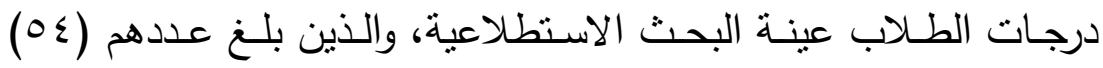

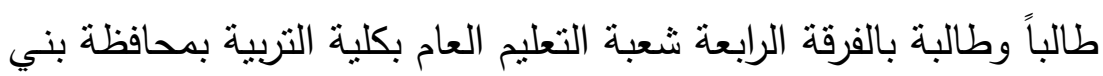
سويف، في هذا المقياس، ودرجاتهم في مقياس عمليات الذاكرة إعداد

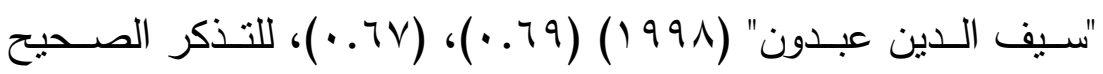
(الذاكرة اللفظية) وتذكر الكلمة الموضوع (الذاكرة الدلالية) على الترتيب.

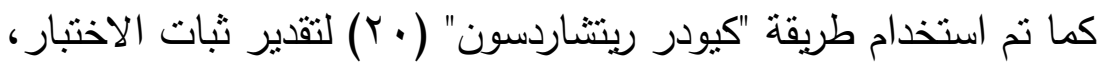

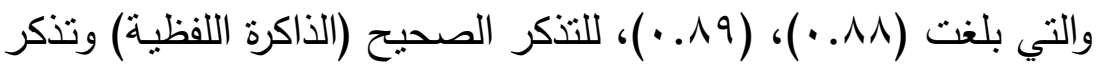
الكلمة الموضـوع (الذاكرة الدلالية) على الترتيب، وهي قيم مرتفعة تدل

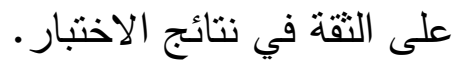


r- مقياس الحالة المزاجية: إعداد الباحث (ملحق ؛ )

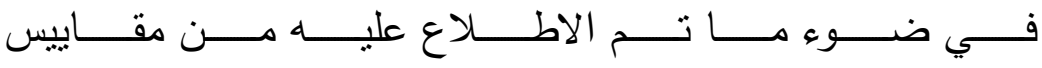
$\ddot{2}$

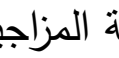

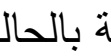
وت مرتبط

(Mayer\&Gaschke1988;Killgore,1999;Marja\&Lea,2001;Fitness\&Curtis2005) تم إعداد مقياس الحالة المزاجية (ملحق؟) ويتكون المقياس من جزأين؛

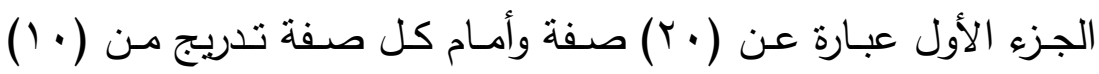
مستويات يختار الطالب المستوى المناسب لهه في ضوء حالته المزاجية،

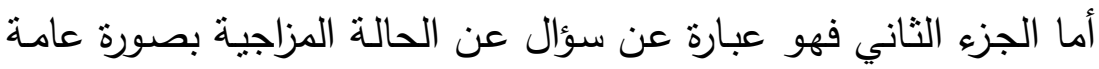

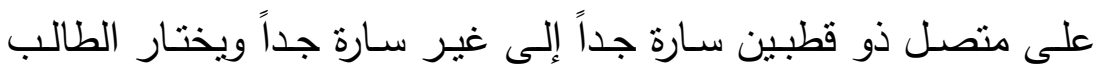
مستوى من (• (1) مستويات في ضوء الحالة المزاجية له. وبعد عرض له المقياس على مجموعة من المحكمين والذين بلغ عددهم (؟) محكمين تم

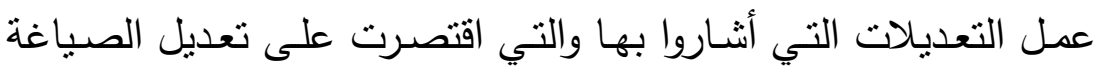

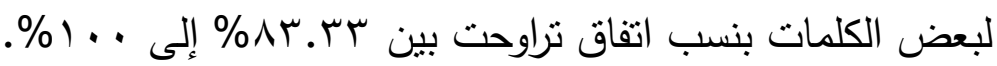

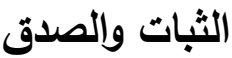

بلغــت قيمــة معامـلـل الارتبــاط لــدرجات طــلاب عينــة البحــث الاستطلاعية، والذين بلغ عددهم (ع) طالباً وطالبة بالفرقة الرابعة شعبة التعليم العام بكلية التربية بمحافظة بني سويف، على المقياس ودرجاتهم

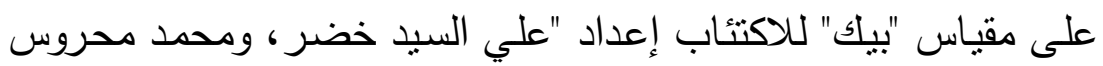

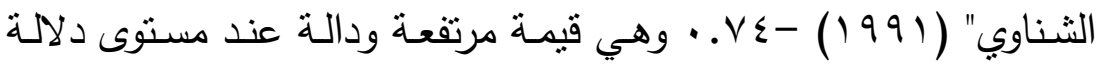

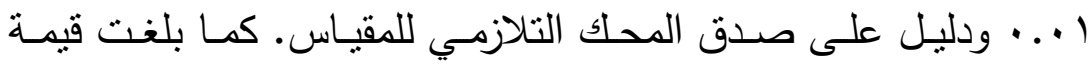

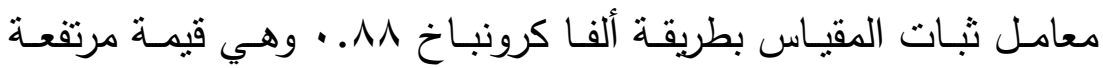




\section{إجراءات البحث}

$\ddot{\alpha}$

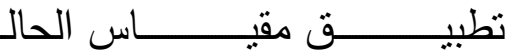

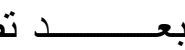

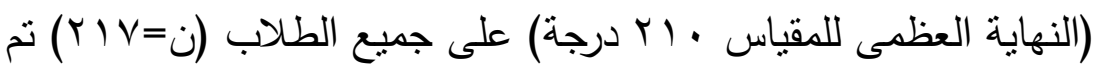
تقسيمه إلى ب مجموعات: الطلاب ذوو الحالة المزاجية الموجبة والذين

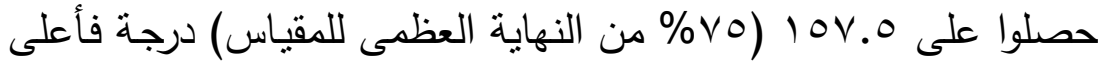

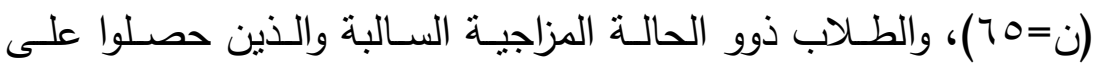

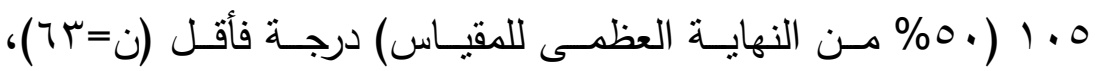

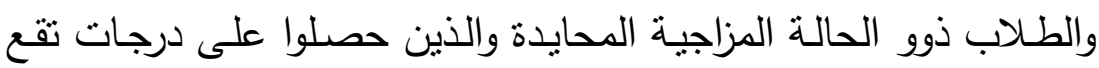

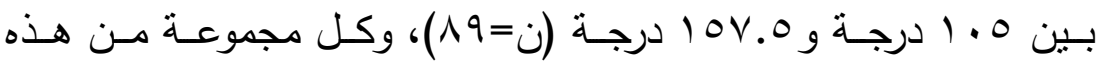

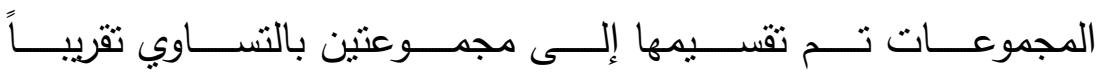
(انظر جدول ا السابق) وتم إتباع الإجراءات التالية مع كل حالة مزاجية

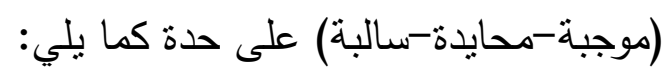
أ- إجراءات مجموعات الانتباه الكلي:

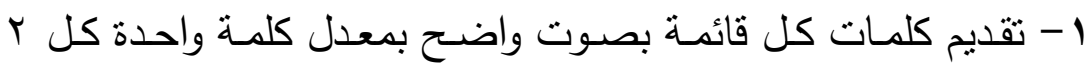

ثُوان.

ץ- تكرار هذه الخطـوات مـع جميـع قوائم البحث؛ الموجبـة والمحايـة

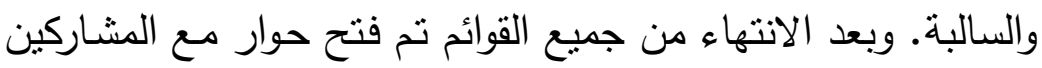

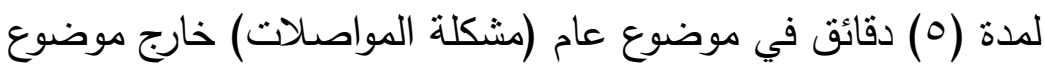
قوائم البحث، كمهمة تشتيت بهدف تقليل آثار حداثة القوائم المقدمة.

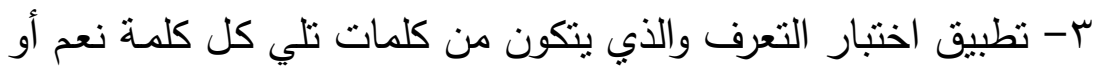
لا وينتم وضـع دائرة على نعم إذا كانت الكلمـة في القوائم التي تم

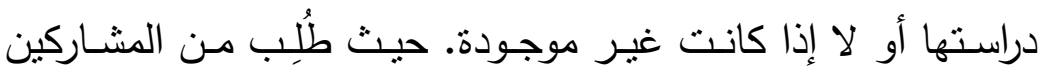
إجابة جميع الفقرات بالترتيب وعدم ترك أي كلمة بدون الإجابة عنها

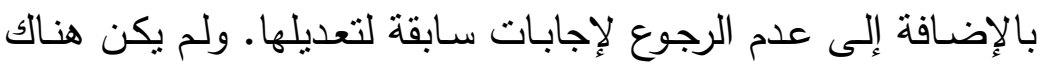
وقت محدد للانتهاء من اختبار التعرف. 


\section{ب- إجراعات مجموعات الانتباه الموزع:}

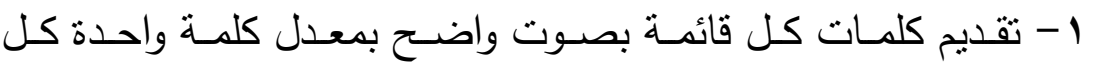

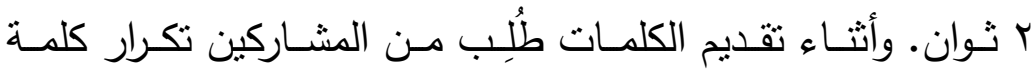
"كوكاكولا" بصوت مرتفع بمعدل مرتين لكل كلمة يتم عرضها عليهم.

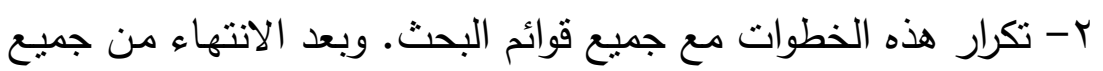

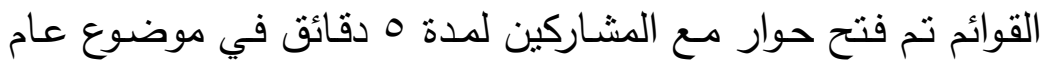

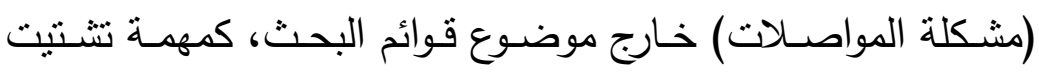
بهدف تقليل آثار حداثة القوائم المقدمة.

r- تطبيق اختبار التعرف والذب يتكون من كلمات تلي كل كلمة نعم أو

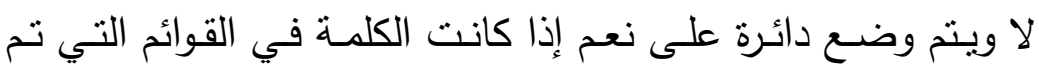

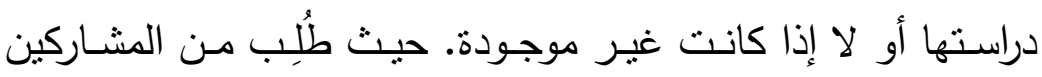
إجابة جميع الفقرات بالترتيب وعدم ترك أي كلمة بدون الإجابة عنها

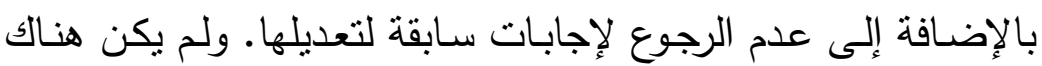

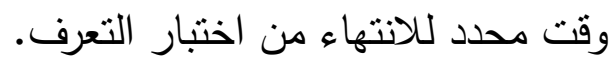
الأساليب الإحصائية

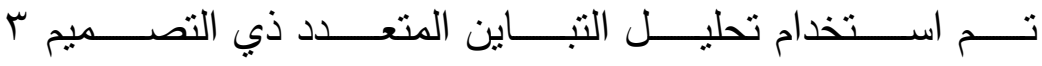

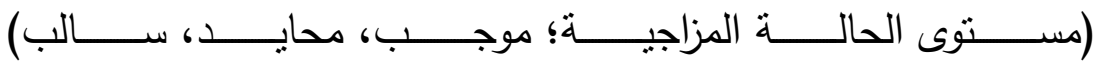
× × (الانتبـاه؛ الكلي والمـوزع)، والمقارنـات المتعـدة باسـتخدام اختبـار

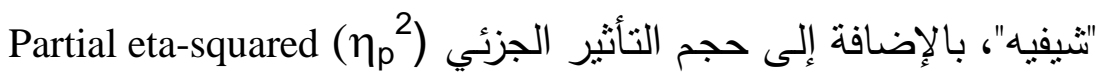
(Cohen,

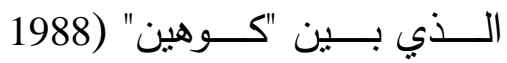

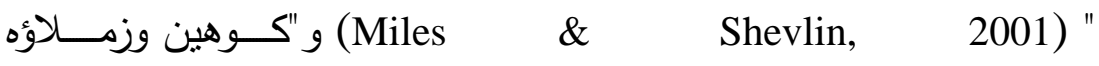

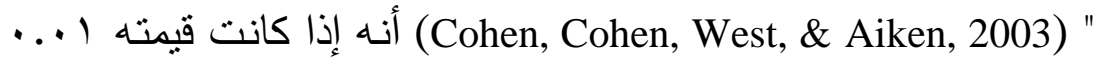

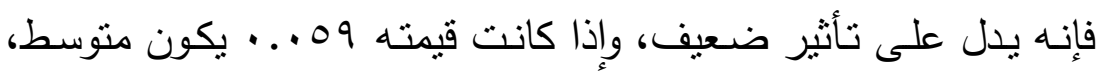

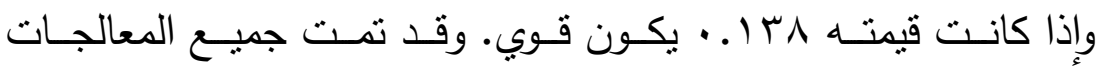




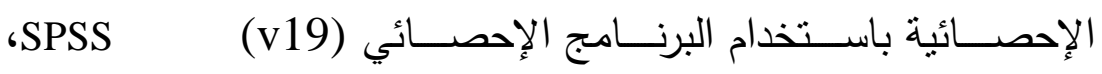

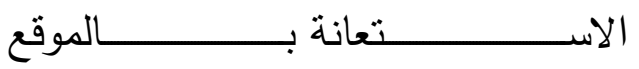
i كم

ف https://www.statstodo.com/LSDScheffe_Pgm.php\#top المقارنـات المتعددة بين مجموعات البحث الست للتفاعل بين الانتبـاه والحالـة المزاجيـة، والتي لا يتت حسابها مـن خـلال البرنـامج الإحصـائي .SPSS (v19) حدود البحث تتحد نتائج البحث الحسالي بالمشـاركين في البحث، وكذلك بقوائم

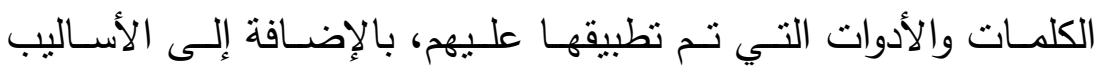
الإحصائية التي تمت معالجة البيانات من خلالها. نتائج البحث تم التأكد من التوزيع الاعتدالي لبيانات البحث؛ حيث تراوحت قيم

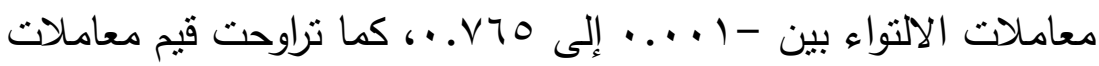

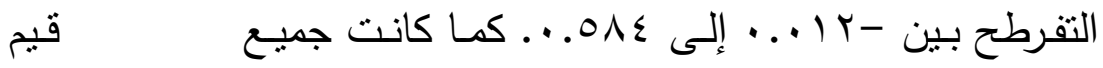

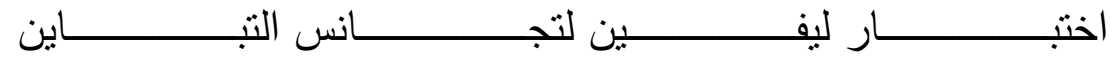
Levene's Test for Equality of Variances

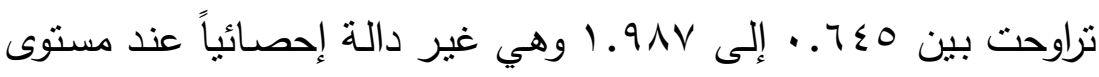

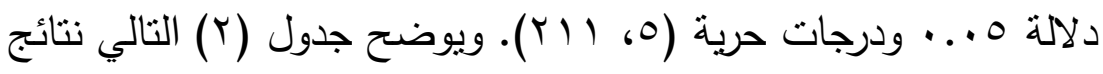

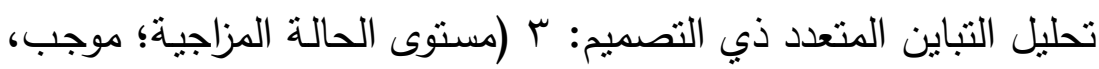
محايد، سالب) × r (الانتباه؛ الكلي والموزع) في الذاكرة اللفظية والدلالية

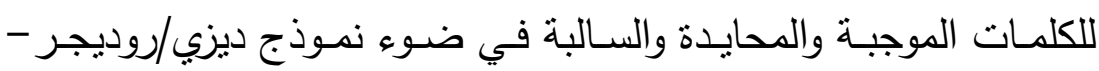

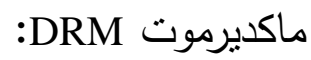




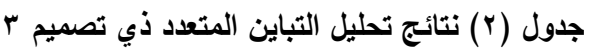

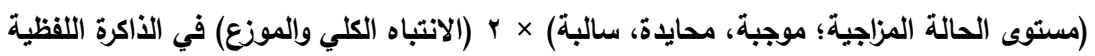

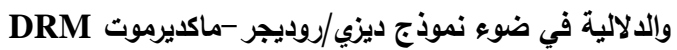

\begin{tabular}{|c|c|c|c|c|c|c|}
\hline التأثير & "ف" & متوسط المريعات & لدرجات & المربعات & المتغيرات التابعة & مصدر التباين \\
\hline צ & 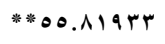 & $1 . \vee \wedge \vee$ & $r$ & r.०VE & ذاكرة لفظية موجبة & \multirow{6}{*}{ مستوى } \\
\hline- & r.Trolr. & $\ldots v \cdot 0$ & r & $-.1 \leq 1$ & ذاكرة لفظية محايدة & \\
\hline .rvaq & 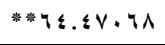 & I.rrv & r & r.7os & ذاكرة لفظية سالبة & \\
\hline . . r94 & $* * 90.0 \wedge \wedge 1 \wedge$ & l.voro & $r$ & r.v.o & ذاكرة دلالية موجبة & \\
\hline- & r.00TVAI & ...040 & r &. $.11 r$ & ذاكرة دلالية محايدة & \\
\hline .rutv & $* * 41.1 .091$ & 1.VY.0 & $r$ & r. $\leqslant \leqslant 1$ & ذاكرة دلالية سالبة & \\
\hline$\cdot r \cdot V$ & $* * \Delta 0_{.} . r \wedge \leq r$ & l.VIr & 1 & I.VTr & ذاكرة لفظية موجبة & \multirow{6}{*}{ مونعتوى } \\
\hline $.1 \mathrm{VV}$ & *** & $1 . Y 1 \leq$ & 1 & $1 . r 1 \leq$ & ذاكرة لفظية محايدة & \\
\hline.$r \cdot T$ & $* * \bullet \leq .4 . \wedge \mid V$ & $1.1 Y \leq$ & 1 & $1.1 r \leq$ & ذاكرة لفظية سالبة & \\
\hline$\because 119$ & $* * \varepsilon q . . \vee \leq Y$ ○ & I.rir & 1 & I.rir & ذاكرة دلالية موجبة & \\
\hline .rir & **०५.ห11 r. & 1.101 & 1 & 1.101 & ذاكرة دلالية محايدة & \\
\hline$\because 1 \wedge$ & 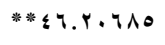 & $1 . r \cdot 1$ & 1 & $1 . r \cdot 1$ & ذاكرة دلالية سالبة & \\
\hline- & r.TAYrro & $\ldots \wedge 4$ & r &..$I V Y$ & ذاكرة لفظية موجبة & \multirow{6}{*}{ الحستة المزاجة } \\
\hline - & . TYEYYY & $\cdots 4$ & $r$ & $\ldots / r$ & ذاكرة لفظية محايدة & \\
\hline- & $1.9 \cdot \leq \leqslant 1 \leqslant$ & ...rar & $r$ & $\ldots \vee \wedge \varepsilon$ & ذاكرة لفظية سالبة & \\
\hline $.19 r$ & *** ץ $0 . . \vee ৭ \leq \Lambda$ &. $.7 v .0$ & r & $1 . r \leqslant 1$ & ذاكرة دلالية موجبة & \\
\hline- & I.Vr...ov & $\ldots r \wedge .1$ & r & ...VY.r & ذاكرة دلالية محايدة & \\
\hline \multirow[t]{7}{*}{$. r \leq r$} & *** $\Gamma \leq . \& \wedge \uparrow \leqslant \Gamma$ & $.9 \times 1$ & $r$ & $1.9 \leq r$ & ذاكرة دلالية سالبة & \\
\hline & & $\ldots r r+1 \leqslant$ & ril & $7.10 \leq 90$ & ذاكرة لفظية موجبة & \multirow{6}{*}{ الخطأ } \\
\hline & & ... YTV० & rll & $0.7 \leq 0.9$ & ذاكرة لفظية محايدة & \\
\hline & & $\ldots$..०ARr & ril & $\varepsilon . r \leq r .1$ & ذاكرة لفظية سالبة & \\
\hline & & ...rYVYO & Yll & $0.7 \leqslant 1.9$ & ذاكرة دلالية موجبة & \\
\hline & & ..rr.qA1 & rll & S.TIYV & ذاكرة دلالية محايدة & \\
\hline & & ...rN104 & rll & $0.9 \leq .94$ & ذاكرة دلالية سالبة & \\
\hline
\end{tabular}

** دالة عند مستوى دلالة إحصائية ال...

يتضح من جدول (r) السابق ما يلي:

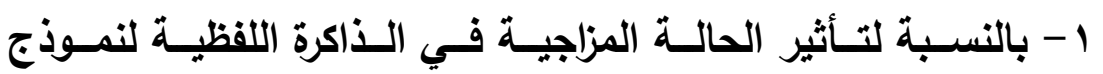

ديزي/روديجر -ماكديرموت DRM:

أ- عدم وجود تأثثر دال إحصائياً للحالة المزاجية (موجبة-سالبة-محايدة)

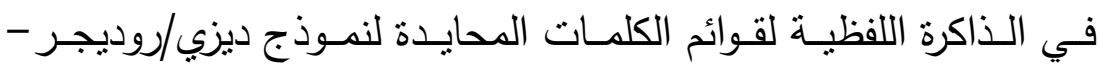

ماكديرموت DRM. 
ب- وجـود تأثنير قوي ودال إحصـائياً عند مستوى دلالـة ا .... للحالـة

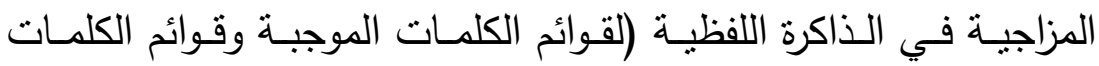
السـالبة)، وللتعرف على اتجـاه هذه الفروق تم استخدام اختبار "نثيفيه"

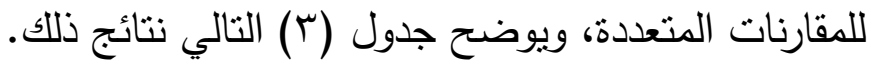

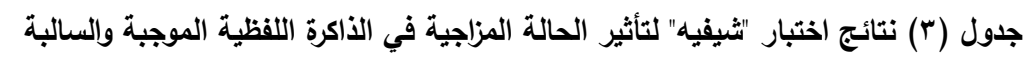

\begin{tabular}{|c|c|c|c|}
\hline فرق المتوسطين (أ-ب) & الحالة المزاجية (ب) & الحالة المزاجية (ا) & الأكرة \\
\hline 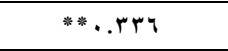 & 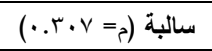 & 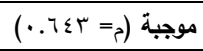 & \multirow{3}{*}{ الألكوة اللفظية } \\
\hline$\ldots+0$ & 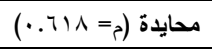 & & \\
\hline "..."ll & محايدة (م= A & 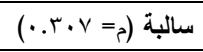 & \\
\hline "*..YA & سالبة (م= TVY. & موجية (م= דوץr.) & \multirow{3}{*}{ الألسالبة اللفظية } \\
\hline$\ldots+4$ & 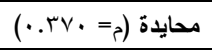 & & \\
\hline "*..r.v & 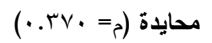 & سالبة (م= TYY. .) & \\
\hline
\end{tabular}

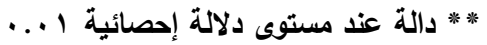

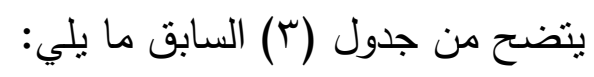

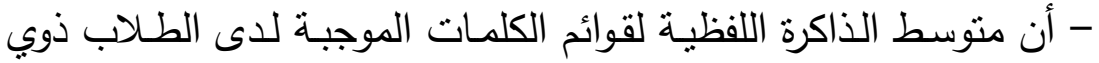
الحالة المزاجية الموجبـة (م= بـ T. . ) أعلى بصورة دالة إحصـائياً من منوسط الذاكرة اللفظية لقوائم الكلمات الموجبة لدى الطلاب ذوي الحالة

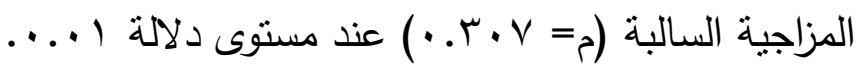

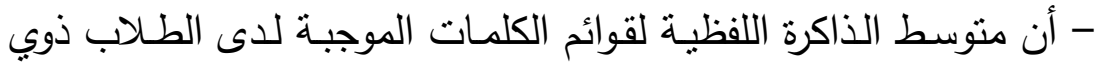

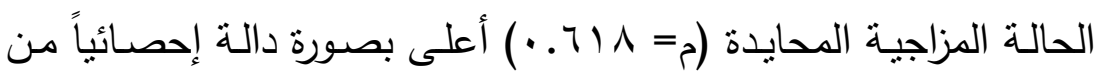
متوسط الذاكرة اللفظية لقوائم الكلمات الموجبة لدى الطلاب ذوي الحالة

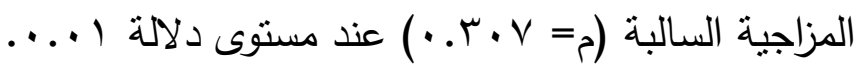
- عدم وجـود فروق دالـة إحصـائياً بين متوسط الذاكرة اللفظيـة لقوائم

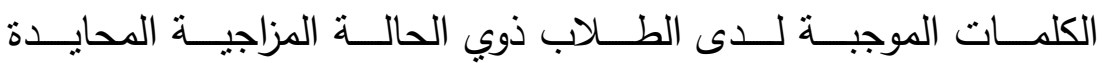

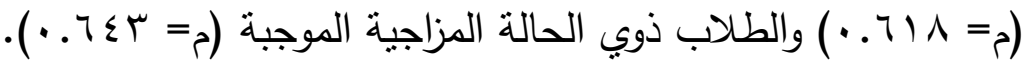

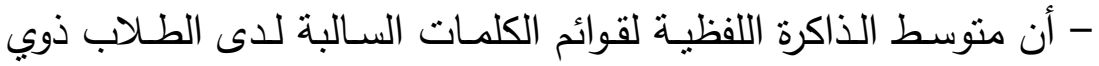

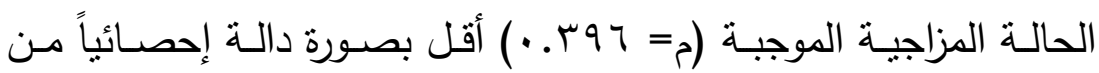


متوسط الذاكرة اللفظيـة لقوائم الكلمـات السالبة لدى الطلاب ذوي الحالـة

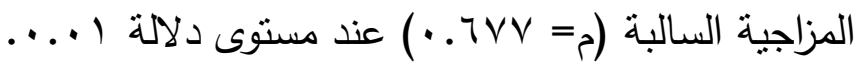

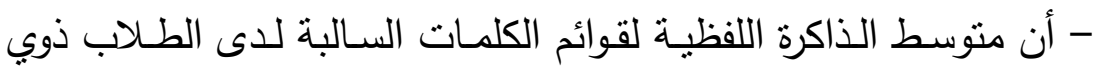

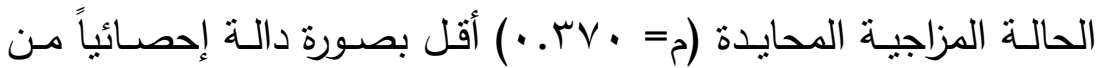
متوسط الذاكرة اللفظيـة لقوائم الكلمـات السـالبة لدى الطلاب ذوبي الحالة

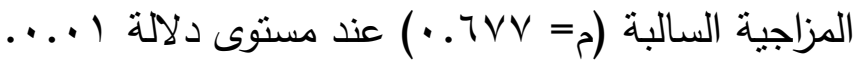
- عدم وجـود فروق دالـة إحصـائياً بين متوسط الذاكرة اللفظيـة لقوائم

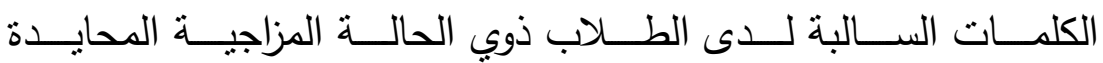

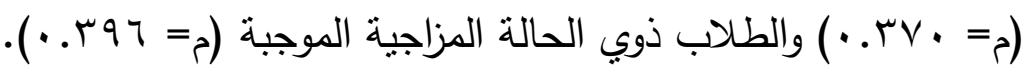

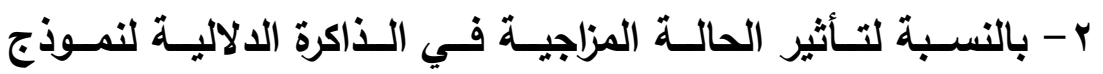

\section{ديزي/روديجر -ماكديرموت DRM}

أ- عدم وجود تأثير دال إحصائياً للحالة المزاجية (موجبة-سالبة-محايدة)

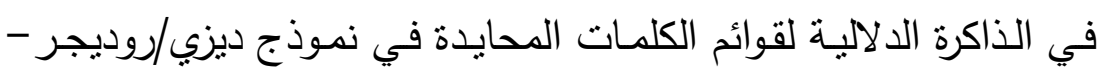
ماكديرموت DRM

ب- وجـود تأثنير قوي ودال إحصـائياً عند مستوى دلالـة ا .... للحالـة المزاجيـة في الذاكرة الدلاليـة (لقوائم الكلمـات الموجبـة وقوائم الكلمـات السـالبة)، وللتعرف على اتجاه هذه الفروق تم استخدام اختبار "ثيفيه" للمقارنات المتعددة، ويوضح جدول (ع ) التالي نتائج ذللك. جدول ( ) نتائج اختبار "ثيفيه" لتأثير الحالة المزاجية في الذاكرة اللالالية الموجبة والسالبة الكالية

\begin{tabular}{|c|c|c|c|}
\hline فرق المتوسطين (أ-ب) & الحالة المزاجية (ب) & الحالة المزاجية (أ) & الذاكرة الدلالية \\
\hline ***.rr & سالبة (م= 1/9. (.) & موجبة (م= & \multirow{3}{*}{ الذاكرة الدلالية } \\
\hline$\ldots r$ & محايدة (م= . . ؟ـ.·) & & \\
\hline **** .r & محايدة (م= . . ؟ .·) & سالبة (م= 119...) & \\
\hline ***.rr & سالبة (م= & موجبة (ج= 9 \ (.) & \multirow{3}{*}{ الذاكرة الدلالية } \\
\hline$\cdots \wedge$ & 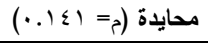 & & \\
\hline **arr & 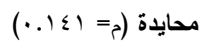 & سالبة (ح= سV & \\
\hline
\end{tabular}

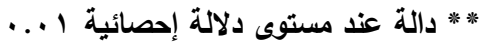


يتضح من جدول (ع) السابق ما يلي:

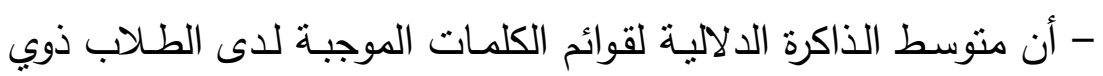

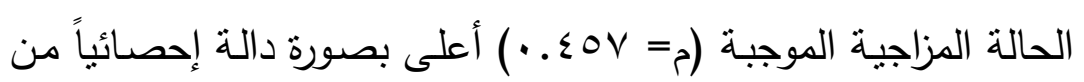

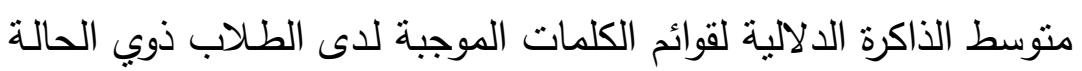

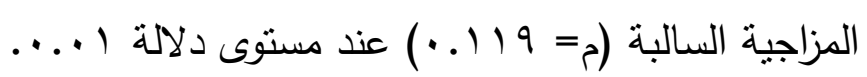

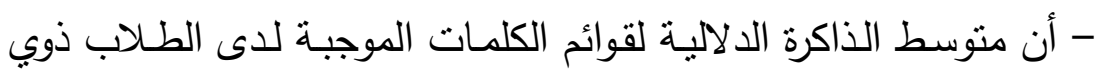

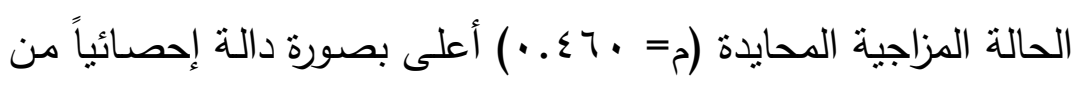

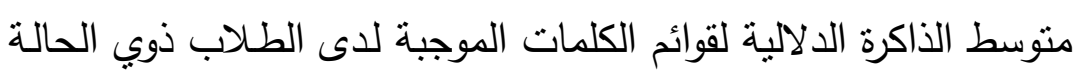

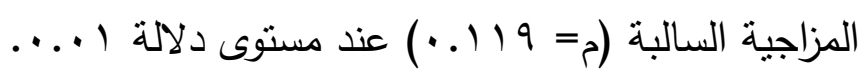
- عدم وجود فروق دالة إحصائياً بين منوسطي الذاكرة الدلاليـة لقوائم

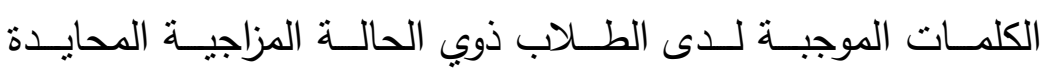

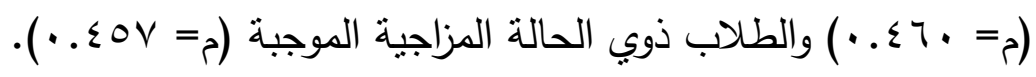

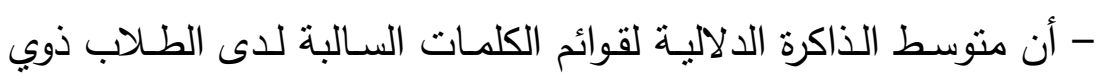

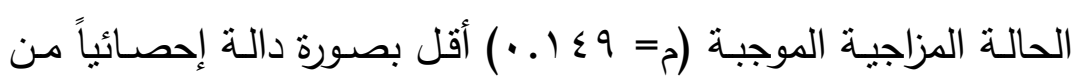

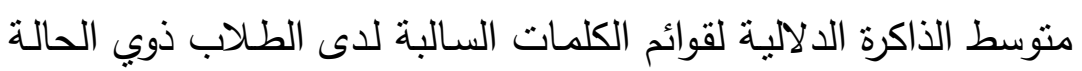

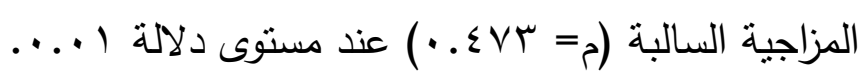

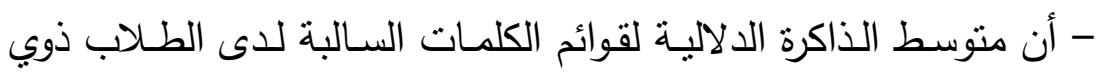

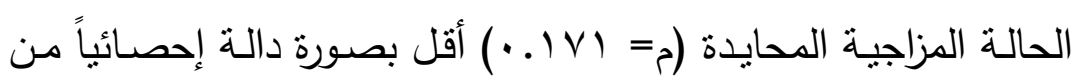

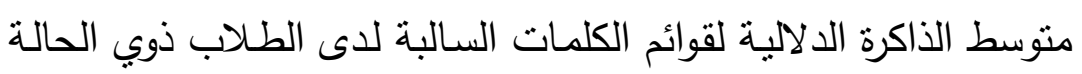

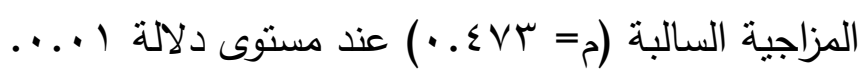
- عدم وجود فروق دالة إحصائياً بين منوسطي الذاكرة الدلاليـة لقوائم

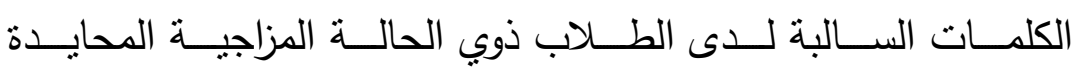

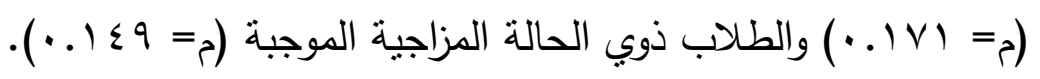


r- بالنسبة لتأثير الانتباه (كلي -موزع) في الذاكرة اللفظية لنموذج ديزي/روديجر -ماكديرموت DRM:

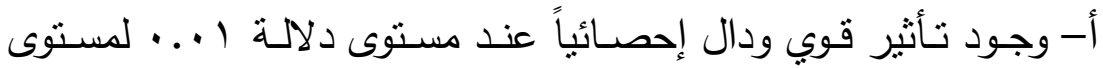
الانتباه (كلي -موزع) في الذاكرة اللفظية لقوائم الكلمات الموجبـة، حيث

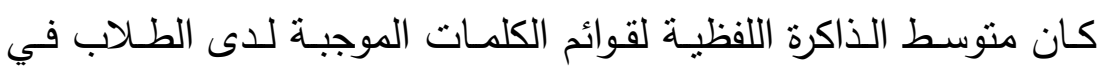

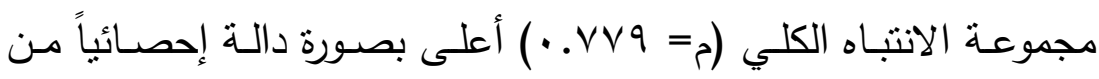

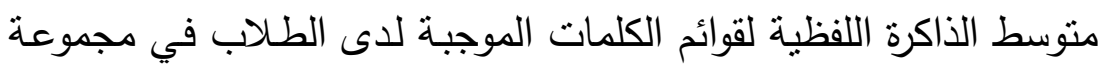

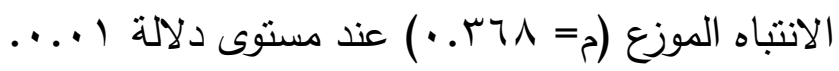

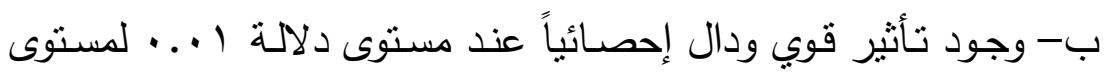
الانتباه (كلي -موزع) في الذاكرة اللفظية لقوائم الكلمات المحايدة، حيث

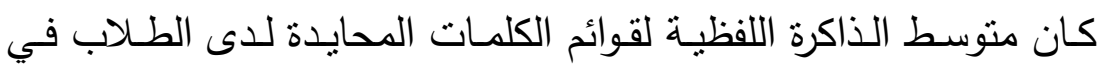

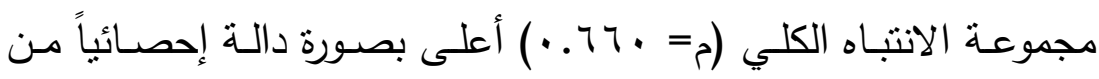
متوسط الذاكرة اللفظية لقوائم الكلمات المحايدة لدى الطلاب في مجموعة

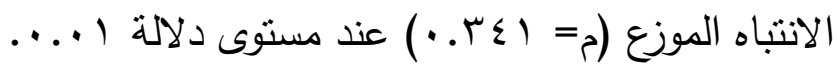

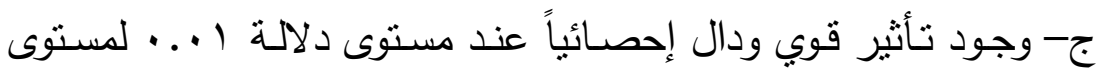
الانتباه (كلي -موزع) في الذاكرة اللفظية لقوائم الكلمات السالبة، حيث كان متوسط الذاكرة اللفظية لقوائم الكلمات السالبة لدى الطلاب في مجموعة الداه

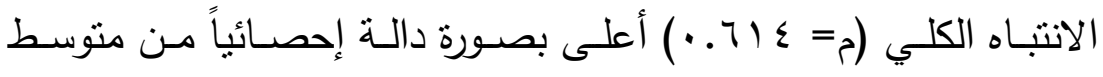
الذاكرة اللفظية لقوائم الكلمات السالبة لدى الطلاب في مجموعة الانتباه

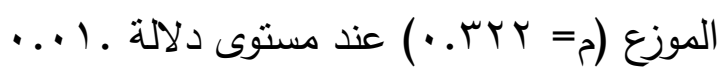
ع - بالنسبة لتأثير الانتباه (كلي -موزع) في الذاكرة الدلالية لنموذج دوله

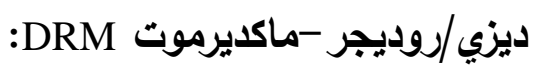

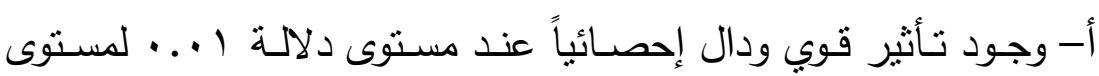
الانتباه (كلي -موزع) في الذاكرة الدلالية لقوائم الكلمات الموجبـة، حيث 


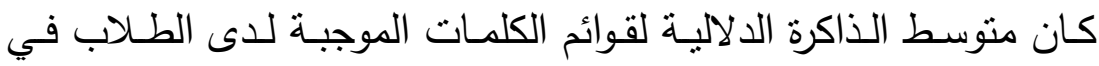

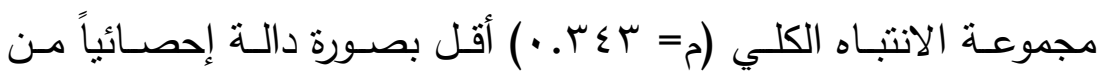
متوسط الذاكرة الدلالية لقوائم الكلمات الموجبة لدى الطلاب في مجموعة

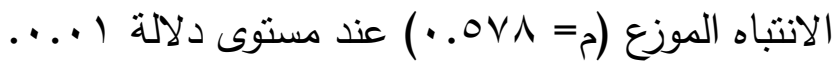

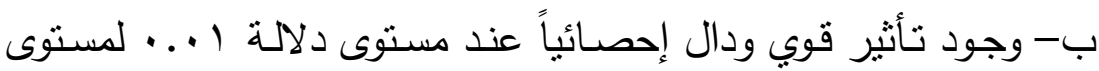
الانتباه (كلي -موزع) في الذاكرة الدلالية لقوائم الكلمات المحايدة، حيث

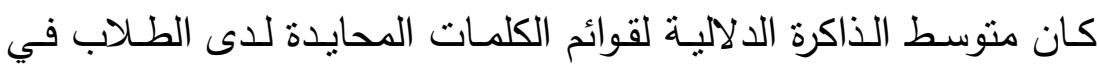

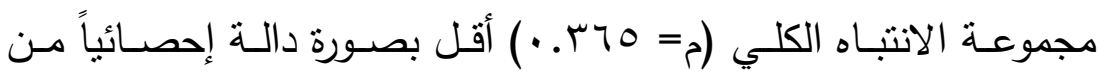

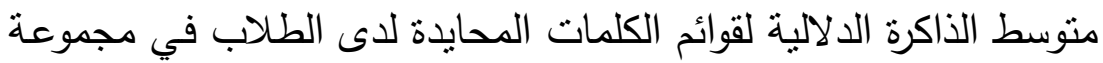
الانتباه الموزع (م= rه . . ) عند مستوى دلالة ا.....

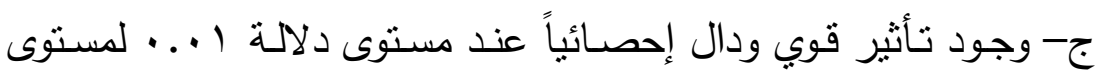
الانتباه (كلي -موزع) في الذاكرة الدلاليـة لقوائم الكلمـات السالبة، حيث دلث

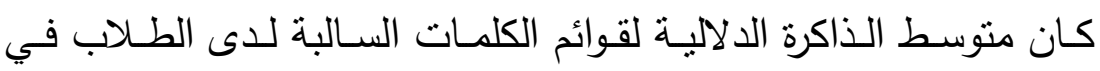

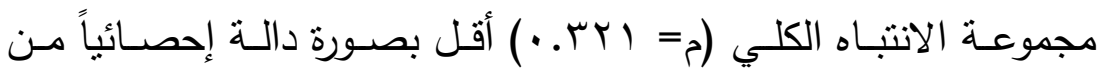
متوسط الذاكرة الدلالية لقوائم الكلمات السالبة لدى الطلاب في مجموعة الداء

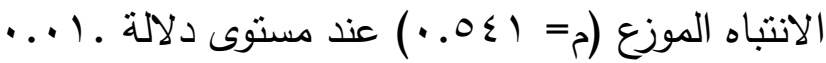

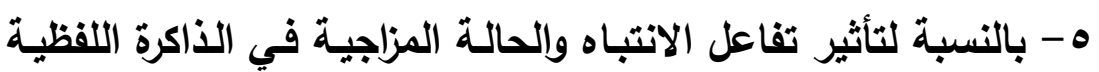
لنموذج ديزي/روديجر -ماكديرموت DRM: يتضح من جدول (Y) السابق عدم وجود تأثير دال إحصائياً للتفاعل بين الانتباه والحالة المزاجية في الذاكرة اللفظية لنموذج ديزي/روديجر -

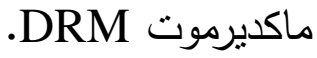


צ- بالنسبة لتأثير تفاعل الانتباه وإلحالة المزاجية في الذاكرة الدلالية

لنموذج ديزي/روديجر -ماكديرموت DRM: لنابه

$$
\text { يتضح من جدول (r) السابق ما يلي: }
$$

- عدم وجود تأثثر دال إحصائياً للتفاعل بين الانتباه والحالة المزاجية في لـاني

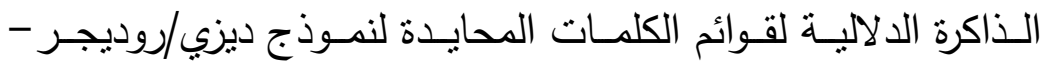

$$
\text { ماكديرموت DRM. }
$$

- وجود تأثنير قوي ودال إحصائياً للتفاعل بين الانتباه والحالة المزاجية في الـذاكرة الدلاليـة لقوائم الكلمـات الموجبـة وقـوائم الكلمـات السـالبة

لنــوذج ديزي/روديجـر -ماكـديرموت DRM، ويوضــح جـدولي (0)

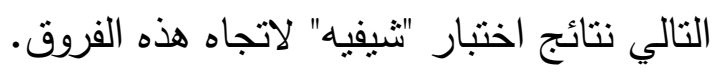

\begin{tabular}{|c|c|c|c|c|c|c|}
\hline محزي & موزع & كلي سالب & كلي محايد & كلي موجب & المجموعة & الألاكية \\
\hline & & & & - & كلي موجب & \multirow{6}{*}{ الدالداكية } \\
\hline & & & - & $\ldots r$ & كلي محايد & \\
\hline & & - &. $.1 r$ & $\ldots 11$ & كلي سالب & \\
\hline & - & ***. *YTI & ***. $. r \leq \wedge$ & ***..YO. & موزع موجب & \\
\hline- & $\ldots+r$ & ***.r. & ***.rIV & $* * . r 19$ & موزع محايد & \\
\hline \multirow[t]{5}{*}{$\ldots .1 \mathrm{~V}$} & $\cdots \leqslant \wedge$ & ***.rIr & ***... & $* * \cdot . r \cdot r$ & موزع سالب & \\
\hline & & & & - & كلي موجب & \multirow{6}{*}{ الالالاكة } \\
\hline & & & - & $\ldots 1 \leq$ & كلي محايد & \\
\hline & & - & r... & $\ldots r q$ & كلي سالب & \\
\hline & - & ***..人r & ***.r|Y & $* * . r \mid r$ & موزع موجب & \\
\hline- & $\ldots 9$ & $* * . . \mid \vee \varepsilon$ & $* * \cdot . r \cdot V$ & $* * \cdot r \cdot r$ & موزع محايد & \\
\hline$\ldots r$ & $\ldots+11$ & $* * . . I V r$ & ***.r.o & $* * . . r .1$ & موزع سالب & \\
\hline
\end{tabular}

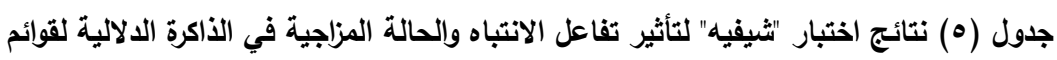

الكلمات الموجبة والسالبة لنموذج ديزي/روديجر -ماكديرموت DRM

$$
\text { يتضح من جدول (0) السابق ما يلي: }
$$

- عدم وجود فروق دالة إحصائياً بين الطلاب ذوبي الانتباه الكلي والحالة

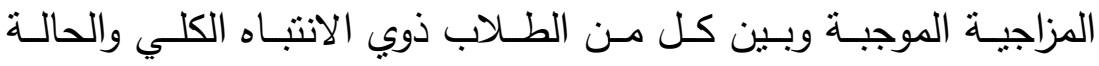


المزاجية السالبة، والطلاب ذوي الانتباه الكلي والحالة المزاجية المحايدة في الذاكرة الدلالية الموجبة والسالبة. - عدم وجود فروق دالة إحصائياً بين الطلاب ذوي الانهان النتاه الكلي والحالة

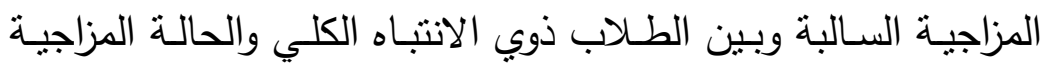
المحايدة في الذاكرة الدلالية الموجبة والسالبة.

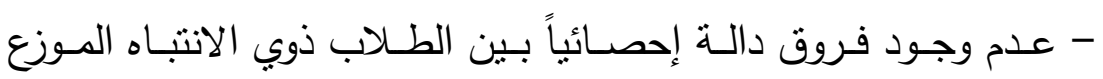
والحالة المزاجية الموجبـة وبين كل من الطلاب ذوي الانتباه الموزع

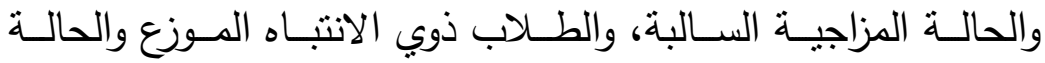
المزاجية المحايدة في الذاكرة الدلالية الموجبة والسالبة.

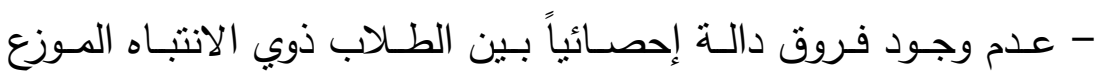
والحالـة المزاجيـة السـالبة وبين الطـلاب ذوبي الانتبـاه الموزع والحالـة المزاجية المحايدة في الذاكرة الدلالية الموجبة والسالبة. - وجود فروق دالة إحصـائياً بين الطلاب ذوبي الانتبـاه الموزع والحالـة المزاجية الموجبة وبين كل من الطـلاب ذوبي الانتباه الكلي والحالـة

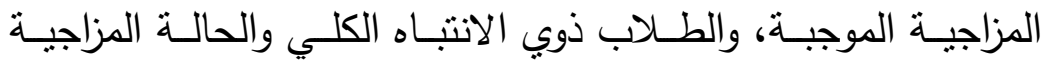

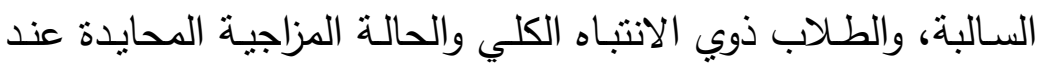

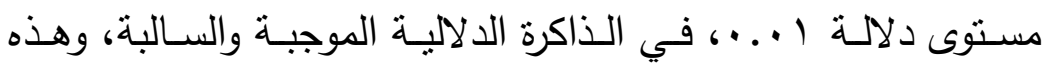
الفروق لصالح الطلاب ذوبي الانتباه الموزع والحالة المزاجية الموجبة، كما يتضح من قيم منوسطات النسب في جدول (آ) التالي.

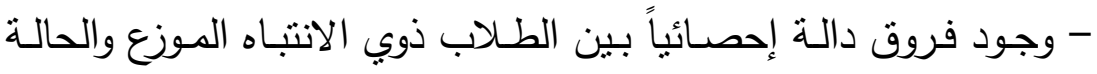
المزاجية المحايدة وبين كل من الطلاب ذوبي الانتباه الكلي والحالـة

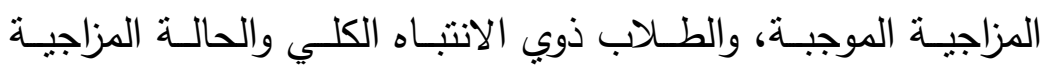

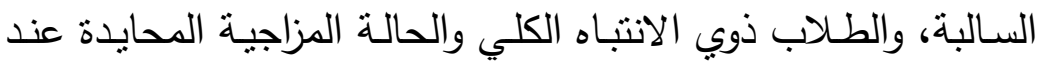

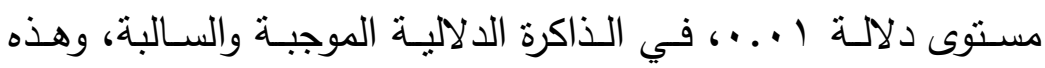


الفروق لصالح الطلاب ذوبي الانتباه الموزع والحالة المزاجية المحايدة، كما يتضح من قيم متوسطات النسب في جدول (آ) التالي.

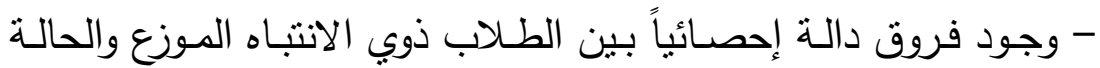

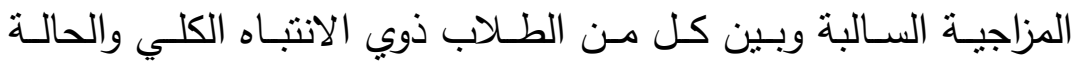
المزاجية الموجبة، والطلاب ذوي الانتباه الكلي والحالة المزاجية السالبة، والطلاب ذوي الانتباه الكلي والحالة المزاجية المحايدة عند مستوى دلالة

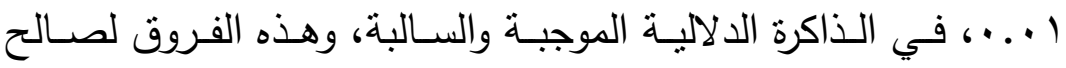

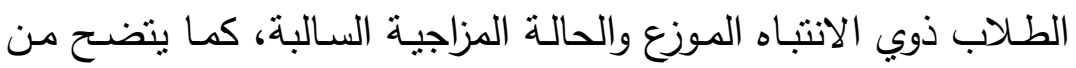
قيم متوسطات النسب في جدول (T) التالي. جدول (†) متوسط نسب التعرف لمجموعات البحث في الأكرة الدلالية الموجبة والسالبة

\begin{tabular}{|c|c|c|}
\hline الذاكرة الدلالية السالبة & الذاكرة الدلالية الموجبة & المجموعة \\
\hline..$r 0$. & $.0+49$ & انتباه كلي وحالة مزاجية موجبة \\
\hline$. r \leqslant 4$ & $. r \leqslant 1$ & انتباه كلي وحالة مزاجية محايدة \\
\hline.$r v q$ &. TrA & انتباه كلي وحالة مزاجية سالبة \\
\hline .074 &. .019 & انتباه موزع وحالة مزاجية موجبة \\
\hline $.00 r$ &. .001 & انتباه موزع وحالة مزاجية محايدة \\
\hline .001 & $.0 \leqslant 1$ & انتباه موزع وحالة مزاجية سالبة \\
\hline
\end{tabular}

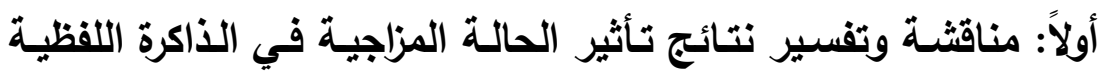
والذاكرة الدلالية لنموذج ديزي/روديجر -ماكديرموت DRM:

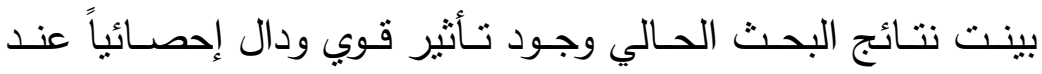
مستوى دلالة ا ... للحالة المزاجية في الذاكرة اللفظية والدلالية (لقوائم الكلمـات الموجبــة وقوائم الكلمــات السـالبة)، حيـث كـان تـذكر الطـلاب

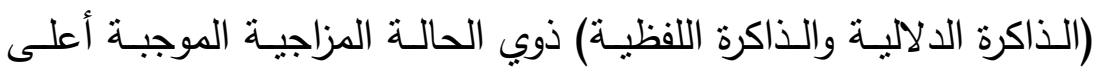
لقوائم الكلمات الموجبة من الطـلاب ذوي الحالة المزاجيـة السالبة، بينما

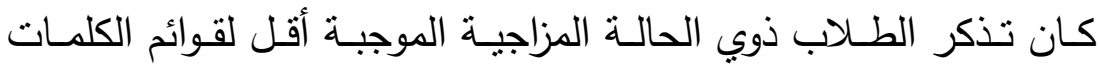
السالبة من الطلاب ذوي الحالة المزاجية السالبة، بينما لم يوجد تأثنير دال 
إحصائياً للحالة المزاجية في تذكر قوائم الكلمات المحايدة. إن هذه النتائج

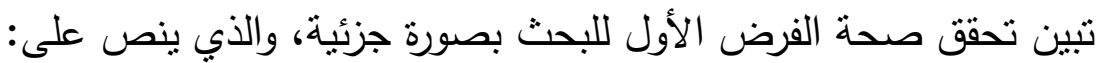

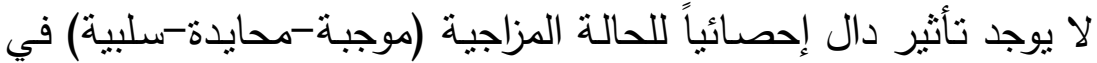

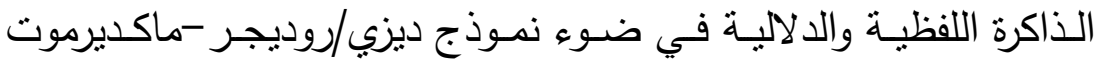

.DRM

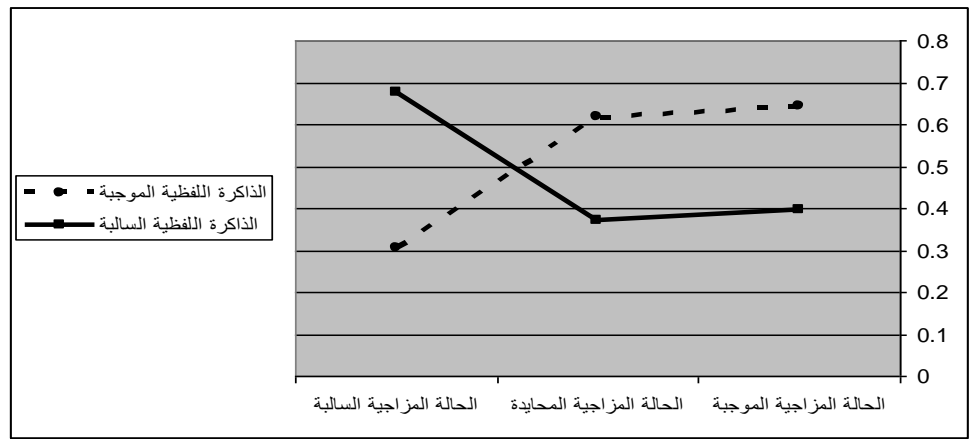

شكل (1) متوسط نسب التذكر الصحيح (الأكرة اللفظية) لقوائم الكلمات الموجبة والسالبة والمحايدة للطلاب ذوي الحالة المزاجية الموجبة والسالبة والمحايدة

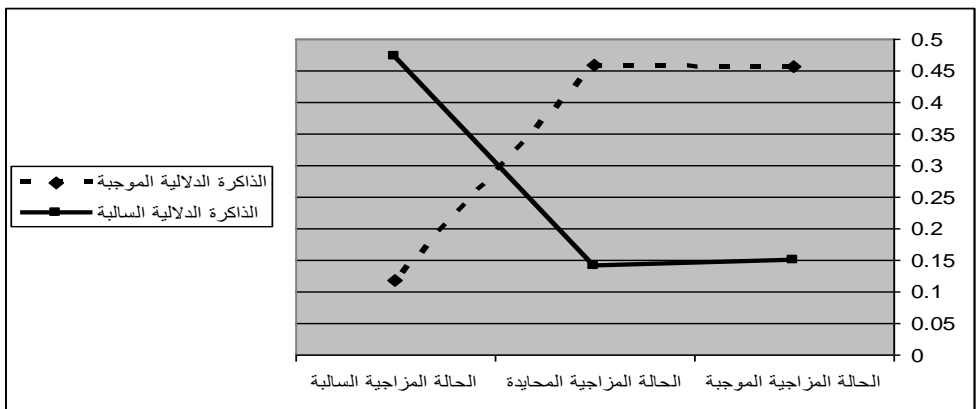

شكل (ץ) متوسط نسب تذكر الكلمة الموضوع (الأكرة الدلالية) لقوائم الكلمات الموجبة والسالبة والمحايدة للطلاب ذوي الحالة المزاجية الموجبة والسالبة وإلمحايدة تبين نتائج البحث: الحسالي أن الذاكرة اللفظئة أو الدلالبهة في ضـوء نمـوذج ديزي/روديجر -ماكديرموت DRM تكـون أفضـل بالنسبة لقوائم الكلمات الانفعالية، حيث يكون التعرف أكبر بالنسبة للكلمات التي بمكن أن تثير الانفعالات مقارنة بالكلمات المحايدة. وقد يرجع ذللك إلى طبيعة الترميز لكل من الكلمات الموجبة والسالبة والتي لها أسـاس في البناء المعرفي للطلاب، كذلك يمكن أن تؤدي العلاقة الدلالية بين الكلمات دوراً 
في هذه النتائج. كذللك قد يرجع هذا التأثير إلى التعرف والألفة والقابلية

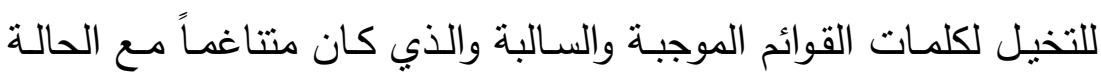
المزاجية للطلاب المشاركين في البحث. لمان.

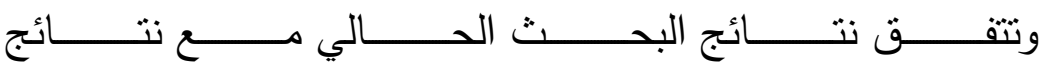

(Ochsner, 2000; Hamann, 2001)

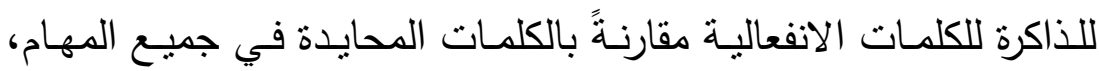
فضلاً عن احتمالية تذكر التفاصيل التي تم تقييمها عن طريق إجراءات ذاتية وموضوعية للكلمات الانفعالية مقارنـة بالكلمات المحايدة. إن هذه

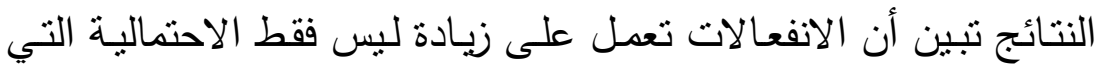
مفادها أن الخبرة الانفعالية يتم تذكرها بصورة أفضل من المحايدة، ولكن

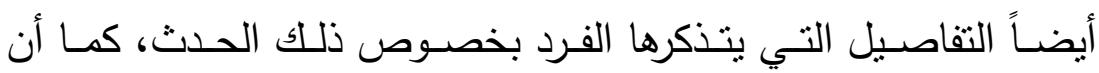

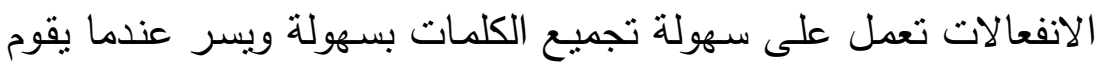

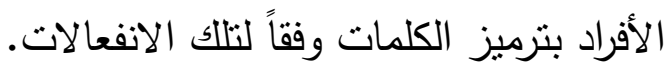

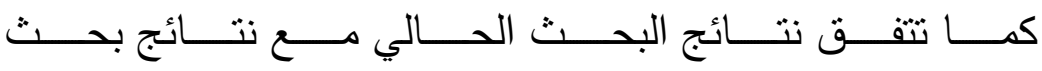
والتـي أثنـارت إلـى وجـود ذكريـات خاطئة (ذاكرة دلالية) منسجمة مع الحالة المزاجية في التعرف على كلمات قوائم نمـوذج ديزي/روديجـر -ماكـديرموت DRM، وعلى الـرغم مـن ارتفـاع

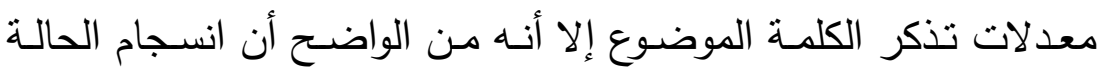

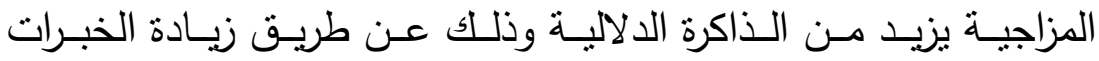
الثخصية لسماع معلومات غير موجودة في قوائم الكلمات، كما يمكن فئرس تفسير هذه النتائج في ضوء نظرية شبكة التأثثر والنتشيط الانتشاري. كما

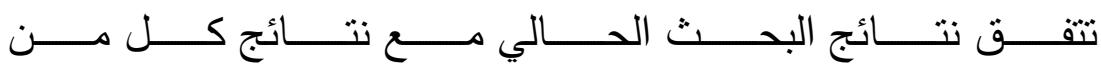
(Roediger \& McDermott, 1995; Watson, Balota, \& Roediger, 2003) 
في أن الذاكرة الدلاليـة تعززهـا الكلمـات الانفعالية المنسجمة مـع الحالـة المزاجية الايجابية والسلبية.

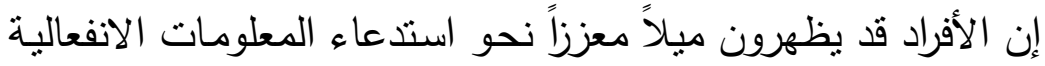

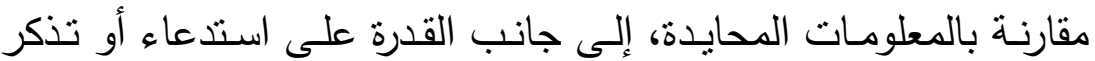
(Ochsner, 2000)

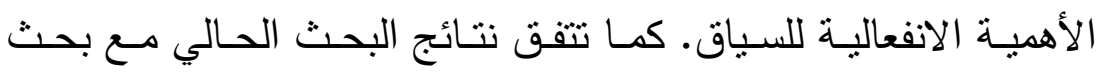
(Doerksen \& Simamura, 2001) أو اللفظية أفضل للكلمات الانفعالية مقارنة بالكلمات المحايدة.

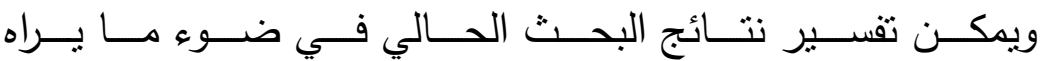
لطبيعة الترميز الذي يمكن أن ينت بأي (Storbeck \& CLore, 2005)

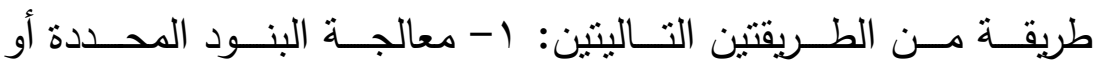
Y- المعالجة العلاقتية، حيث نتتمل معالجة البنود المحددة على ترميز

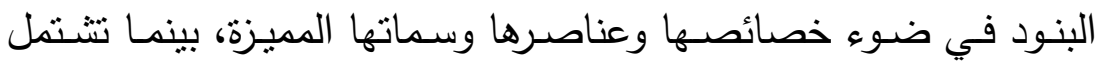
المعالجة العلاقتيـة على ترميز البنود فيما يتعلق بالمفاهيم الأخرى في وهي

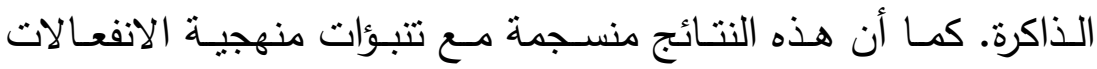
كمعلومات (Clore, Wyer, Dienes, Gasper, Gohm, \& Isbell 2001)، التي تفترض أن الدلالات الانفعاليـة السلبية تؤودي إلى معالجـة البنود

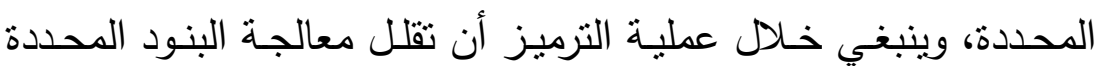
إمكانية الوصول إلى "الجوهر الدلالي" مشتملاً ذلك على إمكانية الوصول

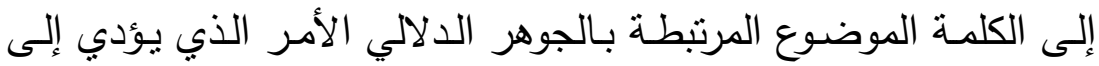

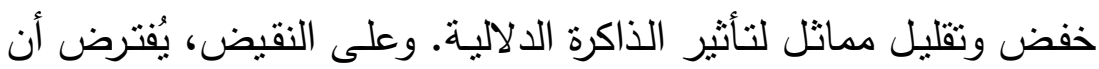
الأفراد الذين هم في حالات مزاجية إيجابية بمكن أن يشاركوا في معالجة علاقتية التي نتتبأ بضرورة تعزيزها لتأثير الذاكرة الدلالية.

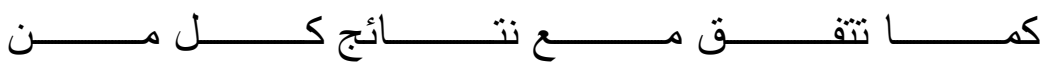

التي توصلت إلى وجود (Corson, 2002; Storbeck \& Clore, 2004) 
تأثثر للحالة الافعالية في التنشيط الدلالي عندما كان الأفراد في حالات

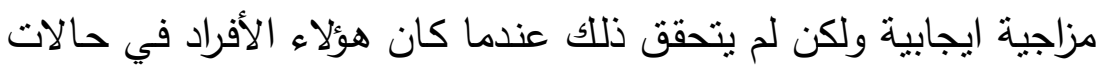

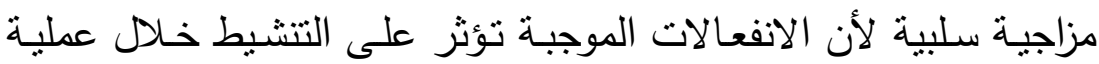

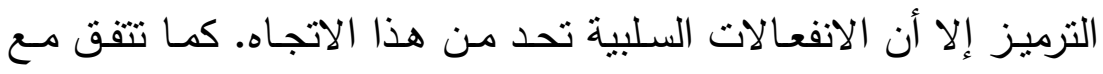
نتائج بحث (Roediger, Balota, et al., 2001) التي بينت أن التنشيط الدلالي يؤثر في الذاكرة الدلالية كما أن للحالة المزاجية تأثنرات متشـابهة

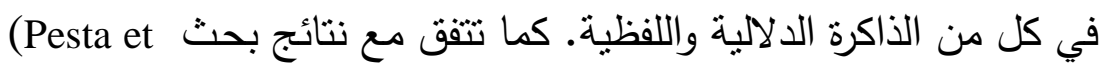
al., 2001) للتعرف على المثير الانفعالي بغض النظر عن التعرض المسبق للمثير.

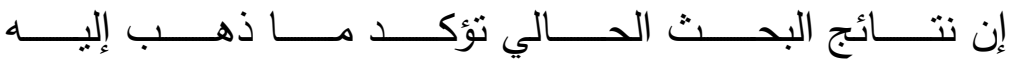

(Arndt \& Reder, 2003; Hege \& Dodson, 2004) تؤثر على المعالجة عن طريق فرضية "الانفعالات كمعلومات" ومن ثم ينبغي أن يميل المشـاركون في الحالات المزاجية الايجابية إلى إظهار

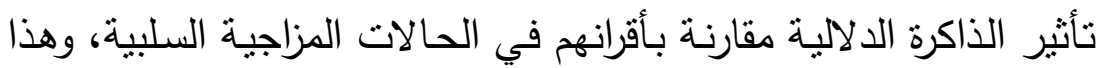

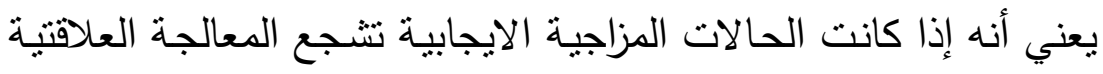

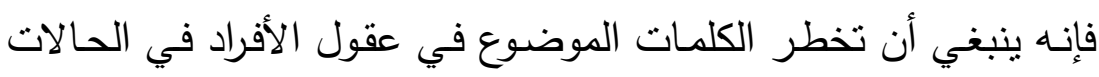

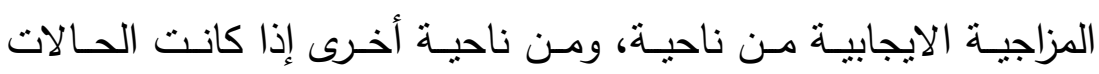

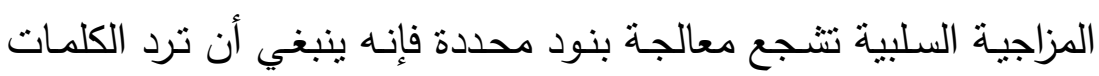

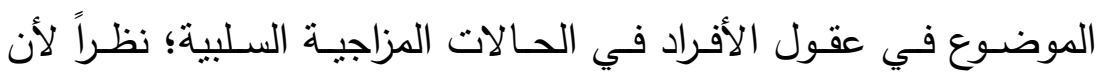
معالجة البنود المحددة تحدث على حساب المعالجة العلاقتية.

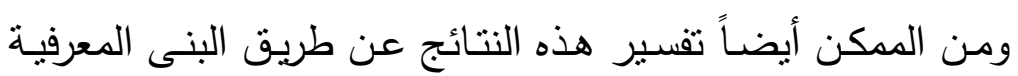

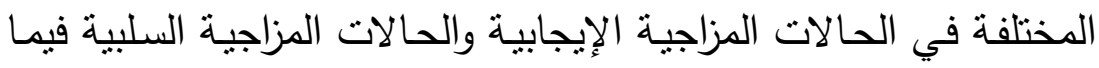

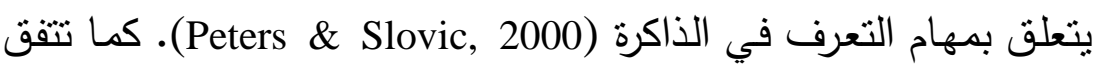
بصورة جزئية مـع نتائج بحث (Ruci et al., 2009) الذي توصل إلى بعلى 
وجود ذاكرة منسجمة مـع الحالـة المزاجيـة فقط للكلمـات الايجابية، بينما كانت في البحث الحالي للنوعين من الكلمات؛ الايجابية والسلبية.

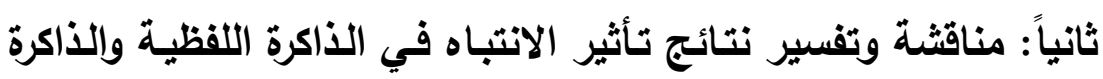

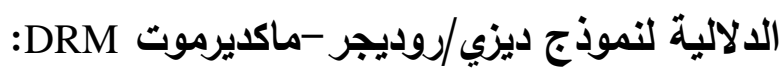

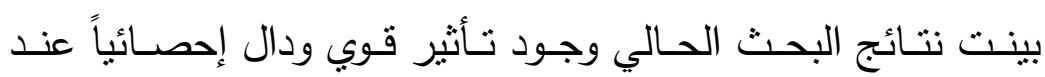
مستوى دلالـة ا ... لمستوى الانتباه (كلي -موزع) في الذاكرة اللفظية فئن والدلالية (لقوائم الكلمات الموجبة وقوائم الكلمات المحايدة وقوائم الكلمات

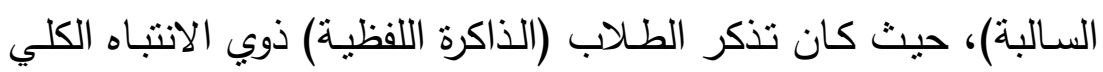
أعلى لقوائم الكلمات الموجبة والمحايدة والسالبة من الطلاب ذوبي الانتباه

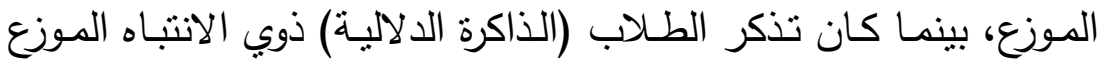

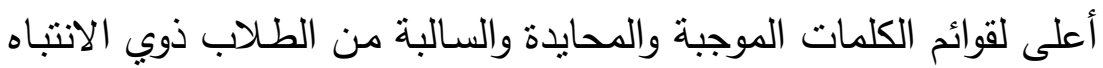
الكلي. إن هذه النتائج تبين عدم صحة الفرض الثاني للبحث، والذي ينص على: لا يوجد تأثثر دال إحصائباً للانتباه (كلي -موزع) في الذاكرة اللفظية والدلالية في ضوء لاءية نموذج ديزي/روديجر -ماكديرموت DRM. وقبول الفرض البديل والذي ينص على: يوجد تأثنير دال إحصائياً للانتباه

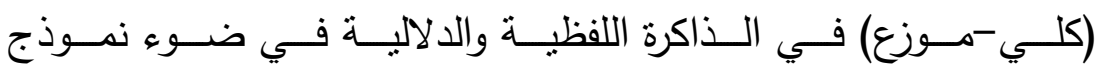
ديزي/روديجر -ماكديرموت DRM.

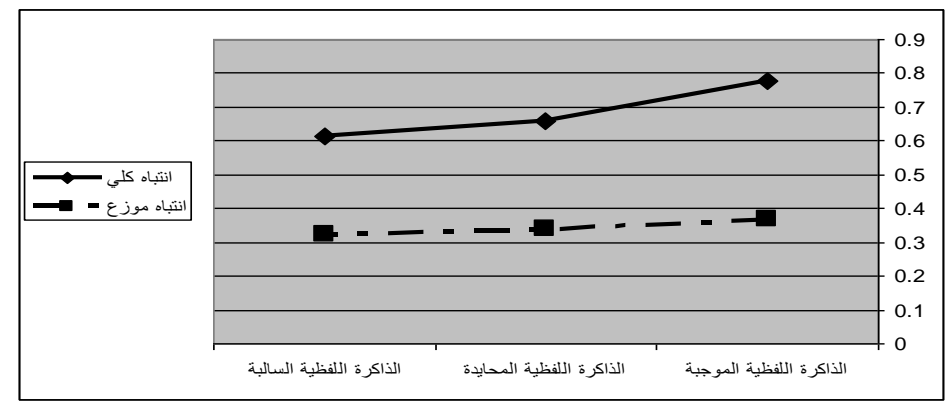

شكل (T) متوسط نسب التذكر الصحيح (الذاكرة اللفظية) لقوائم الكلمات الموجبة والسالبة والمحايدة

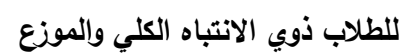




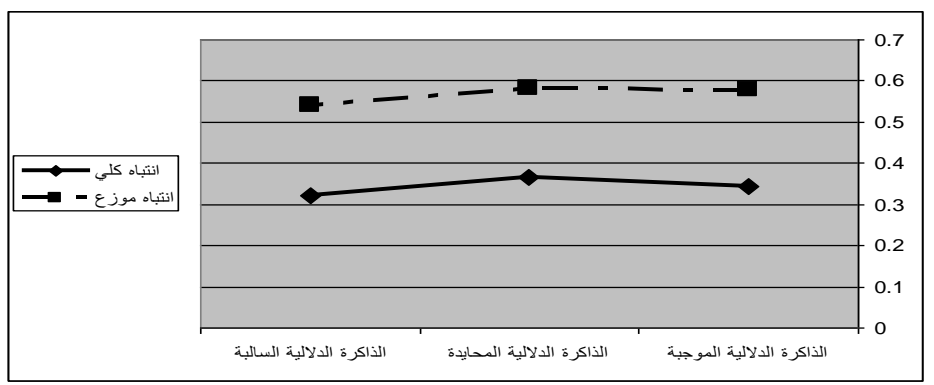

شكل (؛)متوسط نسب تذكر الكلمة الموضوع (الذاكرة الدلالية) لقوائم الكلمات الموجبة والسالبة

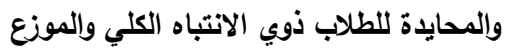

تتفق هذه النتائج مع نتائج بحث (Gallo, 2006) والذي أشـار إلى أن

توزيع الانتباه وزيادة عبء الذاكرة يضعف ويحد من معالجة الكلمات، لذا تزداد احتمالبة تنشيط كلمات دلالية مرتبطة، كما عجز المشـاركون عن التزميز العمبـق لمعنى كل كلمـة مـن الكلمـات لذا عجزوا عـن تحديد العلاقة الدلالية بين الكلمات المقدمة وتلاك غير المقدمة ومن ثم انخفض الاستدعاء الصحيح. كما وتتفق مـع نتائج العديد من البحوث التي بينت أن توزيع الانتباه يحد من الاستدعاء الصحيح ويزيد من استدعاء الكلمة الموضوع (Dewhurst et al., 2005; 2007). كما ثتفق مع نتيجة بحث (Pérez-Mata et al., 2002) المشـاركين مـن ترميز المعلومـات المصـاحبة للكلمات المرتبطـة التي تم دراستها مما أدى لقصور في عملية المراقبة ومن ثم زيادة الذاكرة الدلالية. لقد قدمت العديد من البحوث أدلة على وجود ارتباط بين تتشيط

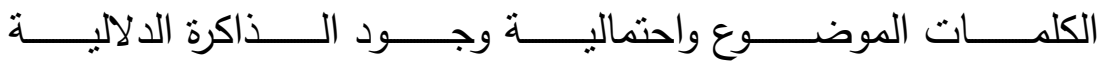
(Goodwin et al., 2001; Marsh \& Bower, 2004) ومسع ذلك فإنه إذا كان هناك عامل على غرار الانتباه الموزع مسئولاً عن ذلك التأثثر ينبغي الحصول على زيادة في الذاكرة الدلالية مع الكف اللفظي Pérez-Mata) et al., 2002; Dewhurst et al., 2005; 2007) أن الكف اللفظي يفرز تأثثرات متناقضـة في الذاكرة الدلاليـة بنـاء على 
تعليمات الاستدعاء، وعلى الرغم من أن الكف اللفظي يحد من التجهيز الخاطئ، إلا أنه يزيد من مستوى الذاكرة الدلالية.

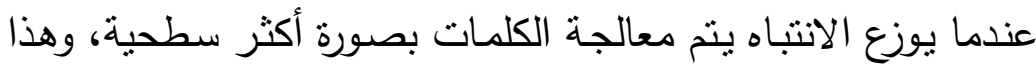
يؤدي إلى ضعف الترميز المتمركز حول الكلمات، ومن ثم يؤدي ذلك إلى نقص في الذاكرة اللفظية وانتشار محدود للتنشيط ومن ثم نقص في فودي تجهيز الذاكرة وضعف مراقبـة الاستجابات التي ترد إلى الذهن خـلال مرحلة الاختيار ومن ثم زيادة في الذاكرة الدلالية، وعندما يتم استرداد

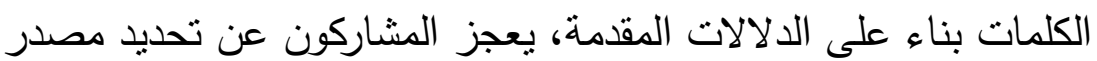
الكلمات الموضوع، وهذا يمكن وضعه في إطار تفسير التتشيط والمراقبة مض الغ لألثن

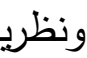

(Van Damme \& d'Ydewalle, 2009) ثالثاً: مناقشة وتفسير تأثير تفاعل الانتباه والحالـة المزاجية في الذاكرة اللفظية والذاكرة الدلالية لنموذج ديزي/روديجر -ماكديرموت DRM: بينت نتائج البحث الحالي عدم وجود نأثير دال إحصائياً للتفاعل بين الانتباه (كلي -موزع) والحالة المزاجية (موجبة-محايدة-سالبة) في الذاكرة

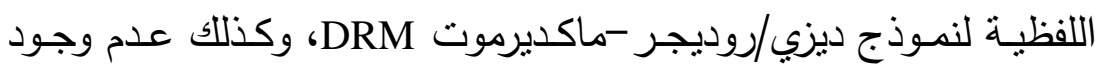
تأثثير دال إحصـائياً للتفاعل بـين الانتبـاه والحالـة المزاجيـة في الـذاكرة

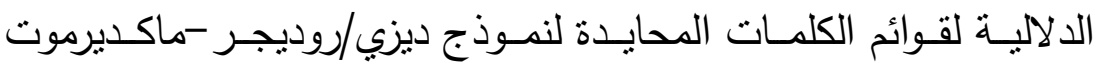
DRM بينما تم التوصل إلى وجود تأثير قوي ودال إحصائياً للتفاعل بين الانتباه والحالة المزاجية في الذاكرة الدلالية لقوائم الكلمات الموجبة وقوائم الكلمات السالبة لنموذج ديزي/روديجر -ماكديرموت DRM، حيث بينت النتائج وجود فروق دالة إحصائياً بين الطلاب ذوي الانتباه الموزع والحالة

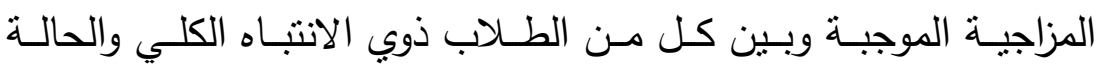
المزاجية الموجبة، والطلاب ذوبي الانتباه الكلي والحالة المزاجية السالبة، والطلاب ذوي الانتباه الكلي والحالة المزاجية المحايدة عند مستوى دلالة 
ا ...، وهذه الفروق لصالح الطلاب ذوي الانتباه الموزع والحالة المزاجية الموجبـة، وكذللك وجـود فروق دالة إحصـائياً بين الطـلاب ذوبي الانتبـاه الموزع والحالة المزاجية المحايدة وبين كل من الطلاب ذوي الانتباه الكلي والحالة المزاجيـة الموجبـة، والطلاب ذوي الانتباه الكلي والحالـة المزاجيـة

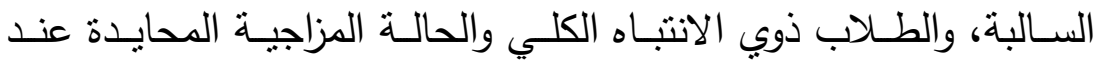
مستوى دلالة ا ...، وهذه الفروق لصـالح الطلاب ذوبي الانتباه الموزع

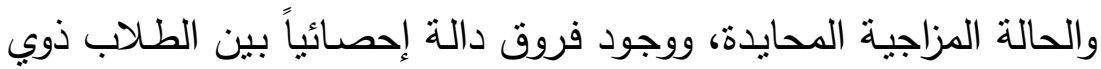
الانتباه الموزع والحالة المزاجية السالبة وبين كل من الطلاب ذوبي الانتباه

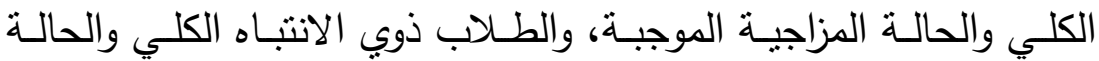
المزاجية السالبة، والطلاب ذوي الانتباه الكلي والحالة المزاجية المحايدة عند مسـتوى دلالـة ا ...، وهذه الفـروق لصـالح الطـلاب ذوي الانتبـاه الموزع والحالة المزاجية السالبة. إن هذه النتائج تبين تحقق صحة الفرض

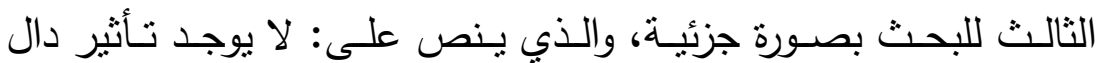

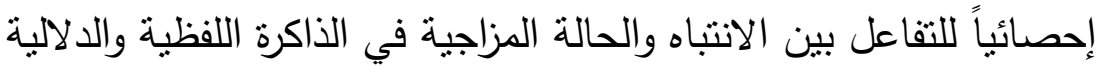

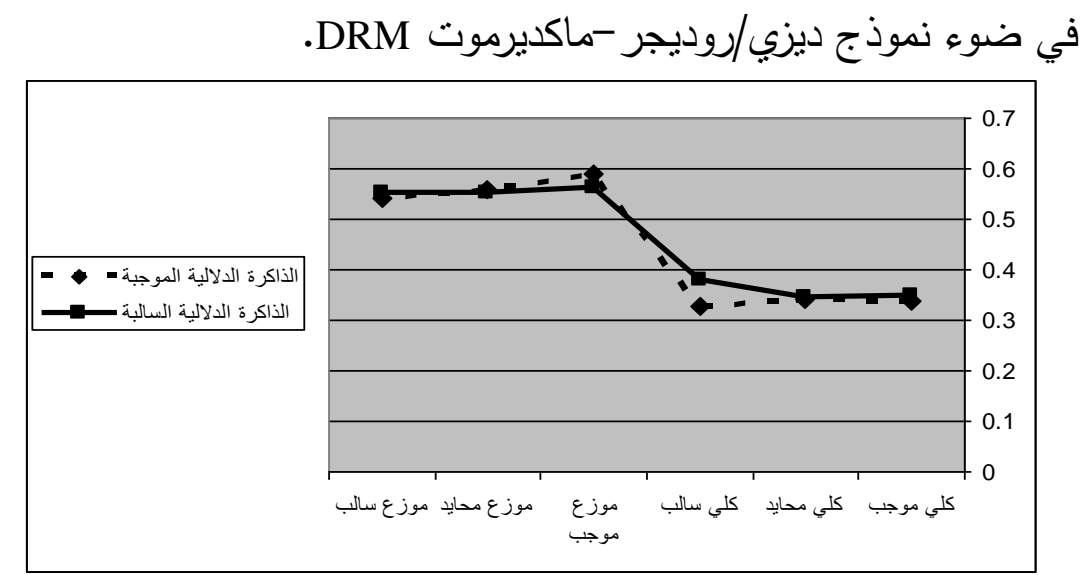

شكل (0) متوسط نسب تذكر الكلمة الموضوع (الذاكرة الدلالية) لقوائم الكلمات الموجبة والسالبة والمحايدة للتفاعل بين الانتباه والحالة المزاجية 
إن نتائج الفرض الحسالي تتسق مـع نتائج الفرضين السـابقين والتي

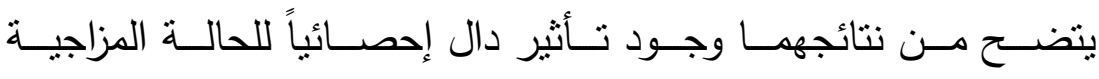

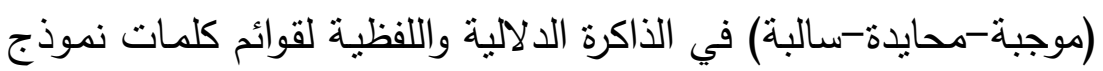
ديزي/روديجر -ماكديرموت DRM الموجبة والسالبة، بينما لم يوجد تأثير دال إحصائياً للكلمات المحايدة، وكذلك وجود تأثير قوي ودال إحصائياً

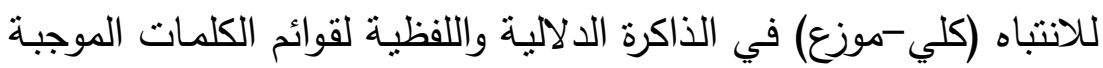
والسالبة والمحايدة لنموذج ديزي/روديجر -ماكديرموت DRM.

\section{ملخص عام وخاتمة}

لقد هدف البحث الحسالي إلى تعرف تأثير كل من: الانتباه الكلي والموزع، والحالة المزاجية؛ الموجبة والسالبة والمحايدة في كل من الذاكرة

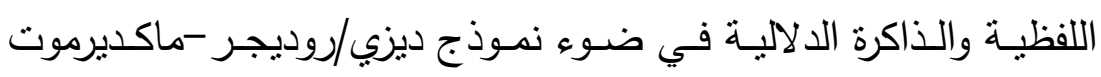

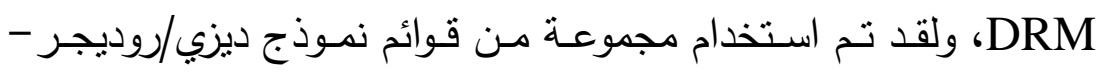
ماكديرموت DRM ذات الطبيعـة الموجبـة والسـالبة والمحايدة، واختبـار تعرف لهذه القوائم، بالإضافة إلى مقياس الحالة المزاجية تم تطبيقها على دلى

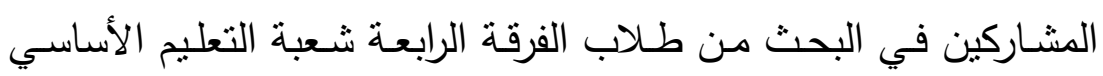
بكلية التربية بجامعة بني سويف، ولقد بينت النتائج وجود تأثثر قوي ودال

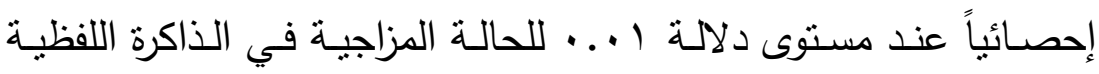
والدلاليـة (لقوائم الكلمـات الموجبـة وقوائم الكلمـات السـالبة)، حيث كـان

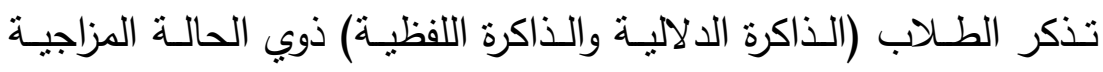
الموجبة أعلى لقوائم الكلمات الموجبة من الطلاب ذوبي الحالة المزاجية السالبة، بينما كان تذكر الطلاب ذوبي الحالة المزاجية الموجبة أقل لقوائم الكلمات السالبة من الطلاب ذوي الحالة المزاجية السالبة، بينما لم يوجد تأثثر دال إحصائيا للحالة المزاجية في تذكر قوائم الكلمات المحايدة.

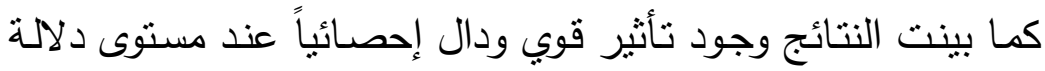
ا ... لمسـتوى الانتبـاه (كلـي -مــوزع) فـي الـذاكرة اللفظيـة والدالاليـة 
(لقوائم الكلمات الموجبة وقوائم الكلمات المحايدة وقوائم الكلمات السالبة)، حيث كان تذكر الطلاب (الذاكرة اللفظية) ذوي الانتباه الكلي أعلى لقوائم

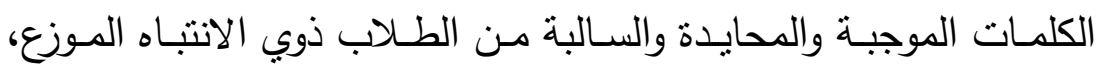
بينما كان تذكر الطلاب (الذاكرة الدلالبة) ذوي الانتباه الموزع أعلى لقوائم الكلمات الموجبة والمحايدة والسالبة من الطلاب ذوي الانتباه الكلي.

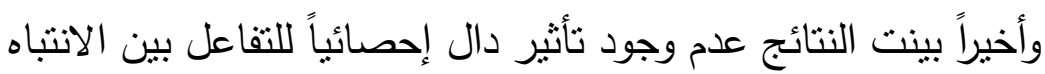
والحالة المزاجية في الذاكرة اللفظية لنموذج ديزي/روديجر -ماكديرموت DRM وكذلك عدم وجود تأثنر دال إحصائياً للتفاعل بين الانتباه والحالة

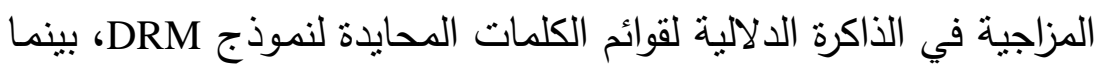

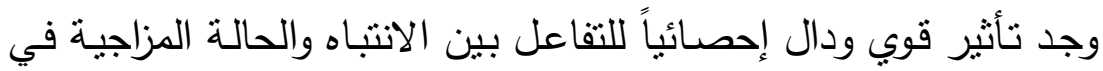

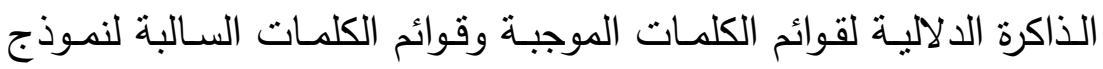
ديزي/روديجر -ماكديرموت DRM. إن نتائج البحث الحالي تؤكد دور الانتباه في الذاكرة بصورة عامـة،

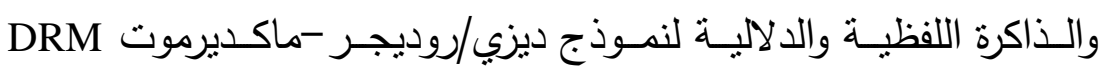

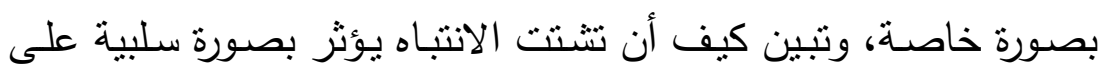

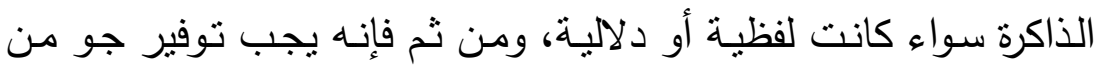
التركيز والبعد عن المشتتات أنثاء التدريس أو أداء الاختبارات. كما بينت ولته

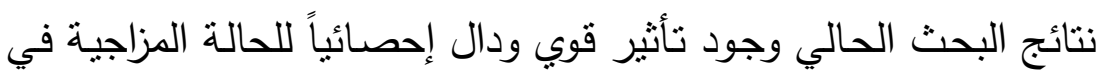

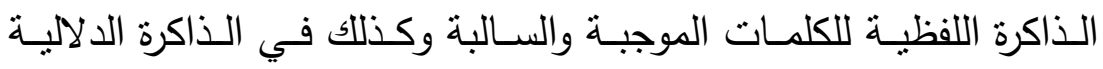
للكلمات الموجبة والسالبة، بينما لم يوجد تأثثر للحالة المزاجية في الذاكرة ولهات اللفظيـة والدلاليـة للكلمـات المحايدة، ومسن ثم ينبغي نوفير بيئة نفسية تربوية تساعد الطلاب على الاتزان الانفعالي والبعد عن المواقف المثيرة

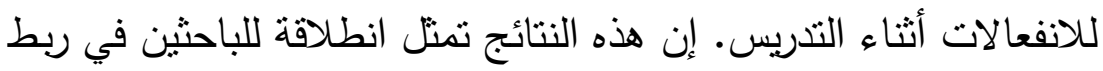
الحالة المزاجية للطلاب بالجانب المعرفي بصورة عامـة والذاكرة اللفظية 
والدلاليـة في ضـوء نمـوذج ديزي/روديجر -ماكديرموت DRM بصـورة

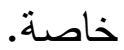

\section{التوصيات}

في ضـوء نتـائج البحـث الحسالي فإنسه يمكـن تقديم مجموعـة مـن

التوصيات والتطبيقات التربوية على النحو التالي:

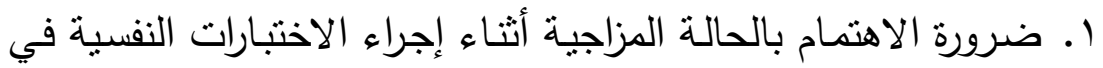

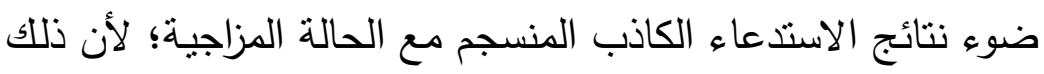
يحتمل أن بشكك في صدق تقارير السير الذاتية لاى المشاركين من

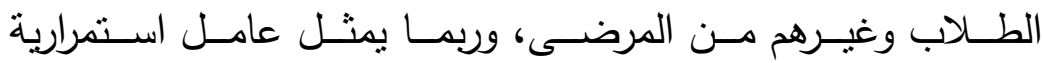
للاضطراب.

r. الاهتمام بالحالة النفسية للطلاب أثناء التدريس لما لها من أثر في استيعاب وفهم ما ينت داخل قاعات الدراسة.

r. مراعاة الحالة النفسية للطلاب أثثاء الامتحانات الثفوية والتحريرية، من خلال عدم تعريض الطلاب لضغوط نفسية تعيقهم عن الإجابة.

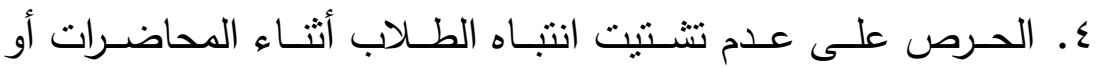
الامتحانات من خلال توفير بيئة آمنة ومساعدة على التركيز وبعيدة عن الضوضاء ومشتتات الانتباه المختلفة. ه. عمل دورات تدريبية لتوعية الطلاب بأساليب الاستذكار الجيدة وإعداد وتجهيز مكان الاستـكار مـن حيث البعد عن المشتنات، والتهيئة النفسية للاستخكار .

7. توعيـة الطـلاب بأهميـة الانتبـاه الجيد أثنـاء المحاضـرات وأثتـاء أداء الامتحانات، وأهمية المحافظة على حالة نفسية متزنة.

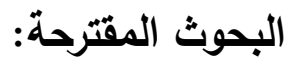

في ضـوء نتائج البحث الحـالي فإنسه يمكن تقديم مجموعـة مـن

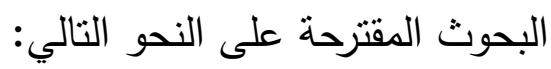


ا. دراسة مماتلة على عينات أكبر حجماً من نفس المرحلة العمرية وفي مراحل عمرية أخرى.

r. دراسـة أثر تفاعل الحالة المزاجية ونوع الإدراك (السمعي والبصري)

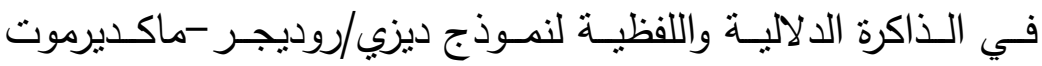
.DRM

r. دراسـة مقارنـة للعلاقة بين الحالة المزاجيـة والذاكرة الدلاليـة واللفظية

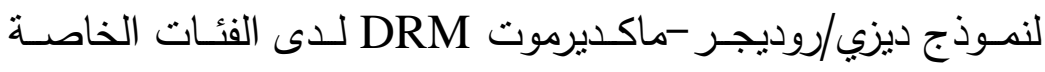
(الموهوبين وذوبي صعوبات التعلم). ـ. دراسـة العلاقة بين الحالة المزاجية والذاكرة الدلاليـة واللفظية لنموذج ودئ ديزي/روديجر -ماكديرموت DRM للأطفال مضطربي الانتباه ذوي

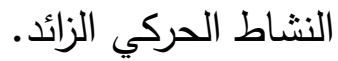




\section{المصادر والمراجع}

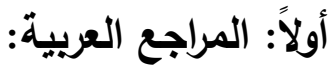

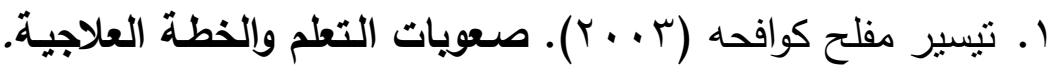
عمان: دار المسيرة للنشر والتوزيع.

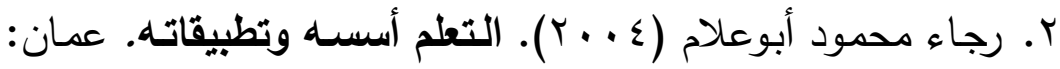
دار السيرة للنشر والتوزيع. r. السيد أحمد ، فائقة بدر (999 (199). اضطراب الانتباه لدى الأطفال، أسبابه وتثخيصه وعلاجه. القاهرة: مكتبة النهضة المصرية. ع. سيف الدين عبدون (991 (1). مقيساس عمليات الذاكرة. القاهرة: دار الفكر العربي. 0. علي السيد خضر ، ومحمد محروس الثناوي (1991). مقياس بيك للاكتئاب. القاهرة: مكتبة الأنجلو المصرية.

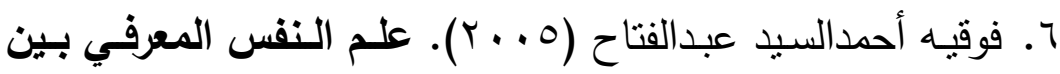
النظرية والتطبيق. القاهرة: دار الفكر العربي.

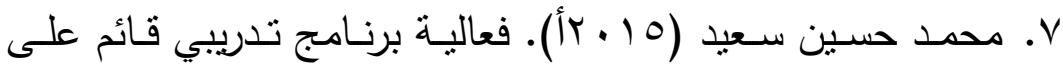
التصور العقلي في تتمية الذاكرة الدلالية والدافعية الداخلية للقراءة لذوي صسوبات تعلم القراءة بالمرحلـة الابتدائية. المجلـة العلميـة

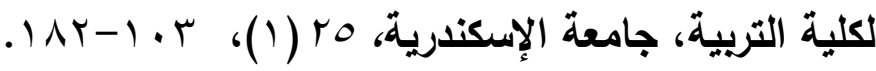

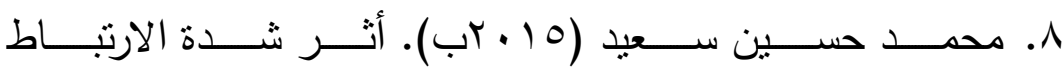

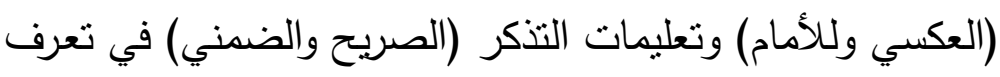
واستداء كلمات قوائم نموذج ديزي/روديجر -ماكديرموت DRM. مجلة البحث في التربية وعلم النفس، كلية التربية جامعة المنسيا،

$$
.0 r-1 ،(r) r \Lambda
$$


9. نبيل عبدالفتاح حافظ (ع . ـ ץ). صعويات التعلم والتعليم العلاجى،

$$
\begin{aligned}
& \text { ط ـ ـ القاهرة: مكتبة زهراء الثرق. } \\
& \text { ثانياً: المراجع الأجنبية }
\end{aligned}
$$

10.Anderson, L. \& Shimamura, A. (2005). Influences of emotion on context memory while viewing film clips. American Journal of Psychology, 118(3), 323-337.

11.Arndt, J. (2012). False recollection: Empirical findings and their theoretical implications. In B. Ross (Ed.), Psychology of learning and motivation (pp. 81-124). New York: Academic Press.

12.Arndt, J., \& Reder, L. (2003). The effect of distinctive visual information on false recognition. Journal of Memory and Language, 48(1), 1-15.

13.Baure, L., Olheiser, E., Altarriba, J., \& Landi N. (2009). Type effects in false recall: Concrete, abstract, and emotion word critical lures. American Journal of Psychology, 122(4), 469-481.

14.Baumeister, F., Finkenauer, C., \& Vohs, D. (2001). Bad is stronger than good. Review of General Psychology, 5(4), 323-370.

15.Beato, M. \& Arndt, J. (2014). False recognition production indexes in forward associative strength (FAS) lists with three critical words. Psicothema, 26(4), 457-463.

16.Beato, M., Cadavid, S., Pulido, R., \& Pinho, S. (2013). No effect of stress on false recognition. Psicothema, 25(1), 25-30

17.Benjamin, A. (2001). On the dual effects of repetition on false recognition. Journal of Experimental Psychology: Learning, Memory, and Cognition, 27(4), 941-947.

18.Blau, M. (2013). Effect of Semantic Features on Gist and Verbatim Memory in Young Adults with 
Language-Learning Disabilities. M. A. Thesis, The University of Texas at Austin, Texas.

19.Brainerd, C., \& Reyna, V. (2002). Fuzzy-trace theory and false memory. Current directions in psychological science, 11(5), 164-169.

20.Buchanan, T., \& Adolphs, R. (2002). The role of the human amygdale in emotional modulation of long-term declarative memory. In S. Moore \& M. Oaksford (Eds.), Emotional cognition: From brain to behavior (pp. 9-34). London, U.K.: Benjamins.

21.Budson, E., Todman, W., Chong, H., Adams, H., Kensinger, A., Krangel, S., \& Wright, I. (2006). False recognition of emotional word lists in aging and Alzheimer disease. Cognitive and Behavioral Neurology, 19, 71-78.

22.Cadavid, S., Beato, S., \& Fernandez, A. (2012). Falso reconocimiento en listas DRM con tres palabras críticas: Asociación directa vs. inversa. Psicológica, 33(1), 39-58.

23.Cahill, L., \& McGaugh, L. (1995). A novel demonstration of enhanced memory associated with emotional arousal. Consciousness \& Cognition, 4(4), 410-421.

24.Cann, D., McRae, K., \& Katz, A. (2011). False recall in the Deese-Roediger-McDermott paradigm: The roles of gist and associative strength. Quarterly Journal Of Experimental Psychology, 64(8), 1515-1542.

25.Carstensen, L. (1992). Motivation for social contact across the life span: A theory of socio-emotional selectivity. Nebraska Symposium on Motivation, 40, 209-254 
26.Carstensen, L. (1995). Evidence for a life-span theory of socioemotional selectivity. Current Directions in Psychological Science, 4(5), 151-156.

27.Choi, H. \& Kensinger, E. (2013). Emotional content enhances true but not false memory for categorized stimuli. Memory \& Cognition, 41(3), 403-415.

28.Clore, L., Wyer, S., Dienes, B., Gasper, K., Gohm, C., \& Isbell, L. (2001). Affective feelings as feedback: Some cognitive consequences. In L.L. Martin \& G.L. Clore (Eds.), Theories of mood and cognition: A user's guidebook (pp. 27-62). Mahwah, NJ: Erlbaum.

29.Cohen, J. (1988). Statistical power analysis for the behavioral sciences (2nd ed.). Hillsdale, NJ: Erlbaum.

30.Cohen, J., Cohen, P., West, S., \& Aiken, L. (2003). Applied multiple regression/correlation analysis for the behavioral sciences. (3rd ed.). Routledge: New York.

31.Corson, Y. (2002). Effects of positive, negative, and neutral moods on associative and semantic priming. Current Psychology of Cognition, 21(3), 33-62.

32.Deese, J. (1959). Influence of inter-item associative strength upon immediate free recall. Psychological Reports, 5, 305-312.

33.Denburg, L., Buchanan, W., Tranel, D., \& Adolphs, R. (2003). Evidence for preserved emotional memory in normal older persons. Emotion, 3(3), 239-253.

34.Dewhurst, A., Barry, C., \& Holmes, J. (2005). Exploring the false recognition of category exemplars: Effects of divided attention and explicit generation. European Journal of Cognitive Psychology, 17(6), 803-819. 
35.Dewhurst, A., Barry, C., Swannell, R., Holmes, J., \& Bathurst, L. (2007). The effects of divided attention on false memory depend on how memory is tested. Memory \& Cognition, 35(4), 660-667.

36.Dodd, D., \& MacLeod, M. (2004). False recognition without intentional learning. Psychonomic Bulletin \& Review, 11(1), 137-142.

37.Doerksen, S., \& Shimamura, A. (2001). Source memory enhancement for emotional words. Emotion, 1(5), 5-11.

38.Fitness, J., \& Curtis, M. (2005). Emotional intelligence and the trait meta-mood scale: Relationships with empathy, attributional complexity, self-control and response to interpersonal conflict. E-Journal of Applied Psychology: Social section, 1(1), 50-62.

39.Gallo, A. (2006). Associative illusions of memory: false memory research in DRM and related tasks. New York: Psychology Press.

40.Gallo, D. (2010). False memories and fantastic beliefs: 15 years of the DRM illusion. Memory \& Cognition, 38(7), 833-848.

41.Gilboa-Schechtman, E., Erhard-Weiss, D., \& Jeczemien, P. (2002). Interpersonal deficits meet cognitive biases: Memory for facial expressions in depressed and anxious men and women. Psychiatry Research, 113, 279-293.

42.Goodwin, A., Meissner, A., \& Ericsson, A. (2001). Toward a model of false recall: Experimental manipulation of encoding context and the collection of verbal reports. Memory \& Cognition, 29(6), 806-819.

43.Gray, J. (2001). Emotional modulation of cognitive control: Approach withdrawal states double- 
dissociate spatial from verbal two-back task performance. Journal of Experimental Psychology: General, 130(3), 436-452.

44.Gray, J., Braver, T., \& Raichle, M. (2002). Integration of emotion and cognition in the lateral prefrontal cortex. Proceedings of the National Academy of Sciences, USA, 99(6), 41154120.

45.Grossmann, I., Karasawa, M., Kan, C., \& Kitayama, S. (2014). A cultural perspective on emotional experiences across the life span. Emotion, 14(4), 679-692.

46.Hamann, S. (2001). Cognitive and neural mechanisms of emotional memory. Trends in Cognitive Sciences, 5(9), 394-400.

47.Hege, G., \& Dodson, S. (2004). Why distinctive information reduces false memories: Evidence for both impoverished relational-encoding and distinctiveness heuristic accounts. Journal of Experimental Psychology: Learning, Memory, and Cognition, 30(4), 787-795.

48. Howe, M., Wimmer, M., Gagnon, N., \& Plumpton, S. (2009). An associative-activation theory of children's and adults' memory illusions. Journal of Memory and Language, 60(2), 229-251.

49.Jou, J., \& Flores, S. (2013). How are false memories distinguishable from true memories in the Deese-Roediger-McDermott paradigm? A review of the findings. Psychological Research, 77(6), 671-686.

50.Kensinger, A., \& Corkin, S. (2003a). Effect of negative emotional content on working memory and long-term memory. Emotion, 3(4), 378-393.

51.Kensinger, A. \& Corkin, S. (2003b). Memory enhancement for emotional words: Are emotional words more vividly remembered than 
neutral words?. Memory \& Cognition, 31(8), 1169-1180.

52.Kensinger, A., \& Corkin, S. (2004). The effects of emotional content and aging on false memories. Cognitive, Affective, \& Behavioral Neuroscience, 4, $1-9$.

53.Kensinger, A., Brierley, B., Medford, N., Growdon, H., \& Corkin, S. (2002). Effects of normal aging and Alzheimer's disease on emotional memory. Emotion, 2(2), 118-134.

54.Killgore, W. (1999). The visual analogue mood scale: can a single-item scale accurately classify depressive mood state?. Psychologica Reports, 85(3), 1238-1243.

55.Knight, M. \& Mather, M. (2009). Reconciling findings of emotion-induced memory enhancement and impairment of preceding items. Emotion, 9(6), 763-781.

56.Marja, K., \& Lea, P. (2001). Examination of the paths between personality, current mood, its evaluation, and emotion regulation. European Journal of Personality, 15(2), 83-104.

57.Marsh, J., \& Bower, H. (2004). The role of rehearsal and generation in false memory creation. Memory, 12(6), 748-761.

58.Mather, M., \& Carstensen, L. (2003). Aging and attentional biases for emotional faces. Psychological Science, 14(5), 409-415.

59.Mayer, D., \& Gaschke, N. (1988). The experience and meta-experience of mood. Journal of Personality and Social Psychology, 55(1), 102-111.

60.Mckeon, S., Pace-Schott E., \& Spencer, R. (2012). Interaction of sleep and emotional content on the 
production of false memories. Plos ONE, 7(11), 17.

61.Miles, J. \& Shevlin, M. (2001). Applying Regression and Correlation: A Guide for Students and Researchers. Sage: London.

62.Moritz, S., Glascher, J., \& Brassen, S. (2005). Investigation of mood-congruent false and true memory recognition in depression. Depression and Anxiety, 21(1), 9-17.

63.Ochsner, N. (2000). Are affective events richly "remembered" or simply familiar? The experience and process of recognizing feelings past. Journal of Experimental Psychology: General, 129, 242-261. 64.Otgaar, H., Peters, M., \& Howe, M. (2012). Dividing attention lowers children's but increases adults' false memories. Journal of Experimental Psychology: Learning, Memory, \& Cognition, 38(1), 204-210.

65.Pérez-Mata, N., Read, D., \& Diges, M. (2002). Effect of divided attention and word concreteness on correct and false memory reports. Memory, 10(3), 161-177.

66.Pesta, J., Murphy, D., \& Sanders, E. (2001). Are emotionally charged lures immune to false memory? Journal of Experimental Psychology: Learning, Memory, \& Cognition, 27(2), 328-338.

67.Peters, E., \& Slovic, P. (2000). The springs of action: Affective and analytical information processing in choice. Personality and Social Psychology Bulletin, 26(12), 1465-1475.

68.Peters, V., Jelilic, M., Gorski, B., Sijstermans, K., Giesbrecht, T., \& Merckelbach, H. (2008). The corrective effects of warning on false memories in the DRM paradigm are limited to full attention conditions. Acta Psychologica, 129(2), 308-314. 
69.Piguet, O., Connally, E., Krendl, A., Huot, J., \& Corkin, S. (2008). False memory in aging: effects of emotional valence on word recognition accuracy. Psychology and Aging, 23(2), 307-314.

70.Pimentel, E., \& Albuquerque, P. (2011). Deeseroediger-McDermott paradigm: Effect of previous recall and type of memory task. Psicologia: Teoria e Pesquisa, 27(3), 315-325.

71.Pimentel, E., \& Albuquerque, P. (2013). Effect of divided attention on the production of false memories in the DRM paradigm: A study of dichotic listening and shadowing. Psicológica, 34(2), 285-298.

72.Rhodes, G., \& Anastasi, S. (2000). The effects of a levels-of-processing manipulation on false recall. Psychonomic Bulletin \& Review, 7(1), 158-162.

73.Roediger, H., \& McDermott, K. (1995). Creating false memories: Remembering words not presented in lists. Journal of Experimental Psychology: Learning, Memory, and Cognition, 21(4), 803814.

74.Roediger, H., Balota, D., \& Watson, J. (2001). Spreading activation and the arousal of false memories. In H. Roediger, J. Nairne, I. Neath, \& A. Surprenant (Eds.), The nature of remembering: Essays in honor of Robert G. Crowder (pp. 95-115). Washington, DC: American Psychological Association.

75.Roediger, H., Watson, J., McDermott, K., \& Gallo, D. (2001). Factors that determine false recall: A multiple regression analysis. Psychonomic Bulletin \& Review, 8(3), 385-407.

76.Rozin, P., \& Royzman, B. (2001). Negativity bias, negativity dominance, and contagion. Personality and Social Psychology Review, 5(4) 296-320. 
77.Ruci, L., Tomes, J., \& Zelenski, J. (2009). Moodcongruent false memories in the DRM paradigm. Cognition and Emotion, 23(6), 1153-1165.

78.Santrock, J. (2008). A Topical Approach to LifeSpan Development. New York, NY: McGraw-Hill.

79.Seamon, G., Goodkind, S., Dumey, D., Dick, E., Aufseeser, A., Strickland, E. (2003). "If I didn't write it, why would I remember it?" Effects of encoding, attention, and practice on accurate and false memory. Memory \& Cognition, 31(4), 445457.

80.Storbeck, J., \& Clore, L. (2004). Turning on and off affective and categorical priming with mood. Manuscript submitted for publication.

81.Storbeck, J., \& Clore, L. (2005). With sadness comes accuracy, with happiness, false memory: Mood and the false memory effect. Psychological Science, 16(10), 785-791.

82.Sugrue, K., \& Hayne, H. (2006). False Memories Produced by Children and Adults in the DRM Paradigm. Applied Cognitive Psychology, 20(5), 625-631.

83.Surguladze, A., Young, W., Senior, C., Bre'bion, G., Travis, J., \& Phillips, L. (2004). Recognition accuracy and response bias to happy and sad facial expressions in patients with major depression. Neuropsychology, 18(2), 212-218.

84.Thapar, A., \& McDermott, B. (2001). False recall and false recognition induced by presentation of associated words: Effects of retention interval and level of processing. Memory \& Cognition, 29(3), 424-432.

85.Toglia, P., Neuschatz, S., \& Goodwin, A. (1999). Recall accuracy and illusory memories: When more is less. Memory, 7(2), 233-256. 
86.Van Damme, I., \& d'Ydewalle, G. (2009). Memory loss versus memory distortion: The role of encoding and retrieval deficits in Korsakoff patients' false memories. Memory, 17(4), 349-366.

87.Van Damme, I., \& d'Ydewalle, G. (2010). Incidental versus intentional encoding in the DeeseRoediger-McDermott paradigm: Does amnesic patients' implicit false memory depend on conscious activation of the lure? Journal of Clinical and Experimental Neuropsychology, 32(5), 536-554.

88. Van Damme, I., Menten, J., \& d'Ydewalle, G. (2010).The effect of articulatory suppression on implicit and explicit false memory in the DRM paradigm. Memory, 18(8), 822-830.

89.Wimmer, C., \& Howe, L. (2010). Are children's memory illusions created differently from those of adults? Evidence from levels-of-processing and divided attention paradigms. Journal of Experimental Child Psychology, 107(1), 31-49.

90.Windmann, S., \& Kutas, M. (2001). Electrophysiological correlates of emotion-induced recognition bias. Journal of Cognitive Neuroscience, 13(5), 577-592.

91.Wu, L., \& Barsalou, L. (2009). Perceptual simulation in conceptual combination: Evidence from property generation. Acta Psychologica, 132(2),173-189. 


\section{الملخص}

هدف البحث إلى تعرف تأثثير كل من: الانتباه (كلي-موزع) والحالة المزاجيـة (موجبة-محايـدة-سـالبة) في الذاكرة اللفظيـة والدلاليـة في ضـوء نمـوذج ديزي/روديجر -ماكديردوت DRM، بالإضـافة إلى تعـرف تـأثير التفاعل بينهما في الذاكرة اللفظيـة والدلاليـة لـدى عينـة مـن طـلاب الفرقة الرابعة شعبة التعليم الأساسي بكلية التربية بمحافظة بني سوبف (ن= V

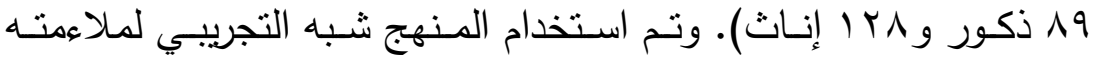

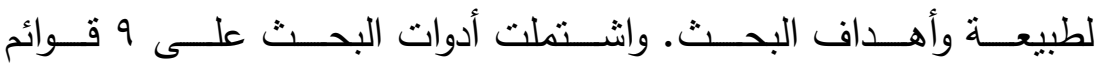
(T موجبة-r سالبة-r محايدة) من قوائم "روديجر وزمالائه" وتعريب محمد حسين سـعيد (10 • باب)، بالإضـافة إلى اختبـار التعرف ومقيـاس الحالـة المزاجية من إعداد الباحث. وتم استخدام تحليل التباين المتعدد ذي التصميم r (مستوى الحالة المزاجية؛ موجبة، محايدة، سـالبة) × ب (الانتباه؛ الكلي والمـوزع)، واختبـار "شـيفيه" وحجم التأثير • وبينـت نتـائج البحث مـا يلي: 1 - وجـود تـأثير قـوي ودال إحصـائياً عند مسـتوى دلالـة ا ... لـ للحالـة المزاجية في الذاكرة اللفظية والدلالية (لقوائم الكلمات الموجبة وقوائم الكلمات السـالبة)، حيث كان تذكر الطـلاب (الذاكرة الدلالية والذاكرة اللفظيـة) ذوي الحالـة المزاجيـة الموجبـة أعلى لقوائم الكلمـات الموجبـة مـن الطـلاب ذوبي الحالـة المزاجيـة السـالبة، بينمـا كـان تـذكر الطـلاب ذوي الحالـة المزاجيـة الموجبـة أقـل لقـوائم الكلمـات السـالبة مـن الطـلاب ذوي الحالـة المزاجيـة السالبة، بينمـا لم يوجد تأثير دال إحصـائيا للحالة المزاجية في تذكر قوائم الكلمات المحايدة. ب- وجود تأثير قوي ودال إحصـائياً عند مستوى دلالة ا +. . لمسـتوى الانتبـاه (كلي -مـوزع) في الذاكرة اللفظيـة والدلاليـة (لقوائم الكلمـات الموجبة وقوائم الكلمات المحايدة وقوائم الكلمات السـالبة)، حيـث كان تذكر الطلاب (الذاكرة اللفظية) ذوي الانتباه الكلي أعلى لقوائم الكلمات الموجبة والمحايدة والسالبة من الطلاب ذوي الانتباه الموزع، بينما كان تذكر 
الطلاب (الذاكرة الدلالية) ذوي الانتباه الموزع أعلى لقوائم الكلمات الموجبة

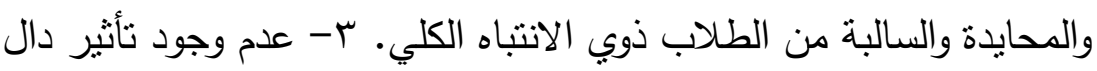

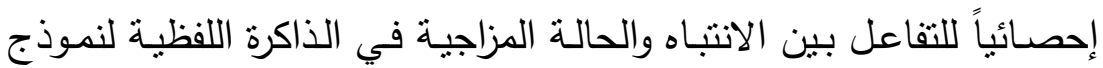

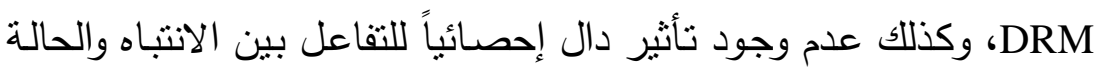

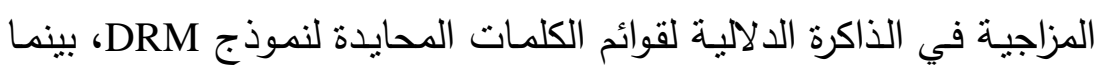

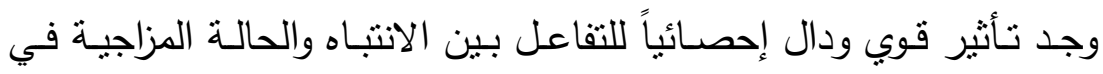

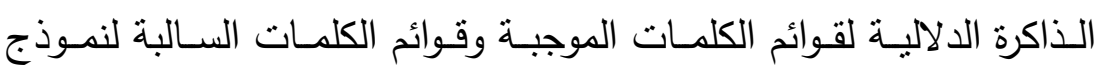
.DRM

الكلمـات المفتاحيـة: الانتبـاه-الحالــة المزاجيـة-الذاكرة اللفظيـة-الذاكرة الدلاليـةنموذج ديزي/روديجر -ماكديرموت. 


\section{Abstract}

The current research aimed at identifying the effect of: attention (total -divided) and mood (positive-negativeneutral) on verbal and gist memory in the light of Deese-Roediger-McDermott (DRM) paradigm, besides identifying the effect of interaction between them on both verbal and gist memory of fourth year students in faculty of education, elementary section, in Beni-Suef $(\mathrm{n}=217 ; 89$ males and 128 females). The quasiexperimental method was used. Research tools included; 9 lists (3 positive- 3 negative- 3 neutral) of (Roediger, Watson, et al., 2001) lists adapted by Mohamed Hussein Said (2015-b); beside recognition and mood tests developed by the researcher. Multivariate analysis of variance MANOVA with design 3(mood: positive-neutral-negative) $\times 2$ (attention: total-divided), Scheffe multiple comparisons, and effect size. Research results revealed: 1- the existence of significant effect at 0.01 of mood on verbal and gist memory (for positive and negative word lists); as students with positive mood memorized (verbal and gist memory) higher positive words than students with negative mood, whereas students with positive mood memorized negative words lower than students with negative mood, whereas there wasn't significant effect of mood on memorizing neutral word lists. 2- the existence of significant effect at 0.01 of attention (total -divided) in verbal and gist memory (for positive, neutral and negative word lists); as students with total attention memorized (verbal memory) higher positive, neutral and negative words than students with divided attention, whereas students with divided attention memorized (gist memory) positive, neutral and negative words lower than students with total attention. 3- The non-existence of significant effect of the 
interaction between attention and mood on verbal memory of positive, neutral, and negative word lists of DRM; the non-existence of significant effect of the interaction between attention and mood on gist memory of neutral word lists of DRM, whereas there was significant effect of interaction between attention and mood in gist memory of positive and negative word lists of DRM.

Keywords: Attention - Mood - Verbal Memory - Gist Memory - Deese-Roediger-McDermott DRM Paradigm. 